\title{
Low lamin A levels enhance confined cell migration and metastatic capacity in breast cancer
}

Emily S. Bell ${ }^{1,2}$, Pragya Shah ${ }^{1}$, Noam Zuela-Sopilniak ${ }^{1}$, Dongsung Kim ${ }^{1}$, Alexandra L. McGregor ${ }^{1,3}$, Philipp Isermann ${ }^{1}$, Patricia M. Davidson ${ }^{1}$, Joshua J. Elacqua ${ }^{1}$, Jonathan N. Lakins ${ }^{4}$, Linda Vahdat ${ }^{5}$, Valerie M. Weaver ${ }^{4,6}$, Marcus B. Smolka ${ }^{1}$, Paul N. Span ${ }^{7}$, Jan Lammerding ${ }^{1,3,{ }^{*}}$

${ }^{1}$ Weill Institute for Cell and Molecular Biology, Cornell University, Ithaca, NY

${ }^{2}$ Current address: Department of Biochemistry and Molecular Biology, The Pennsylvania State University, University Park, PA

${ }^{3}$ Nancy E. and Peter C. Meinig School of Biomedical Engineering, Cornell University, Ithaca, NY

${ }^{4}$ Center for Bioengineering and Tissue Regeneration, Department of Surgery, University of California, San Francisco, San Francisco, CA

${ }^{5}$ Department of Medicine, Weill Cornell Medicine, New York, NY

${ }^{6}$ Helen Diller Cancer Center, Department of Bioengineering and Therapeutic Sciences, and Department of Radiation Oncology, University of California, San Francisco, San Francisco, CA

${ }^{7}$ Department of Radiation Oncology, Radiotherapy \& Oncolmmunology laboratory, Radboud University Nijmegen Medical Center, Nijmegen, the Netherlands

*Correspondence to Jan Lammerding: jan.lammerding@cornell.edu

ORCID: 0000-0003-4335-8611

\section{Abstract}

Aberrations in nuclear size and shape are commonly used to identify cancerous tissue. However, it remains unclear whether the disturbed nuclear structure directly contributes to the cancer pathology or is merely a consequence of other events occurring during tumorigenesis. Here, we show that highly invasive and proliferative breast cancer cells have lower expression of the nuclear envelope proteins lamin A/C, leading to increased nuclear deformability that permits enhanced cell migration through confined environments that mimic interstitial spaces encountered during metastasis. Importantly, increasing lamin A/C expression in highly invasive breast cancer cells altered expression of numerous other proteins implicated in metastatic progression. Further supporting an important role of lamins in breast cancer metastasis, analysis of lamin levels in human breast tumors revealed a significant association between lower lamin A levels and decreased disease-free survival. These findings suggest that downregulation of lamin A/C may influence both biochemical and physical properties of the cell to promote breast cancer metastatic progression. 


\section{Introduction}

Abnormalities in the size and shape of cell nuclei have long been recognized as consistent and pervasive features across many types of cancer; accordingly, these features are routinely used in cancer diagnosis and prognosis (de Las Heras and Schirmer, 2014). However, this predictive power does not distinguish whether nuclear shape abnormalities have direct functional contributions in cancer progression or simply serve as morphological biomarkers. The nucleus is the largest and stiffest organelle, measuring $\approx 2$ - to 10 -times stiffer than the cell cytoplasm (Caille et al., 2002; Denais and Lammerding, 2014; Guilak et al., 2000; Tseng et al., 2004). Consequently, deformation of the nucleus can limit cell movement through confined environments (Wolf et al., 2013), including interstitial spaces in vivo, where passageways range from 0.1 to $30 \mu \mathrm{m}$ in diameter (Doerschuk et al., 1993; Stoitzner et al., 2002; Weigelin et al., 2012). Increased nuclear deformability facilitates transit through confined environments (Davidson et al., 2014; Harada et al., 2014; Lautscham et al., 2015; Mukherjee et al., 2020). Thus, cancer-associated nuclear alterations that result in softer nuclei could favor tumor invasion and metastasis.

Altered nuclear morphology can be driven by changes in chromatin organization (Bustin and Misteli, 2016; Reddy and Feinberg, 2013) or perturbed expression of nuclear envelope (NE) proteins (Bell and Lammerding, 2016; Irianto et al., 2016b; Pombo and Dillon, 2015). The NE separates the nuclear interior from the cytoplasm and includes the inner and outer nuclear membranes, nuclear pore complexes, and the nuclear lamina, which is a network of lamin intermediate filaments underlying the inner nuclear membrane (Hetzer, 2010). In somatic cells, the nuclear lamina is comprised primarily of A-type lamins (lamins $A$ and $C$ ), which are alternatively spliced from the LMNA gene, and B-type lamins (lamin B1 and B2), which are encoded by the LMNB1 and LMNB2 genes. A-type lamins are the main determinants of nuclear stiffness for large deformations, whereas chromatin structure and composition govern nuclear stiffness during small scale nuclear deformations (Lammerding et al., 2006; Lammerding et al., 2004; Schape et al., 2009; Stephens et al., 2017; Stephens et al., 2018; Swift et al., 2013). Accordingly, A-type lamins play an important protective role for stabilizing the nucleus in mechanically-stressed cells, such as in skeletal and cardiac tissues (Cho et al., 2019; Earle et al., 2020; Swift et al., 2013; Zwerger et al., 2013), and in cancer cells (Vargas et al., 2012), particularly when migrating through confined 3D environments (Denais et al., 2016; Harada et al., 2014; Raab et al., 2016) and resisting fluid sheer stress in circulation (Mitchell et al., 2015).

In addition to providing mechanical stability, the nuclear lamina acts as a scaffold for interactions guiding the localization and assembly of protein complexes such as transcriptional regulators or other NE proteins, tethering and transcriptional silencing of regions of chromatin, and connecting the nuclear interior to the cytoskeleton via the Linker of Nucleoskeleton and Cytoskeleton (LINC) complex (Andres and Gonzalez, 2009; Gruenbaum and Foisner, 2015; Maurer and Lammerding, 2019). A critical role for lamin A/C in tissue function is supported by the multitude of mutations throughout the LMNA gene that cause human diseases (Schreiber and Kennedy, 2013; Wong and Stewart, 2020). Since lamins regulate diverse cellular characteristics, it is striking, but perhaps not surprising, that changes in lamin $A / C$ expression have been documented in many types of human cancer (Bell and Lammerding, 2016; Dubik and Mai, 2020; Irianto et al., 2016b), including breast cancer (Alhudiri et al., 2019; Capo-chichi et al., 2011; Matsumoto et al., 2015; Wazir et al., 2013). These studies have established 
links between lamin alterations and clinicopathological features but have not sufficiently addressed the mechanisms of lamin A/C downregulation nor the functional consequences of altered lamin levels on cancer cell biology. Given the prevalence of lamina alterations in tumors and the complex nature of the network of laminregulated cellular processes, there is a critical need to establish cause-and-effect relationships for the role of lamins in cancer progression.

In this study, we report that variable expression of A-type lamins determines nuclear deformability across a large panel of human and mouse breast cancer lines. Low lamin A levels and increased nuclear deformability were associated with invasive and metastatic breast cancer, increased Akt signaling, and predicted decreased breast cancer survival. Notably, decreased lamin A levels in aggressive breast cancer cells modulated not only nuclear deformability and migration through confined spaces, but also influenced cell morphology, proliferation, and expression of numerous proteins involved in cell adhesion, cytoskeletal dynamics, and extracellular remodeling. Taken together, our findings suggest that A-type lamins may act as a regulatory node influencing both the biochemical and physical properties of the cell, the dysregulation and downregulation of which promotes tumor progression and metastasis through enhanced proliferation and migration abilities.

\section{Results}

Invasive breast cancer cells exhibit increased nuclear deformability correlating with lower A-type lamin levels.

Breast cancer is a heterogeneous disease that can be categorized into subtypes with distinct prognoses and treatment options (Onitilo et al., 2009; Sorlie et al., 2001). To investigate the role of nuclear deformability in breast cancer pathogenesis, we used a novel microfluidic micropipette aspiration assay (Davidson et al., 2019) to assess nuclear mechanics in a panel of breast cancer cell lines reflecting the diverse molecular and cellular phenotypes of breast cancer (Fig. 1 A, Fig. S1 A, Video 1, and Table 1). Nuclear deformability varied dramatically across different cell lines (Figs. 1 B and C, Fig. S1 B), suggesting that some lines harbor intrinsic changes that influence nuclear mechanical properties. Importantly, the three cell lines (BT-549, MCF7, and MDA-MB-231, hereafter MDA-231) with the most deformable nuclei have all been previously characterized to be highly invasive in vitro, fast growing, and amenable to use in metastasis assays in immunocompromised mice (Table 1), suggesting that increased nuclear deformability could be a characteristic feature of highly metastatic breast cancer cells. Since lamin A/C are major determinants of nuclear deformability (Lammerding et al., 2006), we assessed lamin levels in the panel of cell lines. Cell lines with highly deformable nuclei had decreased lamin $A / C$ levels, and this association was stronger for lamin A than for lamin C (Figs. 1 D-G). Interestingly, decreased ratios of lamin A to lamin $C$ also associated with increased nuclear deformability, though this association did not reach statistical significance (Fig. S1 C). Unlike lamin A/C, decreased lamin B1 levels did not correlate with increased nuclear deformability (Fig. S1 D-E), but the ratio of lamin A/C to lamin B1 by immunofluorescence showed a strong inverse correlation with nuclear deformability (Fig. S1 F). Decreased lamin A/C or lamin A/C:B1 ratios also strongly correlated with larger nuclear area (Figs. $1 \mathrm{G}$ and H, Fig. S1 G), whereas lamin B1 levels alone showed no significant correlation with nuclear area (Fig. 1 I). As enlarged nuclei are a feature of advanced grade cancers and worse 
prognosis (Bussolati et al., 2014), these data further support an association between decreased lamin $\mathrm{A} / \mathrm{C}$ levels and advanced, aggressive breast cancer.

\section{A-type lamin expression is a major determinant of breast cancer nuclear deformability.}

In addition to the composition of the nuclear lamina, the mechanical properties of the nucleus can be influenced by chromatin organization (Pajerowski et al., 2007; Stephens et al., 2017; Stephens et al., 2018) and the actin cytoskeleton (Davidson and Cadot, 2021; Lee et al., 2015; Wang et al., 2018). To evaluate the contributions of each of these components to the nuclear deformability characteristics observed across the breast cancer cell lines, we selectively depleted lamin A/C or targeted either actin polymerization or histone deacetylation in the MDA-468 cell line, which had low nuclear deformability and high lamin A/C levels (Fig. $1 \mathrm{E}$ and F, Fig. S1 B). Cells were modified by either shRNA-mediated depletion of lamin A/C (Fig. 2 A), inhibition of histone deacetylases with Trichostatin A (TSA) (Yoshida et al., 1990), or targeting actin polymerization using Cytochalasin D (CytoD)(Goddette and Frieden, 1986)(Fig. 2 B). As expected, depletion of lamin A/C resulted in a large (2.3-fold) increase in nuclear deformability compared to non-target shRNA controls (Fig. 2 C). In contrast, disrupting actin filaments with CytoD resulted in only a mild (1.4-fold) increase in nuclear deformability, and manipulating euchromatin levels with TSA did not significantly change nuclear deformability (Fig. 2 C), indicating that alterations in lamin $A / C$ expression are the main determinants of the variable nuclear stiffness observed across the panel of breast cancer cells (Fig. 2 C). In further support of this idea, increasing lamin A levels by $\approx 1.5-$ 2.5-fold (Fig. 2 D, E, G, and H) through stable exogenous expression in two highly invasive breast cancer cell lines, BT-549 and MDA-231, which originally had low lamin A/C levels and very deformable nuclei, resulted in significantly reduced nuclear deformability (Figs. $2 \mathrm{~F}$ and I).

\section{Decreased Lamin A levels and increased nuclear deformability facilitate migration through confined spaces.}

During progression through the metastatic cascade, cells disseminating from the primary site encounter various passageways substantially smaller than the diameter of the nucleus, such as during invasion through the basement membrane, migration through tight interstitial spaces, or during intra- and extravasation (Doerschuk et al., 1993; Stoitzner et al., 2002; Weigelin et al., 2012). Deformation of the nucleus to squeeze through such confined spaces can impose a rate-limiting step on cell passage (McGregor et al., 2016; Wolf et al., 2013). Therefore, loss of A-type lamin levels may contribute to metastatic progression by increasing nuclear deformability and enhancing migration through confined environments. To test this hypothesis, we assessed whether depletion of lamin A/C by shRNA enhanced confined migration in cells with high lamin A/C levels, and conversely whether exogenous expression of lamin $A$ in cells with low lamin $A / C$ levels impaired their migration through tight spaces. To precisely control the degree of confinement, we used microfluidic migration devices that contain small $\left(1 \times 5 \mu \mathrm{m}^{2}\right.$ and $\left.2 \times 5 \mu \mathrm{m}^{2}\right)$ constrictions, as well as larger $\left(15 \times 5 \mu \mathrm{m}^{2}\right)$ control channels that do not require nuclear deformation (Fig. S2)(Davidson et al., 2014; Davidson et al., 2015; Denais et al., 2016). MDA-468 cells depleted for lamin A/C migrated significantly faster through small constrictions than non-target control cells; in contrast, lamin $\mathrm{A} / \mathrm{C}$ depleted and non-target controls had similar transit times in the larger control channels 
(Figs. $3 \mathrm{~A}$ and $\mathrm{B}$, Video 2), indicating that loss of lamin A/C specifically enhanced migration through confined spaces. Conversely, exogenous expression of lamin A in BT-549 and MDA-231 cells, which normally have low lamin A/C expression and high nuclear deformability (Fig. 1B-F), resulted in decreased nuclear deformability (Figs. 2 F and I) and slower transit through small constrictions relative to control cells (Figs. 3 C-F, Video 3), indicating that nuclear deformability acts as a critical determinant of confined migration efficiency even in highly invasive cancer cells. In contrast, the effect of lamin A overexpression was much less pronounced in the larger control channels, which overall allowed faster cell transit (Figs. $3 \mathrm{D}$ and F). Taken together, these results highlight that breast cancer cells with diminished lamin A/C levels and corresponding highly deformable nuclei have a migration advantage specifically in confined environments, which may facilitate invasion and metastatic progression.

\section{Lower lamin A levels are associated with metastatic progression.}

Our findings support that downregulation of A-type lamins could be a feature of aggressive, metastatic breast cancer. However, a relationship with metastatic progression is difficult to assess solely through comparison of cancer cell lines collected from individuals with different genetic backgrounds and containing distinct molecular mechanisms driving tumor progression. To better assess whether a relationship exists between metastatic progression and downregulation of lamin $A / C$, we compared lamin levels in isogenic cell lines derived from murine mammary cancer driven by expression of the polyomavirus middle T antigen (PyMT) (Guy et al., 1992). The PyMT mammary epithelial cell line was compared with the highly metastatic Met1 variant derived from the same model in a syngeneic background (Borowsky et al., 2005). The metastatic Met1 cells had significantly lower levels of lamin $\mathrm{A}$ and lamin $\mathrm{C}$ than the primary PyMT line, based on the analysis of protein (Fig. 4 A) and transcript (Fig. 4 B) levels. Accordingly, Met1 cells had significantly more deformable nuclei than the primary tumor PyMT line (Fig. 4 C). Depletion of lamin A/C via IPTG-inducible shRNA was sufficient to increase nuclear deformability in the primary PyMT line to approximately that of Met1 cells (Figs. S3). These findings provide further support that metastatic breast cancers are characterized by increased nuclear deformability driven by decreased A-type lamin levels.

The above findings suggest that decreased expression of A-type lamins may provide a selective advantage at some point during breast cancer metastasis. Metastasis is a multi-step process involving local invasion, intravasation, survival in circulation, arrest in vasculature, extravasation, and secondary tumor growth (Sahai, 2007). To evaluate which stage of metastasis is associated with the decrease in A-type lamins, we analyzed lamin expression in the isogenic 4T1 progression series. These sister cell lines were all isolated from a single, spontaneously arising tumor from a Balb/cfC3H mouse and are each capable of progressing to different stages of metastasis (Aslakson and Miller, 1992; Dexter et al., 1978). Strikingly, increased metastatic capacity was associated with a significant decrease in lamin A levels. The 67NR cell line, which does not leave the primary site, had the highest lamin A levels; cells capable of disseminating to the lymph nodes (168FARN cells) and lungs (4T07) had significantly lower lamin A expression, and lamin A levels were lowest in cells capable of metastasizing to the lungs and bone (4T1) (Aslakson and Miller, 1992; Lelekakis et al., 1999) (Fig. 4 D and E). In contrast, lamin B1 and lamin C levels did not vary significantly across the progression series (Fig. 4 D). These findings support that a decrease in 
lamin A levels is acquired or selected for during the early invasion or intravasation stages of the metastatic cascade.

\section{Increasing lamin A in breast cancer cells alters mediators of cell metabolism, extracellular remodeling, adhesion, and cytoskeleton dynamics.}

In addition to influencing nuclear deformability and stability, the nuclear lamina participates in diverse cellular processes, including chromatin organization, DNA damage repair, and the regulation of transcription factors and signaling pathways (Bell and Lammerding, 2016; de Leeuw et al., 2018). Consequently, the decrease of lamin $\mathrm{A} / \mathrm{C}$ in invasive breast cancer may promote tumor progression through mechanisms beyond the altered mechanical properties of the nucleus. To assess additional effects of altered lamin levels on tumor progression, we performed quantitative proteomic analysis in BT-549 stably modified to exogenously express lamin A and mock controls, using stable isotope labeling with amino acids in culture (SILAC) and mass spectrometry analysis (Fig. 5 A). With a moderate ( $\approx 2.5$-fold) increase in lamin A (Fig. $2 \mathrm{D}$ and E), resulting in BT-549 cells with lamin A/C levels similar to breast cancer cell lines with high lamin A/C levels, we identified 91 proteins with at least 2-fold difference in expression between the lamin A overexpressing cells and mock controls (Fig. 5 B). Of these, 42 proteins increased in expression with the increase in lamin A levels, and 49 proteins decreased when lamin A was overexpressed. We validated changes in expression for several of the identified proteins by Western blot analysis (Fig. 5 C-G). Strikingly, the majority of proteins affected by lamin A levels were involved in extracellular remodeling, cell metabolism, cell adhesion, and/or cytoskeletal dynamics (Fig. 5 B). For example, increasing lamin A expression in the invasive BT-549 breast cancer cells promoted a switch in extracellular matrix production towards increased fibronectin synthesis, which can be associated with wound healing and fibrosis (To and Midwood, 2011) (Fig. 5 B and C), and decreased collagen VI levels (COL6A1 and COL6A2) (Fig. 5 B and D). COL6A1 and COL6A2 are frequently elevated in cancer relative to normal tissue, have been implicated in migration, Akt signaling, proliferation, and metastasis, and are associated with poor prognosis (Chen et al., 2013; Chen et al., 2019; Chiu et al., 2011; OwusuAnsah et al., 2019; Wan et al., 2015). Consistent with the tumor-promoting effects of low lamin A levels, increased expression of lamin A resulted in an increase in p53 tumor suppressor protein levels (Fig. 5 B and E), which mediates cell-cycle arrest and apoptosis in response to stress in normal cells (Brady and Attardi, 2010). Increasing lamin A also led to elevated Caveolin-1 levels (Fig. 5 B and F), a component of the plasma membrane domains known as caveolae, which influence endocytosis, exocytosis, signal transduction, cell adhesion, actin cytoskeleton, and response to mechanical stress (Echarri and Del Pozo, 2015; Sinha et al., 2011). Considering that A-type lamins have a critical role in tissues that experience high levels of mechanical stress (Isermann and Lammerding, 2013; Swift et al., 2013), it is interesting to note that the protein with the largest increase upon lamin A addition was the molecular chaperone heat shock protein 27 (HSPB1 or HSP27) (Fig. 5 B); a protein that is normally most highly expressed in cardiac and skeletal muscle (Sugiyama et al., 2000). HSPB1 was nearly undetectable in control BT549 cells but increased $\approx 12$-fold upon overexpression of lamin A (Fig. $5 \mathrm{G}$ ). To determine if A-type lamins regulate HSPB1 levels in other breast cancer models, we examined HSPB1 expression in PyMT cells in response to inducible

depletion of lamin A/C (Supp. Fig S3 A-C). HSPB1 levels decreased significantly when lamin A/C levels were 
depleted (Fig. $5 \mathrm{H}$ ). Since HSPB1 has been implicated in mRNA stabilization, antioxidant responses, regulation of apoptosis, cytoskeletal dynamics, and even secretion for an extracellular role in regulation of proliferation and immune response (Batulan et al., 2016; Mymrikov et al., 2011), the scaling of HSPB1 expression with A-type lamins levels could provide a mechanism for the regulation of diverse cellular processes impacting metastasis. In accordance with these diverse roles for HSPB1, BT-549 cells overexpressing lamin A showed HSPB1 localization throughout the cytoplasm and accumulation of HSPB1 in membrane protrusions (Fig. $5 \mathrm{I}$ ).

Since many of the proteins altered upon changes in lamin A expression are involved in cell matrix remodeling, cell adhesion, and actin dynamics, we explored how changes in lamin $A / C$ levels affect cell morphology. BT-549 breast cancer cells are characterized by extensive cell spreading and expansive lamellipodia (Fig. 6 A). Increasing the expression of lamin A in BT-549 cells resulted in reduced cell spreading and more elongated cell morphology with filopodia-like protrusions (Figs. 6 A-F), further highlighting how changes in lamin A expression can affect cellular structure and functions beyond the nuclear envelope. Thus, alteration of lamin $\mathrm{A} / \mathrm{C}$ expression can lead to numerous changes within breast cancer cells, affecting how the cells modify and interact with their physical microenvironment. Collectively, these changes could promote cancer cell invasion and metastatic progression.

\section{Decreased lamin A/C expression is associated with increased breast cancer cell proliferation in vitro and in vivo.}

Since altered lamin expression affected numerous proteins with various cellular functions, we examined whether cell proliferation was also impacted. Even a moderate ( $\approx 1.5$ - to 2.5-fold) increase in lamin A expression in BT-549 and MDA-231 cells, which normally have low levels of lamin A/C (Fig. 2D, E, G, H), slowed cell proliferation and increased population doubling times compared to mock controls (Figs. 6 G-J). In contrast, shRNAmediated depletion of lamin A/C in PyMT cells, which normally express high levels of lamin $A / C$, did not significantly alter proliferation (Figs. S4 A and B). These data suggest that decreasing A-type lamin levels alone may not be sufficient to accelerate cell proliferation in breast cancers with initially high lamin $A / C$ levels, but that the low lamin $A / C$ levels found in highly aggressive breast cancers do contribute to allowing high rates of proliferation. To test whether the link between lamin A/C levels and cell proliferation extends to human breast tumors, we assessed 21 human primary tumor tissue sections for their levels of A-type and B-type lamins in tumor cells, and for the fraction of Ki67-positive tumor cells, a marker for actively cycling cells (Fig. 7 A). Lamin A/C levels were normalized to lamin $B$ levels to account for differences in sample processing and immunolabeling efficiency. Comparing tumors from different patients, we identified a significant correlation between the average lamin $A / C$ levels, normalized to lamin B, and the fraction of Ki67-positive cells within the tumor (Fig. 7 B). Notably, the ratio of lamin $A / C$ to lamin $B$ showed a stronger correlation with the fraction of Ki67-positive cells than either lamin $A / C$ or lamin B staining alone (Fig. 7 B and Figs. S5 A and B), highlighting the merit in normalizing the lamin A/C measurements by the lamin $B$ signal. Importantly, the correlation between low lamin $A / C$ levels and high fraction of Ki67-positive cells also held true at the single cell level within individual tumors. When cells from individual tumors were split into subgroups based on their Ki67 status, the Ki67-positive subgroup had significantly lower average lamin A/C to lamin B ratios than the Ki67-negative subgroup from the same tumor (Fig. 7 C). Nearly every 
tumor analyzed exhibited this trend (13 of 14 tumors), demonstrating that even within a single tumor, decreased lamin $\mathrm{A} / \mathrm{C}$ consistently associates with a more proliferative subset of cells.

\section{Akt signaling promotes decreased lamin A/C}

Progression through the cell cycle is accompanied by phosphorylation-driven disassembly and reassembly of the lamina (Collas, 1999; Peter et al., 1990). Lamins can also be phosphorylated during interphase, contributing to increased degradation (Buxboim et al., 2014; Kochin et al., 2014; Swift et al., 2013). One of the kinases implicated in lamin A phosphorylation and degradation is Akt, which is activated downstream of PI3K (Barati et al., 2006; Bertacchini et al., 2013; Cenni et al., 2008; Naeem et al., 2015). PI3K/Akt signaling is frequently dysregulated in cancers, where it serves as a key driver of growth and division (Fruman and Rommel, 2014). Thus, phosphorylation of lamins by Akt could provide a potential mechanism for downregulation of lamin A/C as a component of a PI3K/Akt-mediated pro-proliferative signaling network proliferation. To explore a potential connection between Akt signaling and lamin $A / C$, we quantified lamin levels in a human breast tumor microarray ( $n=109$ ) that had previously been analyzed to separate tumors into groups negative or positive for phosphorylated Akt, which marks active Akt (Wennemers et al., 2013) (Fig. 7 D). Remarkably, tumors positive for Akt phosphorylation had significantly lower lamin A to lamin B ratios (Fig. $7 \mathrm{E}$ ), highlighting that this pathway could be contributing to downregulation of A-type lamins. To test this hypothesis, we quantified lamin levels in MDA231 cells after treatment with the Akt inhibitor Afuresertib. Akt inhibition resulted in a significant increase in the lamin $A / C$ to lamin B1 ratio compared to vehicle-treated control cells (Figs. $7 \mathrm{~F}$ and $\mathrm{G}$ ). This increase in A-type lamin protein levels occurred without a change in $L M N A$ gene expression (Fig. $7 \mathrm{H}$ ), suggesting that Akt signaling influences A-type lamin levels in breast cancer cells through post-transcriptional mechanisms, such as regulation of protein stability, rather than via transcriptional regulation (Agrelo et al., 2005; Bertacchini et al., 2013; Marmiroli et al., 2009).

\section{Decreased lamin A levels are associated with worse prognosis in breast cancer.}

Our findings suggest that primary breast cancer tumors with lower lamin A/C levels have enhanced proliferation, invasion, and confined migration abilities, which could promote cancer progression and metastasis. To investigate the proposed associations between lamin A/C levels and patient outcomes, we measured lamins levels in primary tumor tissue microarrays representing a retrospective cohort of 122 breast cancer patients, including 54 with triple-negative breast cancers, who did not receive systemic treatment and had been followedup for at least 5 years (Nagelkerke et al., 2011). Lamin levels were assessed using immunofluorescence and segmentation of nuclei for single cell analysis of lamin intensity at the nuclear rim, allowing measurements to reflect differences in the nuclear lamina composition regardless of nuclear morphology (Fig. 8 A). Another advantage of this approach is that nuclei can be selected so that only tumor cells are analyzed and surrounding stromal cells are excluded. The ratio of lamin A to lamin B was calculated for each individual tumor cell, and these measurements were then used to calculate the average ratio for each tumor (Fig. 8 B). Kaplan-Meier survival analysis with log-rank testing found a significant association between disease-free survival and lamin A : B ratio. 
Importantly, patients with breast tumors with low lamin A: lamin B ratios (based on an optimal cutoff ratio of 1.983) had significantly reduced disease-free survival compared to patients with high lamin A:lamin $B$ ratios (Fig. 8C). This correlation with patient survival occurred without any significant association with ER/PR/HER2 status (Fig. $8 \mathrm{D}$ ), suggesting that lamin A downregulation may identify more aggressive breast cancers in a subtypeindependent manner. These findings support that the impact of decreased lamin A levels on cell invasion and proliferation are functionally important for breast cancer progression, as lower lamin A levels are associated with worse disease-free survival across human breast cancer patients.

\section{Discussion}

Despite the widespread and historic use of altered nuclear size and NE morphology for cancer diagnosis and prognosis, an integrated understanding of how these changes arise and how they relate to biochemical and mechanical functions influencing tumor progression has remained elusive. Using a broad panel of human and mouse breast cancer cells lines, we present evidence that the deformability of the nucleus varies dramatically across different breast tumor types and is determined by alterations in the levels of the nuclear envelope protein lamin A and, to a lesser extent, lamin C. Importantly, our analysis of cell lines from isogenic and syngeneic mouse models of breast cancer found that a decrease in lamin A levels was associated with the acquisition of metastatic capabilities. Consistent with these findings, decreased lamin A levels in human tumors correlated with increased proliferation and reduced disease-free survival in breast cancer patients. Notably, proteomic and morphological analysis revealed that the effect of altered lamin A/C levels in invasive breast cancer cells extends well beyond regulation of nuclear deformability, affecting cell proliferation, morphology, and expression of proteins involved in adhesion, cytoskeletal dynamics, stress responses, and extracellular remodeling. Collectively, these findings support that modulation of lamin $\mathrm{A} / \mathrm{C}$ may have a central role in mediating broad reprogramming of cellular functions during cancer progression (Fig. 9).

Lamin A/C expression has been previously reported to exhibit stiffness-dependent scaling as cells sense and respond to their physical environment; lamin A/C levels increase in stiffer environments and in conjunction with force transmission to the nucleus (Buxboim et al., 2014; Cho et al., 2017; Gonzalez-Cruz et al., 2018; Swift et al., 2013). However, we observed variations in lamin $A / C$ in breast cancer cells that could not be explained by differences in substrate stiffness as cells were grown on identical substrates, and lamin $\mathrm{A} / \mathrm{C}$ levels varied between and within patient tumors. Instead, we identified a consistent association between decreased lamin A/C and enhanced invasive, metastatic, and proliferative characteristics in cell lines and tumors. Although it is likely that multiple pathways converge to explain the variable lamin $A / C$ expression observed in different cancers, our findings support a direct connection between oncogenic activation of Akt signaling with the regulation of A-type lamins and nuclear deformability across breast cancers. Akt has previously been reported to regulate lamin A/C through both alterations in gene expression and phosphorylation-mediated targeting for degradation (Bertacchini et al., 2013; Cenni et al., 2008). The PI3K/Akt pathway is hyperactivated in $\approx 60 \%$ of breast cancers (Ortega et al., 2020), and we found that Akt activation was associated with significantly lower lamin A : B ratios in human tumors 
and that Akt helps to maintain low lamin A/C levels in aggressive breast cancer cell lines. Thus, decreasing lamin $\mathrm{A} / \mathrm{C}$ may be a downstream consequence of activation of a proliferative PI3K/Akt signaling network, raising the question of whether downregulation of lamin A/C contributes to Akt-driven enhanced proliferation in breast cancer. In support of this hypothesis, we found that highly proliferative tumors and actively cycling cells exhibited lower lamin A : B ratios, and moderate increase in lamin A through exogenous expression was sufficient to decrease proliferation in aggressive breast cancer cells. This is consistent with previous studies linking a decrease in lamin A/C to enhanced proliferation across multiple cell types (Broers et al., 1997; Ivorra et al., 2006). Notably, multiple studies have linked lamin $A / C$ to cell cycle regulation through interaction with $p R B$, thereby maintaining the ability of this tumor suppressor protein to delay cell cycle entry (Johnson et al., 2004; Nitta et al., 2006; Van Berlo et al., 2005). Taken together, our findings support that the downregulation of lamin A/C can be both a downstream consequence and a contributor in the reprogramming of cancer cells for enhanced proliferation.

Changes in lamina composition resulting in altered mechanical and signaling properties may also be regulated in cancers at the level of relative expression of lamin A versus $C$, which varies across tissues due to alternative splicing (Aljada et al., 2016). However, the majority of studies linking lamin A/C alterations to tumor progression have not distinguished between lamin A and C (Alhudiri et al., 2019; Belt et al., 2011; Coradeghini et al., 2006; Matsumoto et al., 2015; Wang et al., 2018; Wazir et al., 2013; Willis et al., 2008; Wu et al., 2009). Lamins $A$ and $C$ are identical for the first 566 amino acids and cannot be differentially detected by most available antibodies. Interestingly, we found that the association with nuclear deformability was much stronger for lamin $A$ than for lamin C. Furthermore, the gain of metastatic capacity in murine mammary cancer models was associated with downregulation of lamin A to a much greater extent than lamin C. These findings support that decreased levels of lamin A are the more important determinant of enhanced nuclear deformability and cancer disease progression. Consistent with this finding, decreased lamin A, but not lamin C, has been associated with metastasis and decreased disease-free survival in ovarian cancer (Gong et al., 2015), and the ratio of lamin A mRNA to lamin C mRNA has been found to decrease in multiple tumor types relative to normal tissues or less proliferative tumors (Aljada et al., 2016; Venables et al., 2001). Accordingly, we found that aggressive breast cancer cell lines with highly deformable nuclei tend to not only have lower lamin A levels overall, but also decreased lamin $A$ to lamin $C$ ratios. The potential differential roles for lamin $A$ and $C$ in tumor progression contrast with apparent redundant roles in tissue maintenance; mice producing only lamin C appear healthy with only minimal nuclear morphological abnormalities and a mild increase in nuclear deformability (Fong et al., 2006; Lammerding et al., 2006), while mice lacking both lamin A and C die by 7 weeks of age (Sullivan et al., 1999). Continued studies comparing and manipulating levels of lamin $A$ and $C$ isoforms are needed to better understand specific functions of individual lamin isoforms, and how changes in relative expression contribute to differentiation and disease processes.

Lamin A/C bind and regulate a multitude of proteins involved in growth factor signaling cascades, regulation of cell cycle progression, and DNA damage repair (Andres and Gonzalez, 2009; Bell and Lammerding, 2016; Frock et al., 2006; Gonzalo, 2014; Kennedy and Pennypacker, 2014; Maynard et al., 2019; Redwood et al., 2011). The functional and proteomic changes reported here upon modulation of lamin A levels in breast cancer cells suggest that high levels of lamin A can contribute to functions typically associated with tumor suppressor 
proteins, such as growth suppression, and stress responses. However, unlike classic tumor suppressors, the LMNA gene is not frequently deleted or mutated in cancer (Bell and Lammerding, 2016), suggesting that a minimal level of expression is required for cell survival and growth. The balance between pathways promoted and inhibited as a function of lamin A levels may be particularly relevant to metastatic cells invading through tissues. We found that the decreased lamin A levels in highly aggressive breast cancer cells increased nuclear deformability and modulated expression of numerous proteins involved in cell adhesion and matrix remodeling, functions which are critical determinants of efficient cell movement in 3-D environments (Condor et al., 2019; Lautscham et al., 2015; Mekhdjian et al., 2017). As a result, lower lamin A levels promote faster transit through small constrictions requiring nuclear deformation. However, squeezing the nucleus through small confinements can result in DNA damage caused by both the deformation of the nucleus and rupture of nuclear envelope (Irianto et al., 2016a; Raab et al., 2016; Shah et al., 2020). Importantly, mutation or depletion of lamin A/C increases the frequency of nuclear envelope rupture and impairs the ability to efficiently repair and survive rupture events (Denais et al., 2016; Earle et al., 2020; Irianto et al., 2016a; Raab et al., 2016). The importance of maintaining some level of lamin $\mathrm{A} / \mathrm{C}$ for stress resistance and epithelial cell function is further highlighted by studies showing impaired survival and growth of cells harboring severe depletion of lamin A/C (Harada et al., 2014; Mitchell et al., 2015; Raab et al., 2016; Roncato et al., 2021). Thus, we propose that lamin A occupies opposing roles in restricting growth and metastatic dissemination of cancer cells while also being critically important for nuclear stability, maintenance, and cell survival. Accordingly, none of the breast cancer cell lines completely lacked lamin $A / C$, indicating that some minimal lamin $A / C$ expression is needed to balance promoting metastatic progression while avoiding negative effects of loss of lamin A/C.

Taken together, our data support a model where lamin A acts as a determinant of how cells interact with their physical environment, as well as a gatekeeper protecting the integrity of the nucleus in response to those interactions. Our findings support the hypothesis that primary tumors with lower lamin levels may have enhanced

ability to grow and metastasize. However, this could also indicate that the low lamin A levels and highly deformable nuclei occurring in highly aggressive breast cancers are accompanied by increased sensitivity to targeted disruption of repair mechanisms involved in responses to mechanically induced nuclear damage, thus representing a potential target for novel clinical treatment options.

\section{Materials and methods}

Cells and cell culture. The human breast cancer cell lines MDA-231 (HTB-26), MDA-468 (HTB-132), MCF7 (HTB22), SKBR3 (HTB-30), HCC70 (CRL-2315), BT-549 (HTB-122), BT-474 (HTB-20), and T47D (HTB-133) were obtained from the American Type Culture Collection (ATCC). MDA-231, MDA-468, MCF7, SKBR3 and T47D cells were cultured in Dulbecco's Modified Eagle Medium (DMEM) supplemented with $10 \%$ (v/v) fetal bovine serum (FBS, Seradigm VWR) and 1\% (v/v) penicillin and streptomycin (PenStrep, ThermoFisher Scientific). BT-549, BT-474 and HCC70 cells were grown in Roswell Park Memorial Institute medium (RPMI) 1640 media supplemented with 10\% FBS and $1 \%$ PenStrep. All cell lines were cultured under humidified conditions at $37^{\circ} \mathrm{C}$ and $5 \% \mathrm{CO}_{2}$. The murine 
epithelial PyMT Flox3 ("РуMT") tumor cell line was established from an unfloxed tumor arising in the MMTV-PyMT mouse model described in (Pickup et al., 2013) and serves as a less metastatic comparator for the highly metastatic Met1 (CVCL_U373) MMTV-PyMT line (Borowsky et al., 2005; Mekhdjian et al., 2017). PyMT and Met1 cells were maintained in Dulbecco's Modified Eagle's Medium: Nutrient Mixture F-12 (DMEM/F12; Gibco) supplemented with $10 \%(\mathrm{v} / \mathrm{v})$ FBS (Seradigm VWR), and 1\% (v/v) penicillin and streptomycin (PenStrep, ThermoFisher Scientific). The 4T1 murine mammary cancer metastatic progression series cell lines (67NR (CVCL_9723), 168FARN (CVCL_0186), 4T07(CVCL_B383), and 4T1(CVCL_0125))(Aslakson and Miller, 1992) were a kind gift from Dr. Peter Friedl (MD Anderson Cancer Center, Houston, TX, USA). 4T1 progression series cell lines were maintained in RPMI (Gibco) supplemented with L-glutamine (Gibco), sodium pyruvate, 10\% (v/v) FBS (Seradigm VWR), and 1\% (v/v) penicillin and streptomycin (PenStrep, ThermoFisher Scientific). For Akt inhibition experiments, MDA-231 cells were treated with $5 \mu \mathrm{M}$ of Afuresertib (GSK2110183, Selleckchem, Cat \#S7521) or DMSO (Sigma, Cat \#D2650) for 24 hours before analysis. For IPTG-induced knockdown of Lmna in PyMT cells, IPTG was applied at a concentration of $0.25 \mathrm{mM}$ for at least 48 hours prior to the start of experiments. None of the cell lines in this study are listed NCBI Biosample database of commonly misidentified cell lines. All cell lines were tested for mycoplasma at the beginning of studies (tested negative with MycoSensor PCR Assay Kit, Agilent, \#302109) and have never exhibited contamination symptoms after initial testing.

Generation of stably modified cell lines. MDA-468 cell lines were stably modified with lentiviral vectors to express the nuclear reporter NLS-GFP (pCDH-CMV-NLS-copGFP-EF1-blastiS (Denais et al., 2016), available through Addgene (\#132772)). MDA-468 cells were also modified with lentiviral vectors to stably express shRNA to LMNA and (MISSION anti-LMNA shRNA, available through Sigma, TRCN0000061835, NM_170707.1-752s1c1) or control non-target MISSION control shRNA (available through Sigma). MDA-231 and BT-549 cells were modified with NLSRFP (pCDH-CMV-3xNLS-TagRFP-T-EF1-blastiSBT-549 (Denais et al., 2016)) and then additionally modified with lentiviral vectors to express Lamin A (pCDH-CMV-hLamin_A-IRES-copGFP-EF1-puro (Earle et al., 2020), available through Addgene (\#132773)) or the control plasmid, pCDH-CMV-IRES-copGFP-EF1-puro, generated in house). For IPTG-inducible Lmna knockdown, PyMT cells were modified with pLKO.1-EEF1a-mApple-Luc2 and pLKO.1 U63xlaclbs (Miroshnikova et al., 2016) containing shLmna (Sense: GCTTGACTTCCAGAAGAACAT) or shGFP (Sense: GCAAGCTGACCCTGAAGTTCAT) shRNA.

For viral modifications, pseudoviral particles were produced as described (Hanson et al., 2008). In brief, 293-TN cells (System Biosciences, SBI) at 70-80\% confluency were co-transfected with the lentiviral plasmid and lentiviral helper plasmids (psPAX2: Addgene \#12260 and pMD2.G: Addgene \#12259, gifts from Didier Trono) using PureFection (SBI System Biosciences) following the manufactures protocol. Lentivirus containing supernatants were collected at 48 hours and 72 hours after transfection and filtered through a $0.45 \mu \mathrm{m}$ syringe filter. Cells were transduced for 1-3 consecutive days with the viral stock diluted 1:3 with culture media in the presence (or absence for BT-549 cell line) of $8 \mu \mathrm{g} / \mathrm{mL}$ polybrene (Sigma-Aldrich). The viral solution was replaced with fresh culture medium, and cells were cultured for 24-48 hours before selection with $1 \mu \mathrm{g} / \mathrm{mL}$ of puromycin (InvivoGen) or 6 $\mu \mathrm{g} / \mathrm{mL}$ of blasticidine $\mathrm{S}$ (InvivoGen) for 10 days. Cells were also sorted using fluorescence assisted cell sorting 
(FACS) (BD FACSARIA) to ensure a consistent level of expression of the fluorescent reporters.

Fabrication and use of microfluidic migration devices. Confined migration experiments in microfluidic devices were performed as described previously (Davidson et al., 2014; Davidson et al., 2015; Denais et al., 2016). Briefly, the devices contain channels of $5 \mu \mathrm{m}$ height with constriction widths ranging from 1 to $15 \mu \mathrm{m}$ in width. Unconfined regions of $250 \mu \mathrm{m}$ height are found on either side of the migration channels region and cells are loaded into one of these regions (Davidson et al., 2015). Microfluidic devices are produced using molds that were made using twolayered SU-8 photolithography as described previously (Davidson et al., 2014). Polydimethylsiloxane (PDMS) replicas of the molds were made using a Sylgard 184 PDMS kit (Dow Corning) using the (1:10) manufacturer's recipe. After devices were cut to size and holes were punched to allow addition of cells and media, a plasma cleaner (Harrick Plasma) was used to covalently bind microfluidic devices to glass coverslips that had been pretreated with $0.2 \mathrm{M} \mathrm{HCl}$, rinsed, and dried. The assembled devices were placed on a $95^{\circ} \mathrm{C}$ hot plate for 5 min to improve adhesion. Devices were filled with $70 \%$ ethanol for sterilization and then rinsed with sterile deionized water. Devices were then coated with $5 \mu \mathrm{g} / \mathrm{ml}$ fibronectin (Millipore) in PBS (MDA-231 or BT-549) or $50 \mu \mathrm{g} / \mathrm{mL}$ Rat Tail Collagen Type I in $0.02 \mathrm{~N}$ acetic acid (MDA-468) overnight at $4^{\circ} \mathrm{C}$. After the incubation, devices were rinsed with PBS and filled with cell culture medium before loading $~ 30,000$ cells through the side port into one of the $250 \mu \mathrm{m}$ height regions. Cells were allowed to attach in a tissue culture incubator for 6-24 hr, depending on the cell line, prior to the start of imaging. Devices were sealed with a glass coverslip to minimize evaporation and were imaged every 10 min for at least 12 hours in phenol-red free DMEM supplemented with 25 mM HEPES and 10\% FBS (for MDA-231 and BT-549 cells) or a 0.1\%-12\% FBS gradient (for MDA-468 cells). Transit times were calculated through manual analysis. Briefly, transit time of a cell through a constriction was defined as the time between when the front of the nucleus crossed into the region $5 \mu \mathrm{m}$ in front of the constriction center and when the back of the nucleus passed out of the region $5 \mu \mathrm{m}$ behind the constriction center. A similar analysis was performed on cells in the $15 \mu \mathrm{m}$ wide channels to obtain values of the migration transit time of cells under non-constrained conditions.

Fabrication and use of Micropipette aspiration devices. Micropipette aspiration of cells into 3- $\mu \mathrm{m}$-wide, 5- $\mu \mathrm{m}$ high channels was performed using microfluidic devices fabricated as described in (Davidson et al., 2019). Standard lithography techniques were used to produce the mask and wafers for the device at the Cornell NanoScale Science and Technology Facility (CNF). PDMS replicas of the microfluidic device molds were cast using Sylgard 184 (Dow Corning). Devices were cut to size and three entrance port holes were punched and the device was mounted onto a glass slide (pretreated with $0.2 \mathrm{M} \mathrm{HCl}$ ) using a plasma cleaner (Harrick Plasma). Devices were filled with PBS containing $2 \%$ bovine serum albumin (BSA), $0.2 \%$ FBS solution. Cells were trypsinized and resuspended in 2\% BSA, 0.2\% FBS PBS solution containing $10 \mu \mathrm{g} / \mathrm{ml}$ Hoechst 33342 (Invitrogen) to visualize nuclei. The cell suspension $\left(\sim 5 \times 10^{6}\right.$ cells $\left./ \mathrm{ml}\right)$ was perfused into the devices at constant pressure using a MCFS-EZ pressure controller (Fluigent). Pressure at the inlet and outlet ports was set to 1.0 and 0.2 pounds per square inch (relative to atmospheric pressure, $P_{\mathrm{atm}}$ ), respectively. The remaining port was outfitted with a hand-held pipette 
to manually backflush cells from the pockets to allow new cells to enter at the start of each image acquisition sequence. Bright-field and fluorescence images were acquired every 5 seconds for 1-2 minutes. Nuclear protrusion length $(\Delta \mathrm{L})$ was analyzed for each cell at each time point using a custom-written MATLAB program (Davidson et al., 2019), made available on request.

Western Blot analysis. Cells were lysed in high salt RIPA buffer (50 mM Tris pH 8.0, $150 \mathrm{mM} \mathrm{NaCl}$ (or $750 \mathrm{mM}$ for lamins blots to increase solubility), $1 \%$ Nonidet P-40, $0.1 \%$ SDS, $0.5 \%$ sodium deoxycholate) containing freshly added protease (complete EDTA-Free, Roche) and phosphatase (PhosSTOP, Roche) inhibitors. For lamin blots, lysates were vortexed for 5 minutes at $4^{\circ} \mathrm{C}$ and passed through an insulin syringe five times to shear DNA. Lysates were cleared by centrifugation at $13000 \mathrm{rpm}$ for 5 minutes at $4^{\circ} \mathrm{C}$. Protein concentration was quantified using Bio-Rad Protein Assay Dye, and 25-30 $\mu \mathrm{g}$ of protein lysate was combined with Laemmli buffer and heated for 3 minutes at $95^{\circ} \mathrm{C}$. Proteins were separated using an $8 \%, 10 \%$, or $4-12 \%$ polyacrylamide gel with a standard SDSPAGE protocol. Protein was transferred to a methanol-activated PVDF membrane at room temperature at a voltage of $16 \mathrm{~V}$ for 1 hour in a semi-dry transfer apparatus. Membranes were blocked using 3\% BSA in Tris-buffered saline containing $0.1 \%$ Tween-20 (TBST). Primary antibodies were diluted in the same blocking solution and incubated overnight at $4{ }^{\circ} \mathrm{C}$. After three 5-minute rinses in TBST, infrared (IR)-dye conjugate secondary antibodies IRDye 800CW Donkey Anti-Goat (VWR, \#102673-336), IRDye 800CW Donkey Anti-Rabbit (VWR, \#102673-334) and IRDye 680RD Donkey Anti-Mouse (VWR, \#102673-412) were added at 1/5000 in blocking solution for 1 hour at room temperature. After three more TBST washes, membranes were rinsed with water and imaged on an Odyssey CLx imaging system (LI-COR) and quantification was performed in Image Studio Lite (LI-COR). Primary antibodies used for western blots obtained from Santa Cruz Biotechnology, Inc. were Lamin A/C (E-1) (1/1000, $\left.A B \_10991536\right)$, Lamin $A / C(N-18)$ (1/1000, AB_648152), Actin (1/4000, AB_630835), COL6A1(B-4) (1/500, $\left.A B \_2783834\right)$, Fibronectin (EP5) (1/500, AB_627598), p53 (Pab 240) (1/500, AB_628086), and caveolin-1 (4H312) (1/500, AB_1120056). Antibodies were also obtained from the Developmental Studies Hybridoma Bank (DSHB) created by the NICHD of the NIH and maintained at The University of lowa, Department of Biology, lowa City, IA 52242. DSHB antibodies were used at a dilution of $0.5 \mathrm{ug} / \mathrm{ml}$ and include Lamin A/C (AB_2618203, MANLAC1(4A7) deposited by Morris, G.E.), Tubulin (AB_528499, E7 deposited by Klymkowsky, M.), Actin (AB_528068, JLA20 deposited by Lin, J.J.-C.), HSPB1 (AB_2617267, CPTC-HSPB1-1 deposited by Clinical Proteomics Technologies for Cancer). Additional antibodies used for western blots were Tubulin (1/3000, Sigma, AB_477579), Lamin B1 (1/1000, Abcam, AB_10107828), Histone H3 (1/5000, Abcam, AB_2885180). Blots validating SILAC results were conducted as above, but with anti-mouse IgG IgM, HRP-linked (Thermo Fisher Scientific, AB_228321) and antirabbit IgG HRP-linked (Cell Signaling, AB_2099233) secondary antibodies. Bands were detected using SuperSignal West Femto Maximum Sensitivity Substrate (Thermo Scientific) and the c-Digit imaging system (LI-COR) and densitometry was performed in FIJI.

Human tumor tissue sections and tissue microarray. The relationship between lamin levels and phospho-Akt staining, receptor status and breast cancer patient survival was investigated using a breast tumor tissue 
microarray (TMA) described in detail in (Nagelkerke et al., 2011). The TMA consisted originally of samples from 122 patients, and of these 109 tumor cores were undamaged and analyzable for this study. Breast tumor samples were collected from patients who underwent resection surgery of their primary tumors and had not received systemic adjuvant treatment. Patients were treated between January 1991 and December 1996 and data was available from at least 5 years of follow-up or until a recurrence event. Additionally, levels of ER, PR, HER2, and phosphorylated Akt had been previously assessed by immunohistochemistry (Wennemers et al., 2013), allowing our comparison of lamin levels across histological subtypes and in tumors negative or positive for phospho-Akt. Immunofluorescent staining, imaging, and quantification was performed while blinded to breast tumor characteristics or patient outcome. All procedures were conducted according to institutional guidelines and with institutional approval.

Human tumor sections used for analysis of relationships between proliferation (Ki67 positivity) and lamin levels were obtained from Dr. Linda Vahdat (Weill Cornell Medicine, IRB\# 0408007390A002). The 21 paraffinembedded breast tumors analyzed included 8 HER2-positive tumors and 5 triple-negative tumors and surgery dates ranged from February 1995 to June 2009.

Immunofluorescent staining. For staining of cell monolayers, cells were cultured on cover slips for 24-48 hours before fixation with 4\% PFA in PBS for $20 \mathrm{~min}$ at room temperature. Cells were then rinsed in PBS, quenched in $100 \mathrm{mM}$ glycine/PBS for 5 minutes and permeabilized in $0.3 \%$ triton/PBS for 10 minutes. Blocking was in $2 \%$ BSA in washing buffer (PBS with $0.2 \%$ triton X-100 and 0.05\% Tween-20) for 1 hour at room temperature. Cells were stained overnight at $4^{\circ} \mathrm{C}$ with primary antibodies diluted in blocking solutions. After primary antibodies were removed, cells were rinsed three times ( 5 minutes each) in washing buffer, and fluorescently-labeled secondary antibodies were applied in blocking solution for 40-60 minutes. Where applicable, cells were also stained with Alexa Fluor 647 Phalloidin (1/100, Thermo Fisher Scientific, AB_2620155) during secondary antibody incubation. After three more washes in washing buffer, nuclei were counterstained with 4',6-diamidino-2-phenylindole (DAPI) (Invitrogen, $0.1 \%$ stock diluted $1 / 500$ in PBS for use) for 10 minutes prior to rinsing with water and mounting using Hydromount (\#17966 from electron Microscopy Sciences).

For staining of paraffin-embedded human breast tumor tissue sections and tissue microarray, sections were deparaffinized in 3 changes of xylenes followed by 100\% ethanol, 95\% ethanol and 70\% ethanol (all 5 min each). Sections were rehydrated with gently running tap water for 5 minutes. For antigen retrieval, sections were transferred to Tris-EDTA, pH9.0 in a coplin jar and placed in a $55^{\circ} \mathrm{C}$ water bath. After 30 minutes, water bath temperature was increased to $95^{\circ} \mathrm{C}$ and incubation continued for an additional 20 minutes after reaching $95^{\circ} \mathrm{C}$. Water bath was shut off and allowed to cool slowly for 3-4 hours. Each tissue section was circled with a liquid blocker pen and rinsed 5 minutes with PBS. Each section was covered with blocking buffer of 3\% BSA and 5\% filtered horse serum in PBS-T (PBS with 0.05\% triton X-100 and 0.03\% Tween-20) for 1 hour. Primary antibodies diluted in blocking buffer were applied overnight in a humidified chamber at $4^{\circ} \mathrm{C}$. After primary antibody treatment and three rinses (10 minutes each) with PBS-T, fluorescently-labeled secondary antibodies were applied in Block buffer for 1 hour at room temperature followed by three more 10 minute PBS-T washes. Nuclei were 
counterstained with 4',6-diamidino-2-phenylindole (DAPI) (Invitrogen, $0.1 \%$ stock diluted 1/500 in PBS for use) for 10 minutes prior to rinsing with water and mounting using Hydromount (\#17966 from Electron Microscopy Sciences).

Secondary antibodies and dilutions used included Donkey anti-Rabbit Alexa Fluor 488 (1/300, Thermo Fisher Scientific, AB_2535792), Donkey anti-Mouse Alexa Fluor 568 (1/300, Invitrogen, AB_2534013), Donkey antiGoat Alexa Fluor 647 (1/150, Thermo Fisher Scientific, AB_141844), and Donkey anti-Goat Alex Fluor 568 (1/300, Life Technologies, $\left.A B \_142581\right)$. The primary antibodies and dilutions used for immunofluorescence on cell monolayers were Lamin A/C (E-1) (1/200, Santa Cruz, AB_10991536), Lamin A/C (N-18) (1/50, Santa Cruz Biotechnologies, AB_648152), Lamin A (H102) (1/100, Santa Cruz Biotechnologies, AB_648148), Lamin B1 (1/100, Abcam, AB_10107828), Lamin B1 (1/200 Proteintech AB_2136290), Lamin B (M-20) (1/100, Santa Cruz Biotechnologies, AB_648158), and HSPB1 (2 ug/ml, AB_2617267, CPTC-HSPB1-1 deposited to the DSHB by Clinical Proteomics Technologies for Cancer). Primary antibodies and dilutions used for immunofluorescence on human breast tumor tissues were Lamin A/C (E-1) (1/100, Santa Cruz, AB_10991536), Lamin A (H102) (1/100, Santa Cruz Biotechnologies, AB_648148), Lamin B (M-20) (1/100, Santa Cruz Biotechnologies, AB_648158), Ki67 (1/200, Novus Biologicals, AB_10001977).

Fluorescence microscopy and image analysis. Microfluidic migration device experiments and immunofluorescent staining images were collected on inverted Zeiss Observer Z1 microscope equipped with temperature-controlled stage $\left(37^{\circ} \mathrm{C}\right.$ ) and CCD camera (Photometrics CooISNAP KINO) using $20 \times$ air (NA $\left.=0.8\right), 40 \times$ water $(N A=1.2)$ and $63 \times$ oil (NA = 1.4) immersion objectives. Airy units for all images were set between 1 and 2.5. The image acquisition for migration experiments was automated through ZEN (Zeiss) software with imaging intervals for individual sections between 5-10 min. Microfluidic micropipette experiments were collected on a motorized inverted Zeiss Observer Z1 microscope equipped with either charge-coupled device cameras (Photometrics CoolSNAP EZ or Photometrics CoolSNAP KINO) or a sCMOS camera (Hamamatsu Flash 4.0) using a 20× air (NA = 0.8) objective. Cells stained for HSP1B by immunofluorescence were imaged using an Olympus IX83 inverted microscope with Slidebook 6.0 software (Intelligent Imaging Innovations), a $60 x$ oil immersion objective $(N A=1.35)$ and Hamamatsu Orca R2 monochrome CCD camera.

Analysis of immunofluorescent staining of lamins and Ki67 in cell monolayers and human tumors was performed using a custom-written MATLAB program available on request. DAPI-stained nuclei were used for segmentation of individual nuclei. For tumors, regions containing tumor cells, rather than stroma, were manually selected for inclusion in analysis. For each detected nucleus, mean Ki67 fluorescence intensity was calculated, and the nuclear rim was identified as the top $70 \%$ (human tumors) or $20 \%$ (cell monolayers) of pixels in the lamin staining. Intensity of both A-type and B-type lamins in the nuclear rim were quantified and lamin B signal was used for normalization of lamin $A$ to facilitate comparisons across tumor sections. For Ki67 staining, nuclei were counted as positive if the signal was 2 -fold above background for that image. For association of lamin levels and patient survival, the lamin A : lamin B ratios calculated were used to determine the optimal lamin A : lamin B cutoff to divide patients in having a good or bad prognosis (disease free survival). The analysis produced an optimal 
cutoff of the lamin A:lamin B ratio of 1.983 to define high and low groupings. Differences in survival were assessed using a Mantel-Cox log rank test.

Proliferation and cell morphology analysis. Cell lines were plated into 96 -well plate at an initial density of 500, 1000 , or 1500 cells/well and allowed to attach (3-4 hours) at $37^{\circ} \mathrm{C}$. Following this, plates were placed into the IncuCyte (Sartorius) incubator microscope system and imaged with a 20x air objective once every 0.5-1 hour for at least 3 days. Four images per well were taken at each time point. Zoom (Sartorius) software was used to establish an image processing mask and generate confluency percentages over time. Doubling time analysis was performed over data range where cells were in exponential growth phase as determined through IncuCyte imaging. Doubling time was calculated using the formula: Doubling time $=\ln ($ two $) /(\ln ($ CellsT2/CellsT1) $/$ (Time)), where CellsT1 $=$ initial confluency and CellsT2 $=$ final confluency and Time $=$ duration between initial and final counts. Images collected for proliferation experiments in the IncuCyte were also analyzed for cell morphological differences between BT-549 cells with exogenous expression of Lamin A plasmid (+LamA) or control plasmid. Cell spread area and shape analysis was performed using ImageJ (Schindelin et al., 2012). For filopodia analysis, images were blinded and analyzed for number of cells with protrusions.

Quantitative RT-PCR. For Akt inhibition experiments, MDA-231 cells were treated with $5 \mu \mathrm{M}$ of Afuresertib (GSK2110183, Selleckchem, Cat \#S7521) or DMSO (Sigma, Cat \#D2650) for 24 hours before lysis. For analysis of PyMT and Met 1 cells, roughly $3 \times 10^{6}$ cells were lysed in 500 ul of Trizol (Ambion, Cat \#15596018) for 10 min at room temperature. Chloroform (VWR Cat \#0757) was added at a 1:5 ratio, tubes were vigorously shaken and then spun down at full speed for $5 \mathrm{~min}$. The resulting top clear fraction was transferred to a gDNA Eliminator column and RNA extraction was carried out using a RNeasy Plus Mini Kit (Qiagen, Cat \#74136) as per manufacturer's instructions. The cDNA was generated using iScript select cDNA synthesis kit (Bio RAD, Cat \#1708897). The qRTPCR reactions were done using the LightCycler 480 SYBR green I kit (Roche Cat \#04077516001), using the following primers at a concentration of $5 \mu \mathrm{M}$ : Mouse-GAPDH-Frw 5'-GGAGAGTGTTTCCTCGTCCC-3', mouse-GAPDH-Rev 5'ATGAAGGGGTCGTTGATGGC-3', mouse-LMNA-Frw 5'-TCCACTGGAGAAGAGTGC-3', mouse-LMNA-Rev 5'CGCTGCAGTGGGAACCA-3', human-18S-Frw 5'-GGCCCTGTAATTGGAATGAGTC-3', human-18S-Rev 5'CCAAGATCCAACTACGAGCTT-3', human-GAPDH-Frw 5'-TGCGTCGCCAGCCGAG-3', human-GAPDH-Rev 5'AGTTAAAAGCAGCCCTGGTGA-3', human-LMNA-Frw 5'-GACTCAGTAGCCAAGGAGCG-3', human-LMNA-Rev 5'TTGGTATTGCGCGCTTTCAG-3'. Reactions were run on the LightCycler 480/384 machine (Roche serial \#1263) and analyzed using LightCycler 480 software (v 1.5.0).

SILAC Proteomic analysis. Quantitative proteomic sample preparation and analysis were performed as described previously (Bastos de Oliveira et al., 2015; Bastos de Oliveira et al., 2018; Kim et al., 2018). Briefly, BT-549 cells were cultured for a minimum of three passages ( $\approx 2$ weeks) in 'light' or 'heavy' SILAC media as indicated. SILAC media was composed of RPMI 1640 medium for SILAC (Thermo Fisher Scientific) supplemented with 10\% (v/v) dialyzed FBS, $2.0 \mathrm{~g} / \mathrm{L}$ sodium bicarbonate, $105 \mathrm{mg} / \mathrm{L}$ L-leucine, $200 \mathrm{mg} / \mathrm{L}$ proline, and 1\% (v/v) penicillin and 
streptomycin (PenStrep, ThermoFisher Scientific). The 'light' SILAC media was further supplemented with 'light' (normal) lysine $\left({ }^{12} \mathrm{C}_{6},{ }^{14} \mathrm{~N}_{2}\right)$ and arginine $\left({ }^{12} \mathrm{C}_{6},{ }^{14} \mathrm{~N}_{4}\right)$, while 'heavy' SILAC media was supplemented with 'heavy' lysine $\left({ }^{13} \mathrm{C}_{6},{ }^{15} \mathrm{~N}_{2}\right)$ and arginine $\left({ }^{13} \mathrm{C}_{6},{ }^{15} \mathrm{~N}_{4}\right)(100 \mathrm{mg} / \mathrm{L}$ for each). Cells were grown to $50-70 \%$ confluency at the time of sample collection and were collected by washing cells with PBS, briefly scraping to collect cells in PBS, and centrifugation at $1000 \mathrm{rpm}$ for 3 minutes at $4^{\circ} \mathrm{C}$, followed by washing the cell pellet an additional time in PBS. Cells were then lysed in modified RIPA buffer lacking SDS (NaF 50 mM, Tris-Cl pH7.5 50 mM, NaCl 150 mM, NP-40 1\%, EDTA $5 \mathrm{mM}$, Sodium deoxycholate $0.25 \%$ ). After 30 minutes on ice, DNA was sheared, followed by centrifugation for 5 minutes at $4^{\circ} \mathrm{C}$ and protein concentration of the supernatant was determined by Bradford assay. For each experiment ( $A$ and B as indicated), equal amounts of protein from BT- 549 control and +LamA cells were combined. The proteins were denatured and reduced (1\% SDS, $10 \mathrm{mM} \mathrm{DTT)}$ and alkylated with iodoacetamide and then precipitated with three volumes of a solution containing $50 \%$ acetone, $49.9 \%$ ethanol and $0.1 \%$ acetic acid. Proteins were trypsin-digested overnight at $37^{\circ} \mathrm{C}$ in $50 \mathrm{mM} \mathrm{Tris-} \mathrm{HCl}, \mathrm{pH} 8$ with $150 \mathrm{mM} \mathrm{NaCl}$ and $2 \mathrm{M}$ urea. Peptides were acidified ( $0.2 \%$ of trifluoroacetic acid and formic acid) and then purified using a Sep-Pak C18 Vac purification column (Waters). The eluted peptides were resuspended in $80 \%$ acetonitrile/1\% formic acid and fractionated using Hydrophilic Interaction Chromatography (HILIC). HILIC fractions were injected into a Q-Exactive Orbitrap and the data was analyzed using Sorcerer as described previously (Bastos de Oliveira et al., 2015; Bastos de Oliveira et al., 2018).

Statistical analysis. Unless otherwise noted, all values are expressed as mean +/- standard error of the mean and data were generated from a minimum of three independent biological replicates. In figure legends, $N$ is used to indicate the number of independent biological replicate experiments, and $n$ is used to indicate the number of cells analyzed. Values were considered to be significantly different when $p$ values were $<0.05$. The statistical tests used are indicated in the figure legend for each figure and were performed using Prism software (Graphpad) or SPSS (IBM). For correlations shown in Figure 1 (E, F, H, I) and Figure S1 (C-G), there was no significant departure from linearity based on runs test and similar results could be obtained by either Pearson correlation (linear regression $p$ values shown) or Spearman correlation.

\section{Online Supplemental Information}

Fig. S1 provides a schematic of the micropipette aspiration microfluidic device and shows that A-type lamins and lamin $\mathrm{A} / \mathrm{C}$ to lamin $\mathrm{B}$ ratios have an inverse correlation with nuclear deformability and nuclear area. Fig. S2 shows a schematic of the microfluidic device used to assess confined cell migration. Fig. S3 shows that decreasing lamin A/C levels enhances nuclear deformability of PyMT cells. Fig. S4 shows that decreasing lamin A/C levels does not significantly impact proliferation of PyMT cells. Fig. S5 compares the average immunofluorescence intensity of lamin A/C or lamin B in human tumors with the percentage of cells positive for the Ki67 proliferative marker in each tumor. Video 1 shows examples of micropipette aspiration of MDA-231 and HCC70 cells, which have very high and very low nuclear deformability, respectively. Video 2 shows MDA-468 cells migrating more efficiently through confined spaces upon depletion of lamin A/C by shRNA compared to non-target control cells. Video 3 
shows that increasing expression of lamin A impedes transit of MDA-231 cells through confined spaces relative to mock-modified control cells.

\section{Acknowledgements}

We thank Prof. Peter Friedl for the 4T1 progression series cell lines. This work was supported by funding from the National Institutes of Health (R01 HL082792, R01 GM137605, U54 CA210184, and U54 CA193461 to J.L., R35 GM141159 and R01 GM123018 to M.B.S.), the Department of Defense Breast Cancer Research Program (Breakthrough Award BC150580 to J.L), and the National Science Foundation (CAREER Award CBET-1254846 to J.L.).

The authors declare no competing interests.

Author contributions: E.S.B. and J.L. conceptualized and designed the experiments; J.L. supervised the research; E.S.B., P.S., N.Z.S., A.L.M. performed experiments and analyzed data; D.K. and M.S performed the SILAC proteomic analysis; P.I., J.J.E., P.M.D, J.N.L., and V.M.W. contributed to the development of resources, including constructs, cell lines, assays, and/or image analysis methods; P.N.S. and L.V. contributed human breast tumor tissue samples and analysis; E.B. and J.L. wrote the paper; all authors contributed to the editing of the manuscript; and J.L. and M.B.S. acquired funding. 
Page 20 
Table 1. Characteristics of human breast cancer cell lines.

\begin{tabular}{|c|c|c|c|c|c|c|}
\hline $\begin{array}{l}\text { Cell } \\
\text { line }\end{array}$ & Source & Subtype & $\begin{array}{l}\text { In vitro } \\
\text { growth }\end{array}$ & $\begin{array}{l}\text { In vitro } \\
\text { invasion }\end{array}$ & $\begin{array}{l}\text { In vitro 3-D } \\
\text { colony } \\
\text { morphology }\end{array}$ & Tumor growth in immunocompromised mice* \\
\hline $\begin{array}{l}\text { MDA- } \\
231\end{array}$ & $\begin{array}{l}\text { AC, Pleural } \\
\text { effusion } \\
\text { (Cailleau et } \\
\text { al., 1978) }\end{array}$ & $\begin{array}{l}\text { Basal B / } \\
\text { Claudin } \\
\text { low }\end{array}$ & $24 \mathrm{~h}$ & +++++ & Invasive & $\begin{array}{l}\text { Fast growing (lorns et al., 2012), locally invasive (Thompson } \\
\text { et al., 1992), and a commonly used model for breast cancer } \\
\text { metastasis to lung, liver, lymph nodes, bone, brain, and } \\
\text { ovaries (Bos et al., 2009; lorns et al., 2012; Kang et al., 2003; } \\
\text { Minn et al., 2005; Puchalapalli et al., 2016; Yin et al., 1999). }\end{array}$ \\
\hline BT-549 & $\begin{array}{l}\text { PIDC, } \\
\text { Primary } \\
\text { tumor } \\
\text { (Lasfargues } \\
\text { and } \\
\text { Coutinho, } \\
\text { 1981) }\end{array}$ & $\begin{array}{l}\text { Basal B / } \\
\text { Claudin } \\
\text { low }\end{array}$ & $24 \mathrm{~h}$ & +++++ & Invasive & $\begin{array}{l}\text { Originally thought to be non-tumorigenic and may require } \\
\text { addition of Matrigel for growth in MFPs of nude mice (Lee et } \\
\text { al., 2018; Thompson et al., 1992). Infrequently used in vivo } \\
\text { for tumor growth assays (MFP and SC injection) and for lung } \\
\text { metastasis from circulation assays (Banerjee et al., 2011; } \\
\text { Chen et al., 2017; Hahn et al., 1999; Jiang et al., 2020; } \\
\text { Murthy et al., 1995; Tate et al., 2012; Walsh et al., 2017; } \\
\text { Yoon et al., 2012). }\end{array}$ \\
\hline MCF7 & $\begin{array}{l}\text { IDC, Pleural } \\
\text { effusion } \\
\text { (Soule et } \\
\text { al., 1973) }\end{array}$ & Luminal & $48 \mathrm{~h}$ & ++ & $\begin{array}{l}\text { Spherical / } \\
\text { non-invasive }\end{array}$ & $\begin{array}{l}\text { Poorly invasive (Thompson et al., 1992) and rarely } \\
\text { metastatic in nude mice (Clarke, 1996; Ozzello and Sordat, } \\
\text { 1980; Shafie and Liotta, 1980), but some metastasis has } \\
\text { been documented in NSG mice (lorns et al., 2012). } \\
\text { Commonly used as a model of luminal breast cancer when } \\
\text { estrogen supplementation is used to enhance tumorigenicity } \\
\text { (Lacroix and Leclercq, 2004; Ogba et al., 2014). }\end{array}$ \\
\hline T47D & $\begin{array}{l}\text { IDC, Pleural } \\
\text { effusion } \\
\text { (Keydar et } \\
\text { al., 1979) }\end{array}$ & Luminal & $60 \mathrm{~h}$ & + & $\begin{array}{l}\text { Spherical / } \\
\text { non-invasive }\end{array}$ & $\begin{array}{l}\text { Poorly invasive and rarely metastatic in nude mice (Clarke, } \\
\text { 1996). Commonly used as a model of luminal breast cancer } \\
\text { when estrogen supplementation is used to enhance } \\
\text { tumorigenicity (Lacroix and Leclercq, 2004; Ogba et al., } \\
\text { 2014). }\end{array}$ \\
\hline BT-474 & $\begin{array}{l}\text { IDC, } \\
\text { Primary } \\
\text { tumor } \\
\text { (Lasfargues } \\
\text { et al., } \\
\text { 1978) }\end{array}$ & HER2+ & $96 \mathrm{~h}$ & + & $\begin{array}{l}\text { Spherical / } \\
\text { non-invasive }\end{array}$ & $\begin{array}{l}\text { Poorly tumorigenic, and rarely metastatic (lorns et al., 2012), } \\
\text { but growth can be enhanced by addition of Matrigel (Price, } \\
\text { 1996). } \\
\text { Used as a model for HER2-dependent breast cancer. }\end{array}$ \\
\hline SKBR3 & $\begin{array}{l}\text { AC, Pleural } \\
\text { effusion } \\
\text { (Fogh, } \\
\text { 1975) }\end{array}$ & HER2+ & $60 \mathrm{~h}$ & + & $\begin{array}{l}\text { Spherical / } \\
\text { non-invasive }\end{array}$ & $\begin{array}{l}\text { Poorly tumorigenic (Price, 1996; Thompson et al., 1992), but } \\
\text { still used for some in vivo studies as a model for HER2- } \\
\text { dependent breast cancer (Capietto et al., 2011; Cho et al., } \\
\text { 2005). }\end{array}$ \\
\hline $\begin{array}{l}\text { MDA- } \\
468\end{array}$ & $\begin{array}{l}\text { AC, Pleural } \\
\text { effusion } \\
\text { (Cailleau et } \\
\text { al., 1978) } \\
\end{array}$ & Basal A & $48 \mathrm{~h}$ & + & $\begin{array}{l}\text { Spherical / } \\
\text { non-invasive }\end{array}$ & $\begin{array}{l}\text { Slow tumor growth, poorly invasive, and rarely metastatic } \\
\text { (Marusyk et al., 2014; Thompson et al., 1992). }\end{array}$ \\
\hline HCC70 & $\begin{array}{l}\text { DC, Primary } \\
\text { tumor } \\
\text { (Gazdar et } \\
\text { al., 1998) }\end{array}$ & Basal A & $72 \mathrm{~h}$ & N.D. & $\begin{array}{c}\text { Spherical / } \\
\text { non-invasive }\end{array}$ & $\begin{array}{l}\text { Poorly tumorigenic, rarely metastatic (Khawaled et al., 2019) } \\
\text { and not commonly used for in vivo studies. Growth can be } \\
\text { enhanced by addition of Matrigel (Simon et al., 2016). }\end{array}$ \\
\hline
\end{tabular}

Cell sources and subtype refer to the breast tumor type and site of isolation (Neve et al., 2006; Prat et al., 2010). AC = adenocarcinoma, $\mathrm{PIDC}=$ papillary invasive ductal carcinoma, IDC = invasive ductal carcinoma, $\mathrm{DC}=$ ductal carcinoma, $\mathrm{MFP}=$ mammary fat pad, $\mathrm{SC}=$ subcutaneous N.D. = not determined. In vitro growth data based on population doubling time in culture (Nair et al., 2019). In vitro invasion data is based on Boyden chamber invasion through Matrigel (Neve et al., 2006; Thompson et al., 1992), with results ranging from weakly invasive (+) to highly invasive (+++++). In vitro 3-D colony morphology is based on observations of colonies embedded in Matrigel (Kenny et al., 2007; Thompson et al., 1992).

*Note: Direct comparisons of tumorigenicity across studies are difficult as tumor growth varies dramatically depending on cell number used, transplantation site, mouse model (Puchalapalli et al., 2016), and supplementation with Matrigel or estrogen. The most common uses and observations are summarized, but each cell line described is capable of growth in vivo under the right experimental conditions. 

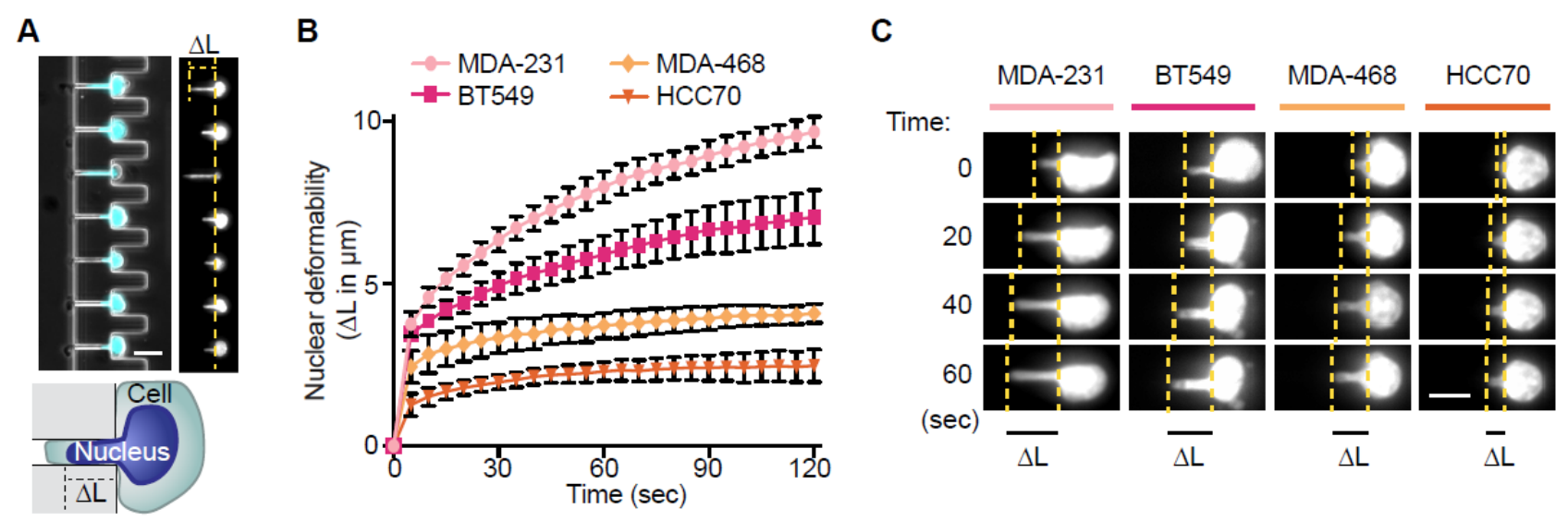

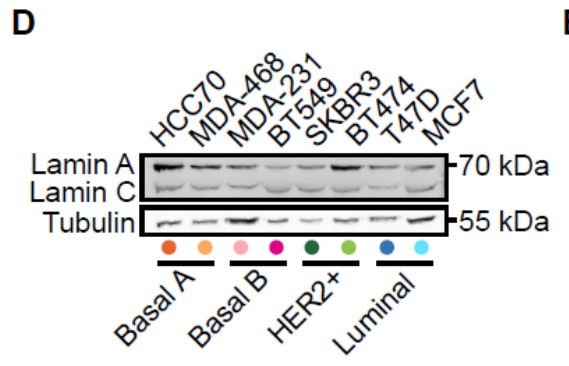

Breast cancer subtype classification
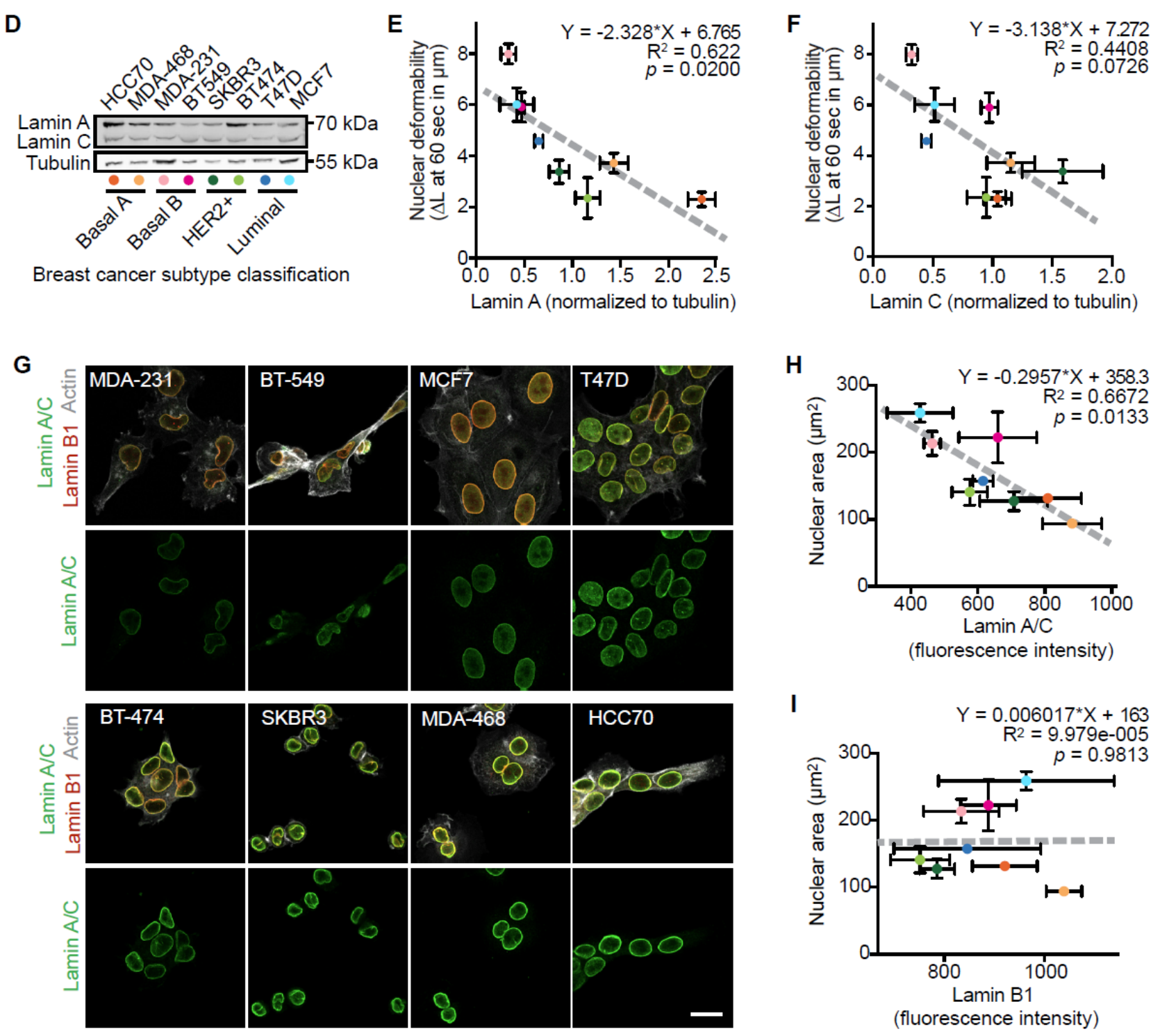

Figure 1. Nuclear size and stiffness vary widely across breast cancer cell lines and correspond to lamin A/C levels.

(A) Images and schematic of nuclear deformation into a microfluidic micropipette aspiration device under an 
externally applied pressure. The length of nuclear protrusion $(\Delta \mathrm{L})$ into the $3 \times 5 \mu \mathrm{m}^{2}$ channel was measured every 5 seconds at constant pressure application. Scale bar $=20 \mu \mathrm{m}$. (B) Nuclear protrusion curves for four representative human breast cancer cell lines with different degrees of nuclear deformability. $N=3$, mean \pm SEM. (C) Representative time-lapse image series of deformation of fluorescently labeled nuclei of MDA-231, BT-549, MDA-468, and HCC70 cells in the microfluidic micropipette aspiration device. Scale bar $=10 \mu \mathrm{m}$. (D) Representative example of Western blot for lamin A/C in a panel of human breast cancer cell lines. Breast cancer subtype classifications are indicated; colored dots correspond to the data for each cell line presented in panels EF. Tubulin served as loading control. (E and F) Nuclear deformability, assessed based on the nuclear protrusion length into the micropipette at 60 seconds of aspiration ( $N=3$ independent experiments), shows an inverse correlation with lamin A (E) and lamin C (F) levels determined by western blot analysis $(N=3)$. Mean \pm SEM. The linear regression results are indicated on each graph. (G) Representative examples depicting lamin $A / C$ immunolabeling and cell morphology for each human breast cell line studied. Scale bar $=20 \mu \mathrm{m}$. (H and I) Quantification of nuclear cross-sectional area and lamin levels in adherent cells plated on glass coverslips and immunofluorescently labeled as shown in panel G. $N=3$, mean \pm SEM. Larger nuclear cross-sectional area correlates with decreased lamin A/C levels. Lamin B1 levels were less variable between cell lines and did not correlate with nuclear cross-sectional area. Linear regression analysis is indicated on each graph. 
A

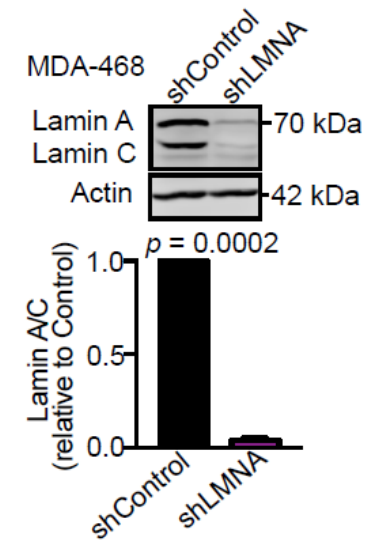

D
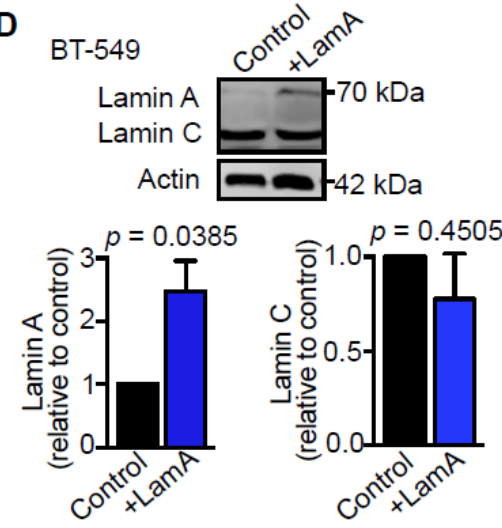

G
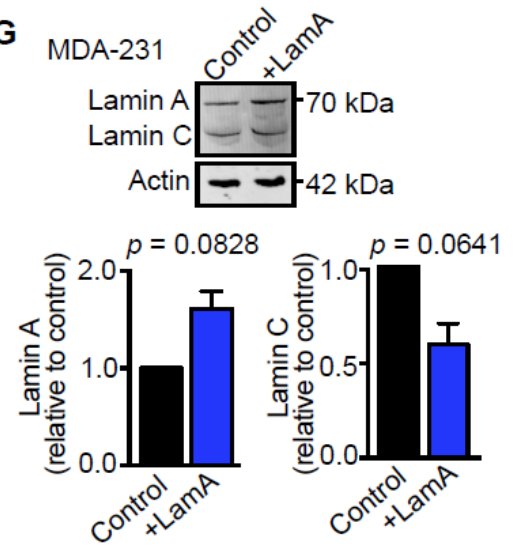

B

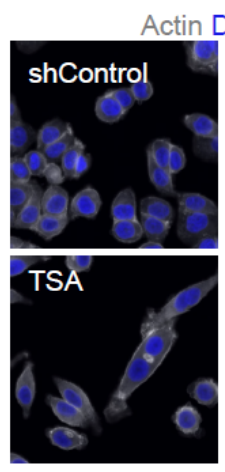

E

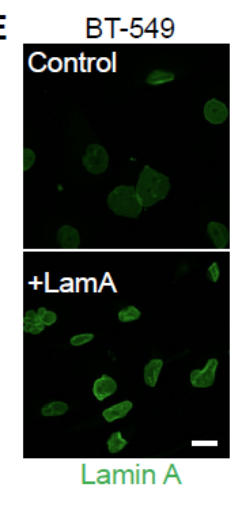

H

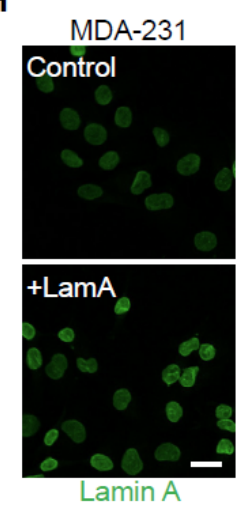

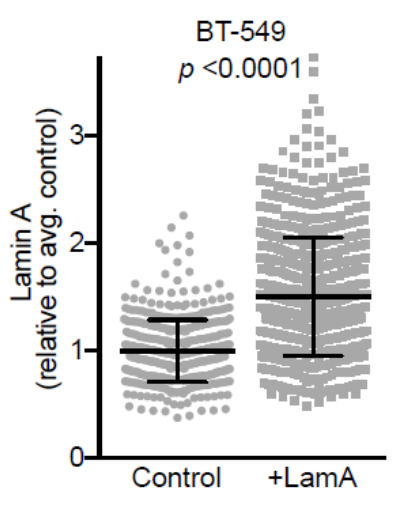

$\mathbf{F}$

BT -549

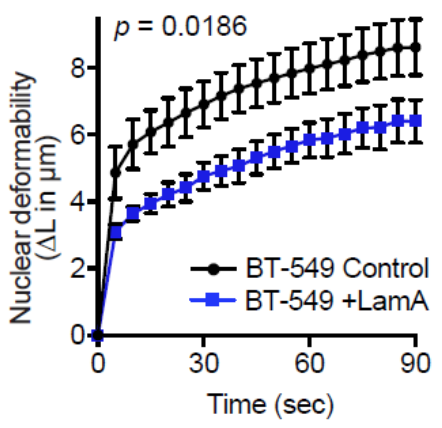

I

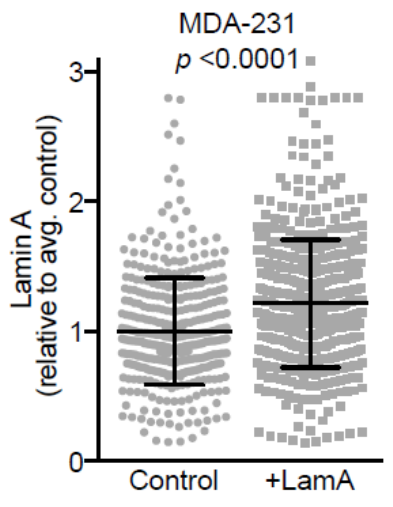

MDA-231

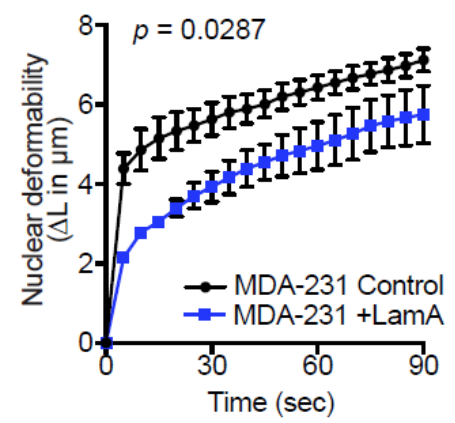

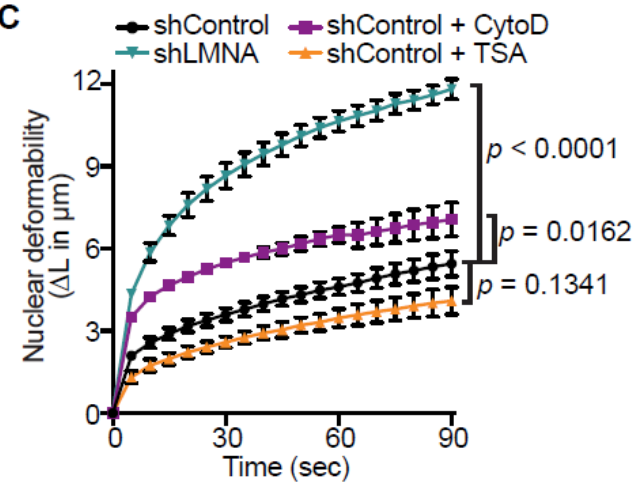

Figure 2. Decreased A-type lamin levels result in the enhanced nuclear deformability of invasive breast cancer cells. (A) Representative western blot and quantification ( $N=3$, mean $\pm S E M)$ showing decreased lamin $A / C$ levels in MDA-468 cells expressing LMNA shRNA or non-target control. Lamin A/C levels were normalized to non-target control in each Western blot. Significance based on one-sample $t$-test compared to a theoretical value of 1. (B) Representative images of MDA-468 cells stained for DNA (DAPI) and F-actin (phalloidin) to assess the effect of lamin $A / C$ depletion (shLMNA), inhibition of actin polymerization by cytochalasin $D$ (CytoD, $4 \mu \mathrm{M}$ for 20 minutes), or inhibition of histone deacetylation by trichostatin A (TSA, 4 nM for 12 hours) on cell and nuclear morphology. Scale bar $=20 \mu \mathrm{m}$. (C) Micropipette aspiration in a microfluidic device was used to assess which cellular components have the greatest impact on nuclear deformability. MDA-468 shLMNA cells and MDA-468 and non- 
target controls (shControl) cells treated with CytoD, TSA, or DMSO vehicle control. Statistical analysis based on two-way repeated measures (RM) ANOVA with Tukey's multiple comparisons test. $N=3$, mean \pm SEM. (D) Representative western blot and corresponding quantification from five independent experiments probed for lamin A/C lamin levels in BT-549 cells with exogenous expression of Lamin A (+LamA) and mock controls. Actin was used as loading control. Statistical analysis based on one-sample $t$ test with a theoretical value of 1 (control). Data shown as mean \pm SEM. (E) Examples of immunofluorescent staining of lamins in BT-549 cells expressing exogenous lamin A (+LamA) or control construct and quantification of nuclear rim lamin A staining intensity. Statistics based on two-tailed unpaired Student's $t$ test. Mean \pm SD, $n=475$ and 661 cells quantified across 3 independent experiments. Scale bar $=20 \mu \mathrm{m}$. (F) BT-549 cells with addition of lamin A exhibit decreased nuclear deformability as determined by micropipette aspiration in a microfluidic device. Statistical analysis based on twoway RM ANOVA. $N=7$, mean \pm SEM. (G) Representative western blot for lamin A in MDA-231 control and +LamA cells and corresponding quantification based on three independent experiments. Statistical analysis based on onesample $t$ test with a theoretical value of 1 . Data plotted as mean \pm SEM. (H) Examples of immunofluorescent staining of lamins in MDA-231 cells expressing exogenous Lamin A (+LamA) or control construct and quantification of nuclear rim lamin staining by immunofluorescence. Statistical analysis based on two-tailed unpaired Student's $t$ test. Mean \pm SD, $n=404$ and 546 cells quantified across 2 independent experiments. Scale bar $=20 \mu \mathrm{m}$. (I) MDA231 cells with addition of lamin A exhibit decreased nuclear deformability as determined by micropipette aspiration in a microfluidic device. Statistical analysis based on two-way RM ANOVA. $N=3$, mean \pm SEM. 
A MDA-468

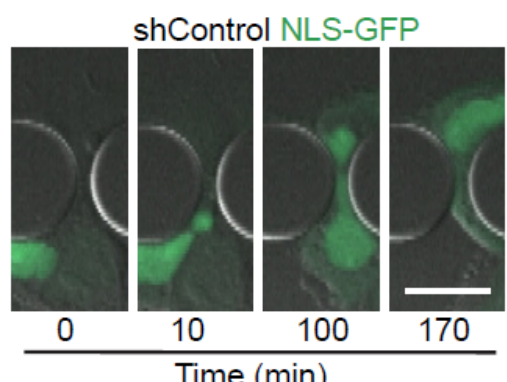

C $\quad$ BT-549

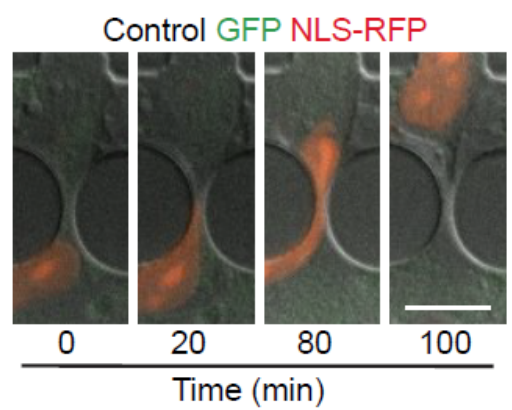

E MDA-231

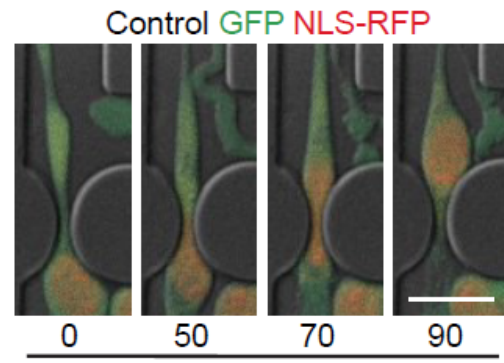

Time (min)

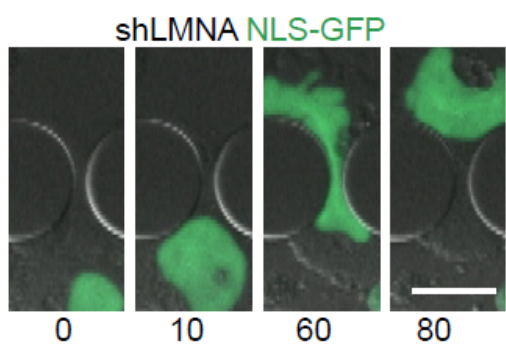

Time ( $\mathrm{min}$ )
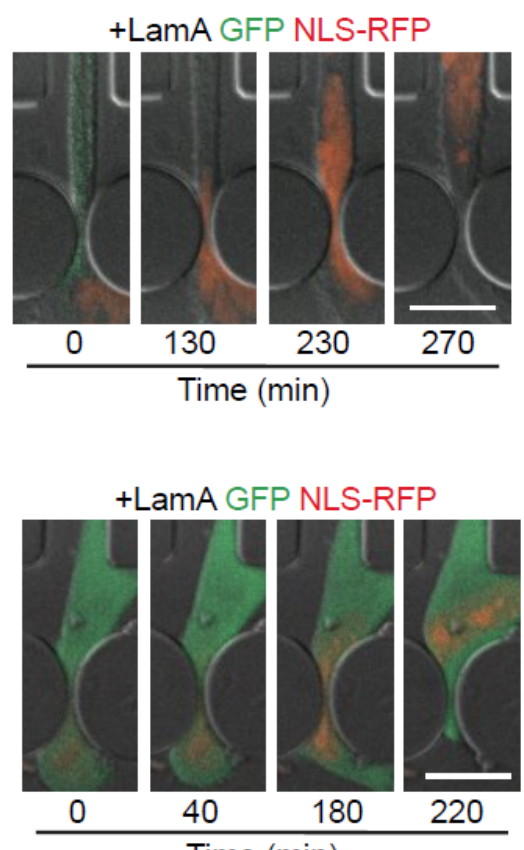

Time (min)
B $\leq 2 \times 5 \mu \mathrm{m}^{2}$
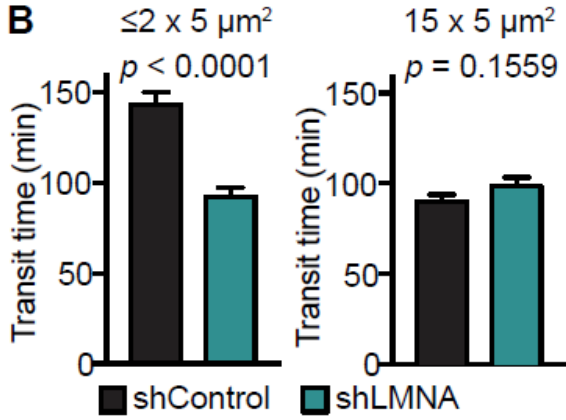

D

$\leq 2 \times 5 \mu \mathrm{m}^{2}$

$15 \times 5 \mu \mathrm{m}^{2}$

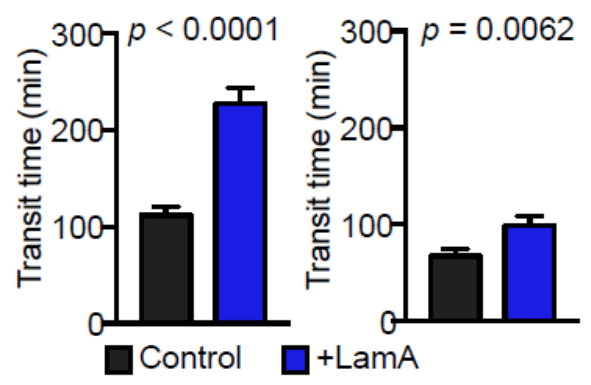

F $\quad \leq 2 \times 5 \mu \mathrm{m}^{2}$

$15 \times 5 \mu \mathrm{m}^{2}$

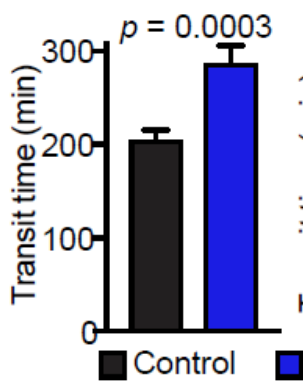

$p=0.5863$

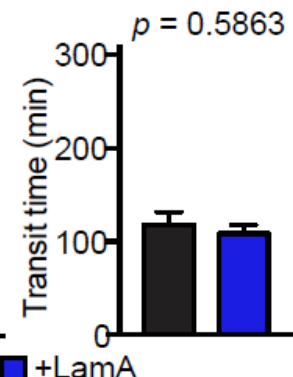

Figure 3. Decreased Lamin A levels facilitate migration through confined spaces. (A) Representative image sequences of MDA-468 cells expressing shControl and shLMNA as the cells migrate through $\leq 2 \times 5 \mu \mathrm{m}^{2}$ constrictions along a $0.1 \%$ to $12 \%$ FBS gradient. (B) Transit times for MDA-468 shControl and shLMNA cells moving through $\leq 2 \times 5 \mu \mathrm{m}^{2}$ ( $n=252$ and 213 cells) or $15 \times 5 \mu \mathrm{m}^{2}$ ( $n=224$ and 206 cells) constrictions along a $0.1 \%$ to $12 \%$ FBS gradient. (C) Representative image sequences of BT-549 Control and +LamA cells migrating through $\leq 2 \times 5$ $\mu \mathrm{m}^{2}$ constrictions. (D) Transit times for BT-549 Control and +LamA cells moving through $\leq 2 \times 5 \mu \mathrm{m}^{2}(n=142$ and 108 cells) or $15 \times 5 \mu \mathrm{m}^{2}$ ( $n=71$ and 61 cells) constrictions. (E) Image sequences of MDA-231 Control and +LamA cells migrating through $\leq 2 \times 5 \mu \mathrm{m}^{2}$ constrictions. (F) Transit times for MDA-231 Control and +LamA cells moving through $\leq 2 \times 5 \mu \mathrm{m}^{2}$ ( $n=142$ and 83 cells) or $15 \times 5 \mu \mathrm{m}^{2}$ ( $n=33$ and 42 cells) constrictions. For all cell lines, transit time calculations were collected from across a minimum of three independent experiments and displayed as mean \pm SEM. Statistical analysis based on two-tailed unpaired Student's $t$ test. Scale bars $=20 \mu \mathrm{m}$. 
A
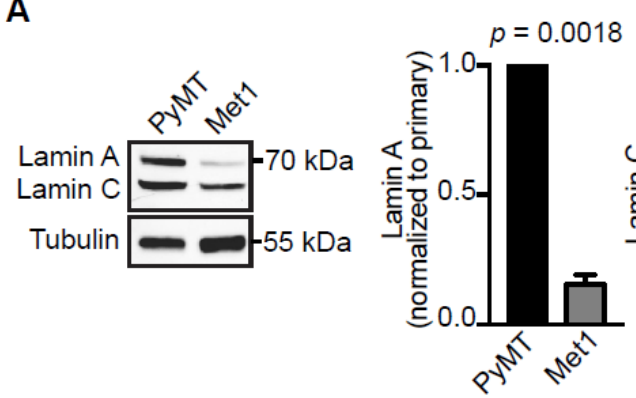

B

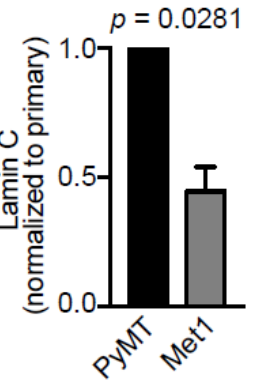

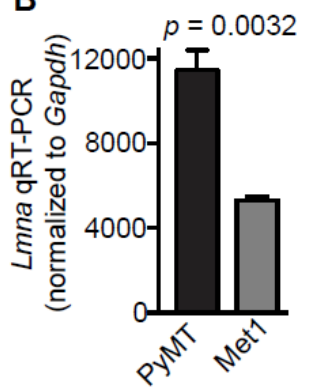

C

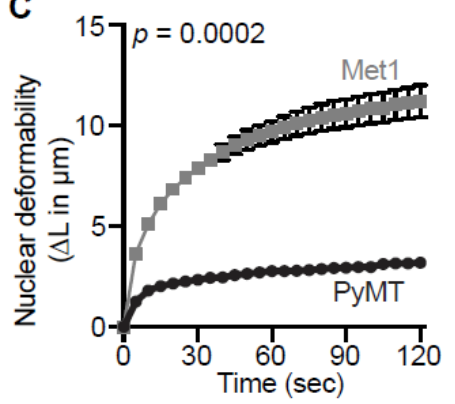

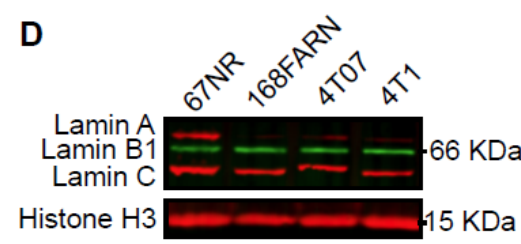

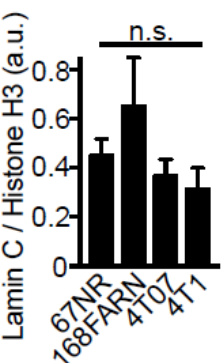

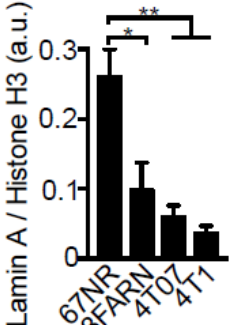

$10^{\circ}$
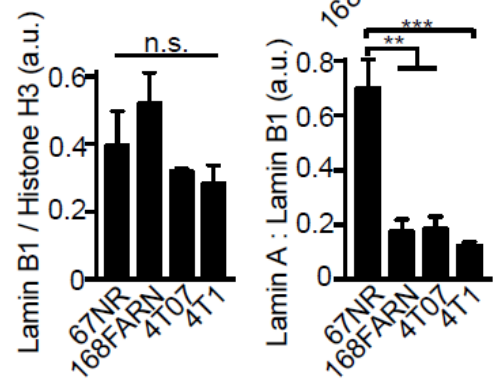

E
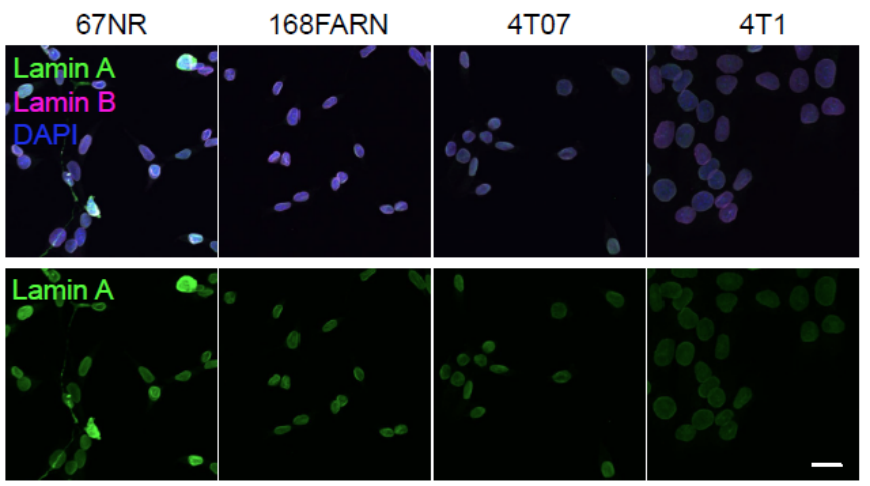

Lamin A level

Metastatic capacity

Figure 4. Breast cancer cells with increased metastatic capacity have reduced lamin $A$ expression. (A) Representative western blot and corresponding quantification $(N=3$, mean $\pm S E M)$ for lamin $A / C$ levels in MMTVPyMT transgenic mouse tumor model cell lines from a primary tumor (PyMT) or the highly metastatic Met1 line derived from a late-stage MMTV-PyMT tumor. Tubulin served as a loading control. Statistical analysis based on one-sample $t$ test with a theoretical value of 1. (B) Quantitative RT-PCR for Lmna mRNA in the metastatic Met1 cells compared to the primary tumor PyMT line. Mean $\pm \mathrm{SEM}, N=3$. Statistical analysis by two-tailed unpaired Student's t test. (C) Nuclear protrusion curves comparing nuclear deformability of Met1 and PyMT cells upon micropipette aspiration in a custom microfluidic device. Mean $\pm \mathrm{SEM}, N=3$. Statistical analysis based on two-way RM ANOVA. (D) Representative western blot and corresponding quantification ( $N=3$, mean \pm SEM) of lamin levels in cell lines from the 4T1 mouse mammary tumor metastatic progression series. Histone $\mathrm{H} 3$ is included as a loading control. Statistical analysis based on one-way ANOVA with Tukey's multiple comparisons. ${ }^{*}, p=0.0192,{ }^{* *}, p$ $<0.01, * * *, p=0.0008$. (E) Representative examples of immunofluorescent staining of lamins in the 4T1 metastatic progression series cell lines. Cell lines are displayed in order of increasing propensity for metastasis during tumor growth in the mouse mammary fat pad. Schematic representation of lamin levels based on the general trend shown in panel D. Scale bar $=20 \mu \mathrm{m}$. 


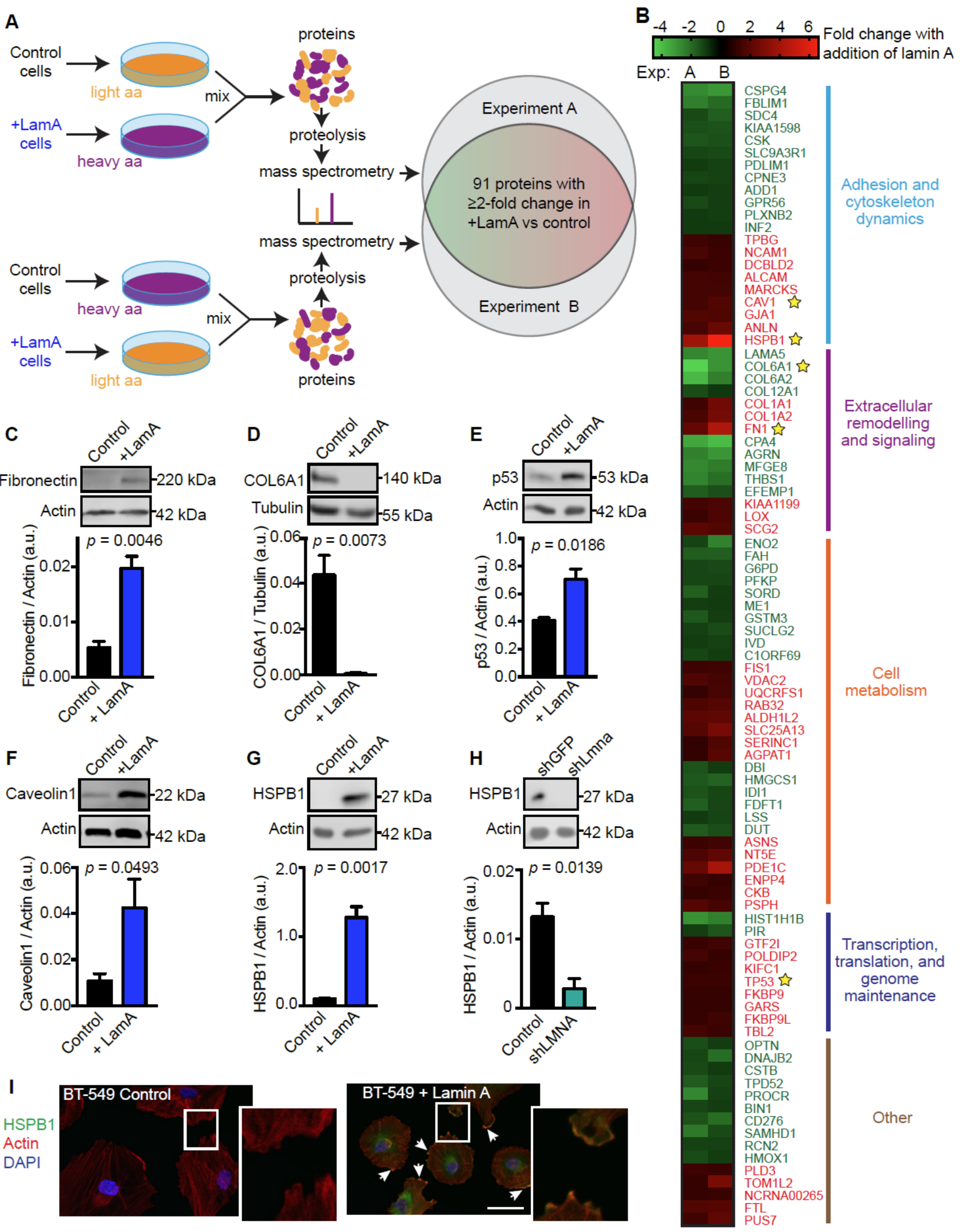


Figure 5. Increasing lamin A in breast cancer cells alters expression of proteins involved in cell metabolism, extracellular remodeling, adhesion, and cytoskeleton dynamics. (A) Schematic for the design of the SILAC experiments to identify proteins altered upon increased lamin A expression in BT-549 cells. Cells were cultured in media containing normal/light amino acids or heavy amino acids (L-lysine ${ }^{13} \mathrm{C}_{6},{ }^{15} \mathrm{~N}_{2}$ and L-arginine ${ }^{13} \mathrm{C}_{6},{ }^{15} \mathrm{~N}_{4}$ ) for 2 weeks prior to analysis. (B) Proteins listed here were detected to have $\geq 2$-fold change in both of two experiments comparing +LamA and control BT-549 cells. Increase (red) and decrease (green) in protein abundance in + LamA cells relative to controls is indicated by color on a log2 scale; proteins are listed in functional groupings. Lamin $A / C$ was detected at $\approx 1$.7-fold increase in +LamA cells compared to control cells in both experiments. Yellow stars indicate proteins selected for validation by western blot analysis. (C-G) Representative western blots and corresponding quantification of protein levels in BT-549 control and +LamA cells to validate SILAC results for fibronectin (FN, $N=3)$, collagen 6A1 (COL6A1, $N=3)$, p53 (TP53, $N=3)$, caveolin $1($ CAV1, $N=4)$, and HSPB1 ( $N=$ 3). Tubulin and actin were used as loading controls. Data displayed as mean \pm SEM. Statistical analysis by twotailed unpaired Student's $t$ test. (H) Representative western blot and corresponding quantification $(N=3$, mean \pm SEM) of HSPB1 levels in PyMT mouse mammary tumor cells with shRNA-mediated knockdown of Lmna or nontargeting control shRNA. Actin was included as a loading control. Statistical analysis by two-tailed unpaired Student's $t$ test. (I) Representative images of immunofluorescence staining of HSPB1 in BT-549 cells. White arrows and insets highlight accumulation of HSPB1 at membrane protrusions in cells expressing exogenous lamin A relative to controls. Scale bar $=20 \mu \mathrm{m}$. 


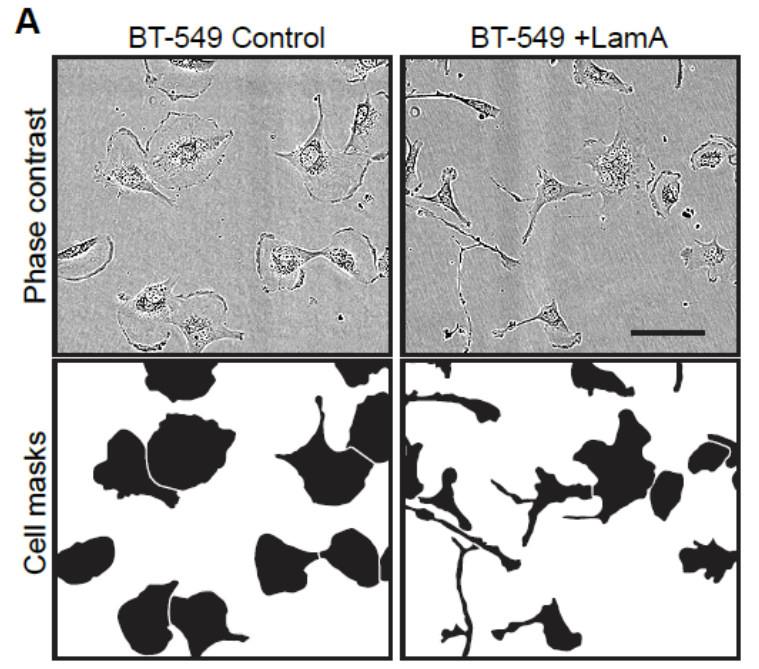

C
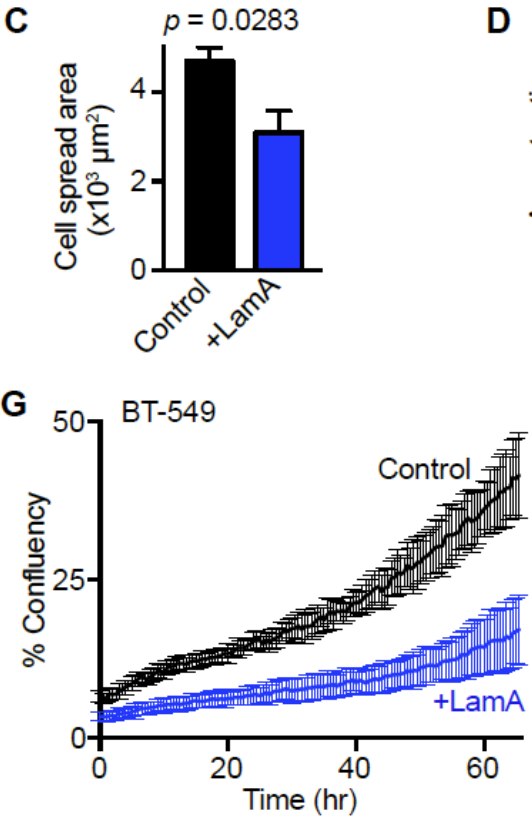

B

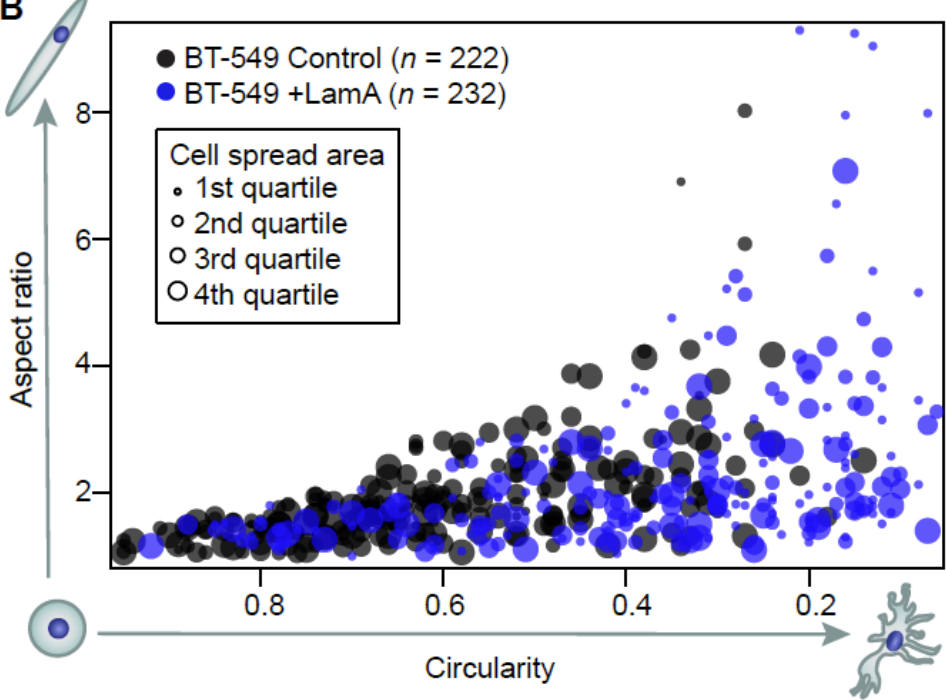

$\mathbf{E}$

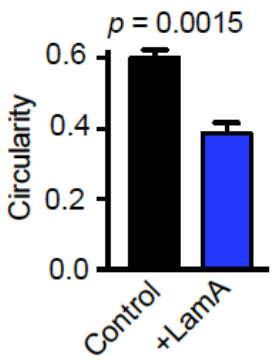

$\mathbf{F}$
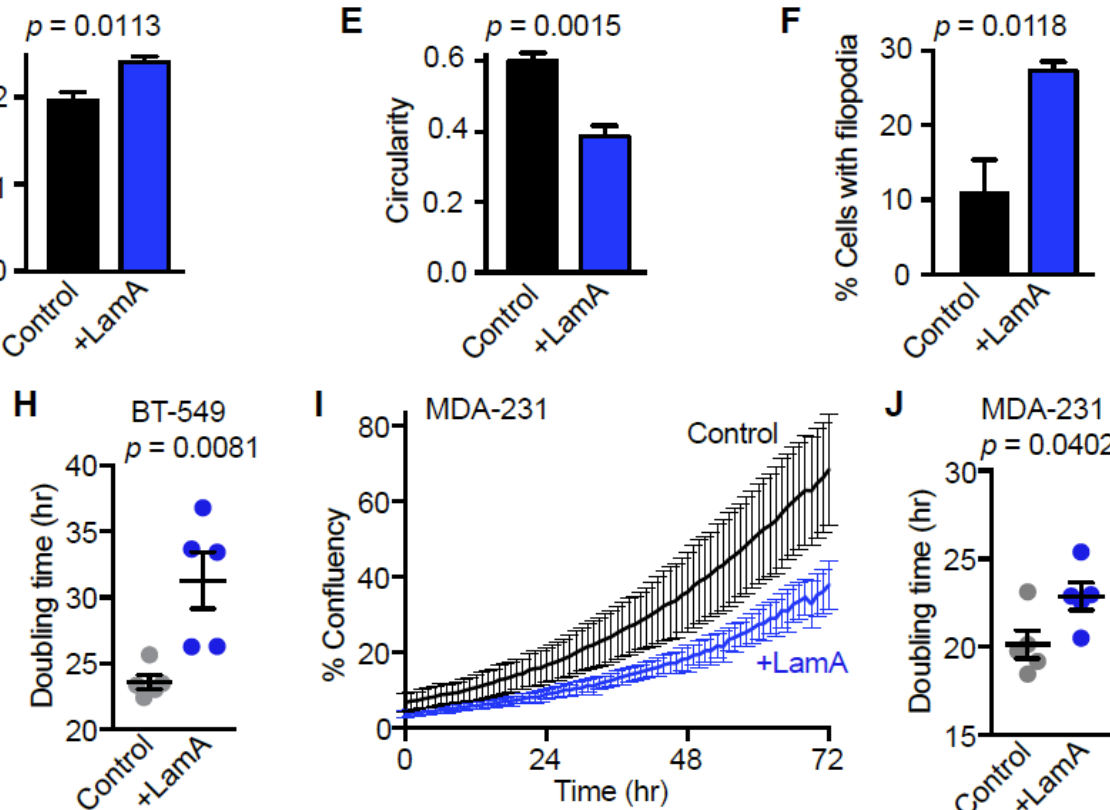

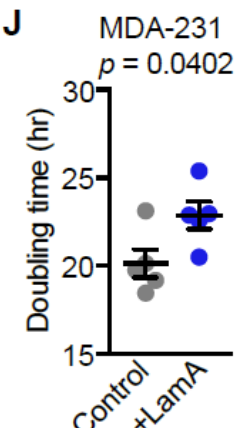

Figure 6. Lamin A levels modulate breast cancer cell morphology and proliferation. (A) Representative images showing morphology of BT-549 control and +LamA cells. Scale bar $=100 \mu \mathrm{m}$. (B) Quantification of cell morphology (circularity, aspect ratio and cell spread area) for BT-549 control and +LamA cells. Larger marker size indicates larger cell spread area. Data shown were collected across 4 independent experiments. (C-F) Adherent BT-549 control and +Lam A cells were quantified $(N=4$, mean \pm SEM) to determine cell spread area $(C)$, cell aspect ratio (D), cell circularity (E), and the percentage of cells exhibiting filopodia-like protrusions (F). Statistical analysis by two-tailed unpaired Student's $t$ test. (G) Representative proliferation curves for BT-549 control and +LamA cells. Data shown represent a single experimental replicate where measurements were collected from images taken every 0.5 hour from 7 wells per condition plotted as mean \pm SD. (H) Doubling times were calculated for BT-549 control and + LamA cells from $N=5$ independent experiments. Data plotted as mean \pm SEM and statistical analysis 
by two-tailed unpaired Student's $t$ test. (I) Representative proliferation curves for MDA-231 control and +LamA cells. Data shown represent a single experimental replicate where measurements were collected from images taken every 0.5 hour from 7 wells per condition plotted as mean \pm SD. (J) Doubling times were calculated for MDA231 control and + LamA cells from $N=5$ independent experiments. Data plotted as mean \pm SEM and statistical analysis by two-tailed unpaired Student's $t$ test. 

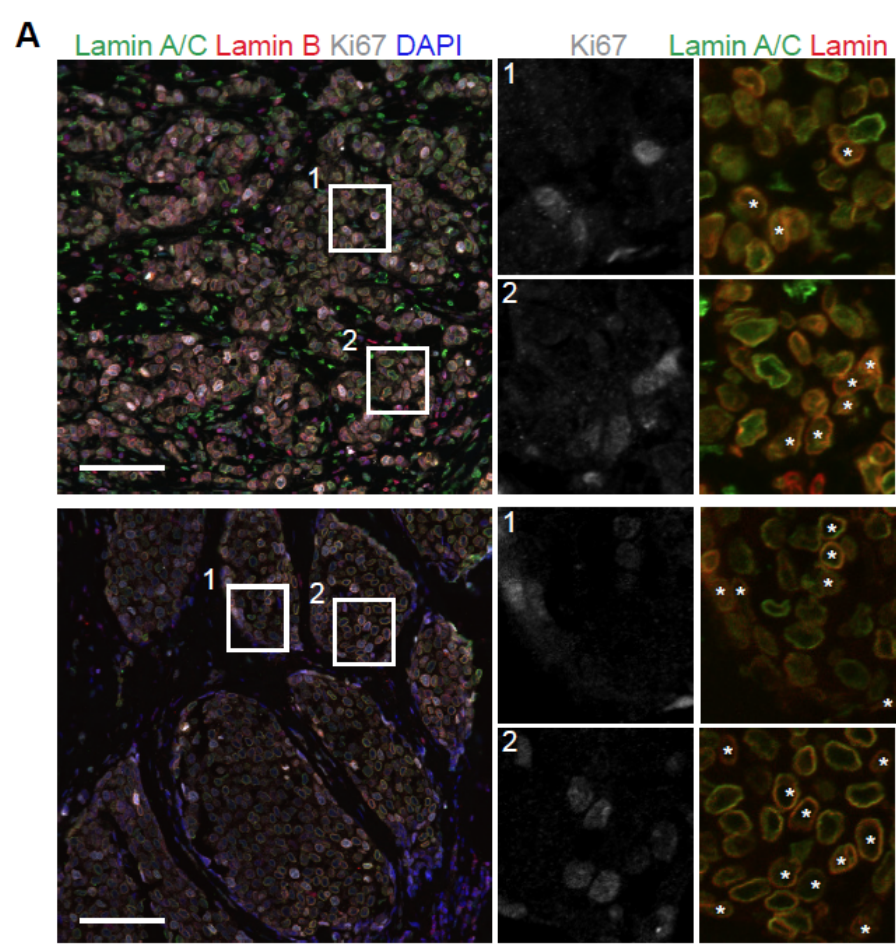

$\mathbf{F}$
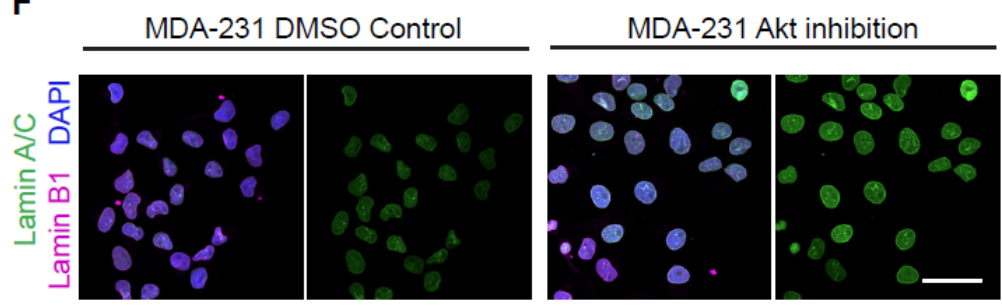

B

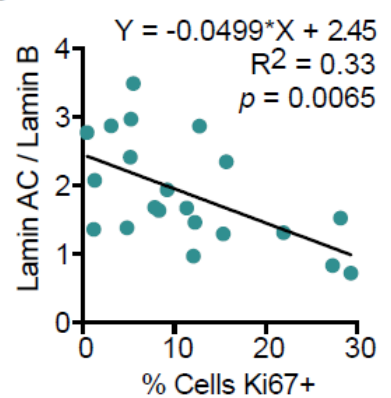

D
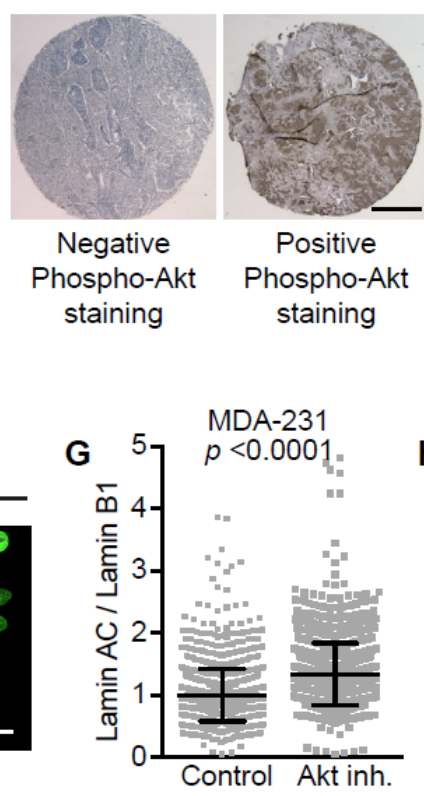

C

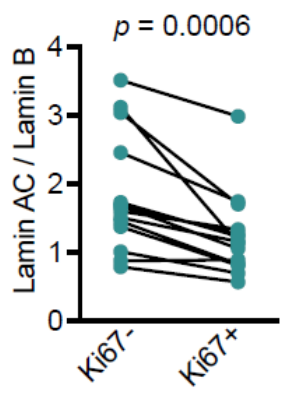

E

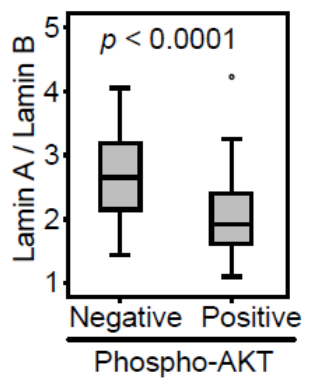

H

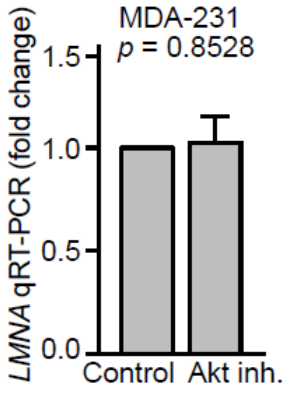

Figure 7. Decreased A-type lamin levels are associated with increased proliferation and Akt signaling in human breast tumors. (A) Images show examples of immunofluorescent staining for lamins and the Ki67 proliferative marker in two human tumor samples. In the inset showing lamin staining, Ki67-positive cells are indicated with white asterisks. Scale bars $=100 \mu \mathrm{m}$. (B) The average lamin A/C to lamin B ratio per tumor ( $N=21$ human tumors) was quantified as nuclear rim lamin intensity from immunofluorescent staining and showed an inverse correlation with the percentage of proliferative cells. Total cell count was based on the number of DAPI-stained nuclei and cells were counted as proliferative when Ki67 positivity was 2-fold above background. The linear regression results are indicated. (C) Pairwise comparison of Lamin A/C to lamin B ratio in Ki67+ (proliferating) cells and Ki67- cancer cells within individual tumors ( $N=14$ tumors). Only tumors with at least 10 Ki67-positive cells were included. Lamin A/C : lamin B ratio calculated from nuclear rim immunofluorescent staining intensity. Statistical analysis by two-tailed paired Student's $t$ test. (D) Representative images of negative and positive immunohistochemistry staining of phospho-Akt in tumor sections from a breast cancer tissue microarray (TMA) generated from patients that had not received any systemic treatment. Scale bar $=500 \mu \mathrm{m}$. (E) Phosphorylation of Akt was previously scored in a breast cancer TMA (Wennemers et al., 2013), and immunofluorescent lamin staining and quantification of nuclear rim staining intensity in this same TMA revealed that Akt signaling was associated with lower lamin A : 
lamin B ratio. Statistical analysis by two-tailed unpaired Student's t test. ( $N=89$ tumors, see Wennemers et al. 2013 for original P-Akt scoring). (F) MDA-231 cells were treated with an Akt inhibitor (Afuresertib, $5 \mu \mathrm{M}$ for 24 hours) and stained for lamins by immunofluorescence. Representative merged image and Lamin A/C alone (green) are shown. Scale bar $=20 \mu \mathrm{m}$. (G) Quantification of lamin immunofluorescent staining intensity in the nuclear rim in MDA-231 cells treated as in (F). Analyzed cells ( $n=1409$ and 1376 cells) were pooled from two independent experiments and plotted as mean \pm SD. Statistical analysis by two-tailed unpaired Student's $t$ test. (H) Analysis of LMNA gene expression by qRT-PCR in MDA-231 cells treated with an Akt inhibitor (Afuresertib, $5 \mu \mathrm{M}$ for 24 hours). Data collected from $N=3$ independent experiments and plotted as mean \pm SEM. Statistical analysis by one-sample $t$ test with a theoretical value of 1 . 
A

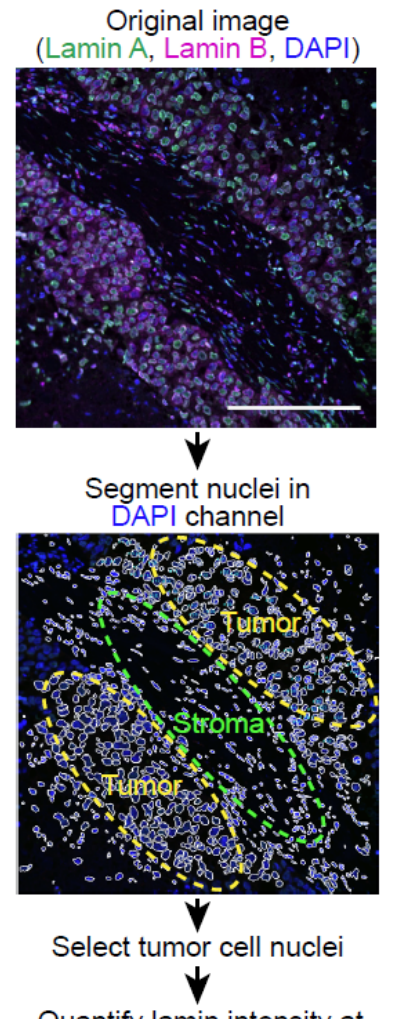

Quantify lamin intensity at nuclear rim of each tumor cell

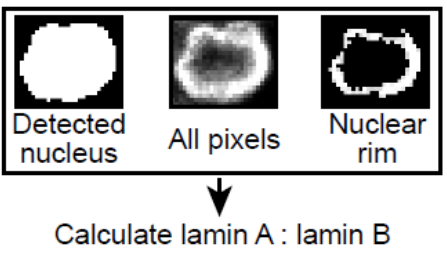
ratio for each cell
B

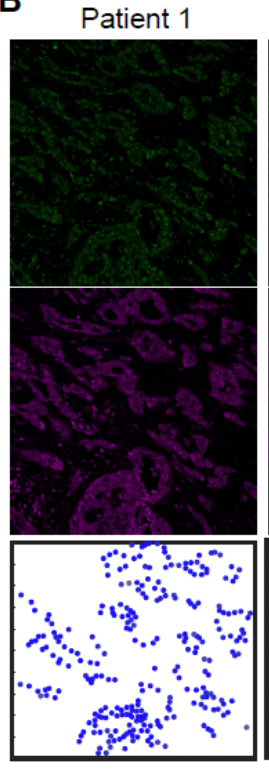

Patient 2

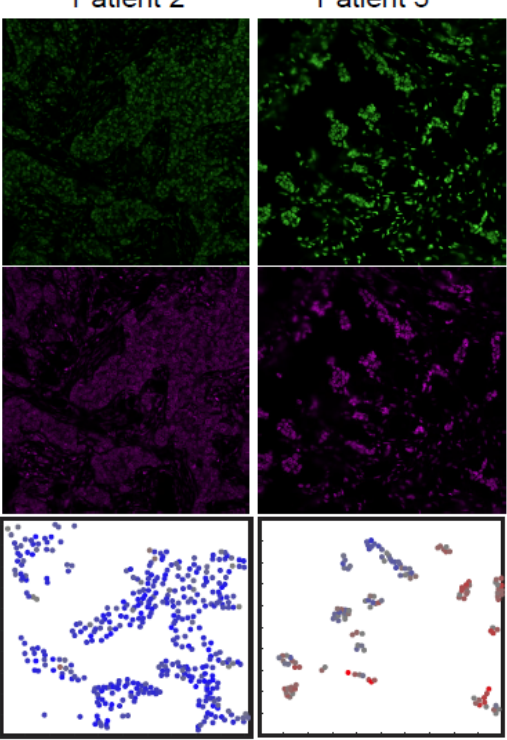

C

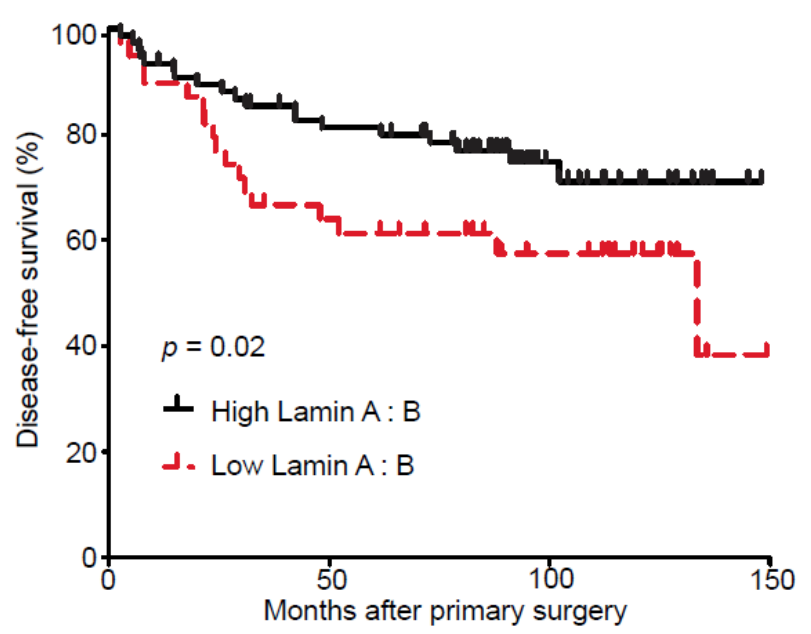

Patient 4

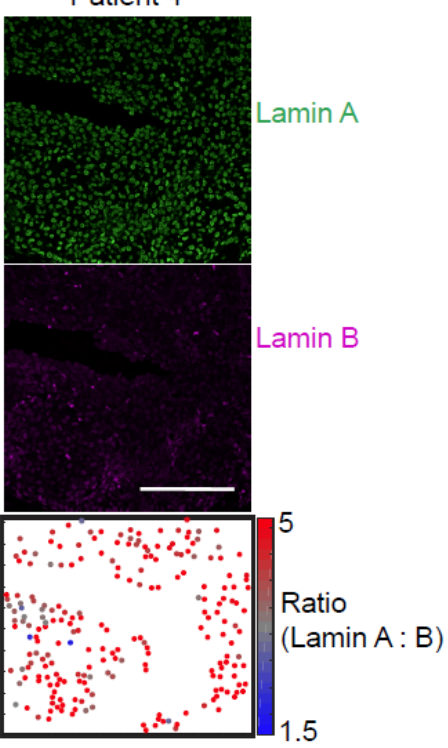

D

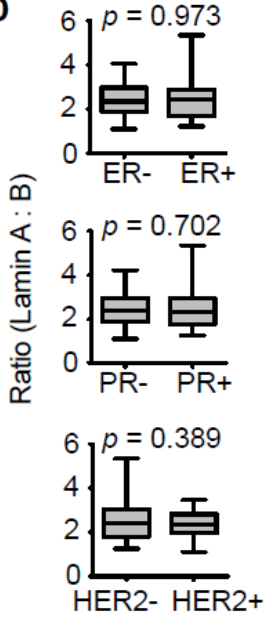

Figure 8. Decreased lamin A levels are associated with worse prognosis in breast cancer. (A) Flow chart for analysis of lamin immunofluorescent staining in human tumors. DAPI-stained nuclei were used for segmentation of individual nuclei followed by selection of regions containing tumor cells to exclude stromal cells from the analysis. Within each detected nucleus, the nuclear rim was segmented based on the top $70 \%$ of pixels above background levels. Both lamin A and lamin B intensity at the nuclear rim were quantified with this method, allowing the lamin B signal to be used for normalization of lamin A across different tumor sections. Scale bar = $200 \mu \mathrm{m}$. (B) Examples of immunofluorescent lamin staining and quantification in patient tumors. Scale bar $=200$ $\mu \mathrm{m}$. (C) The average lamin A : lamin B ratio per tumor was quantified from immunofluorescent staining of the TMA as shown in (A) and (B). The TMA was comprised of node-negative breast cancer patients who had not received systemic therapy and had a minimum of 5 years of follow-up. Decreased lamin A : lamin B ratio was associated with worse breast cancer patient survival as indicated by a Kaplan-Meier plot using an optimal lamin A : lamin B cutoff of 1.983 to define high $(N=74)$ and low $(N=35)$ groupings. A hazard ratio of 0.45 (95\% confidence 
interval: 0.22-0.9, $p=0.02$ ) was calculated for high lamin A: vs low lamin A: B ratio. Patient survival means were 91.6 months \pm 9.1 SEM for low lamin A : B tumors and 120.9 months \pm 5.9 SEM for high lamin A : B tumors. (D) Lamin A : B ratio was not significantly associated with estrogen receptor (ER), progesterone receptor (PR), or HER2, suggesting that lower lamin A levels identify poor prognosis independent of breast cancer histological subtype. Statistical analysis by two-tailed Student's t test. 


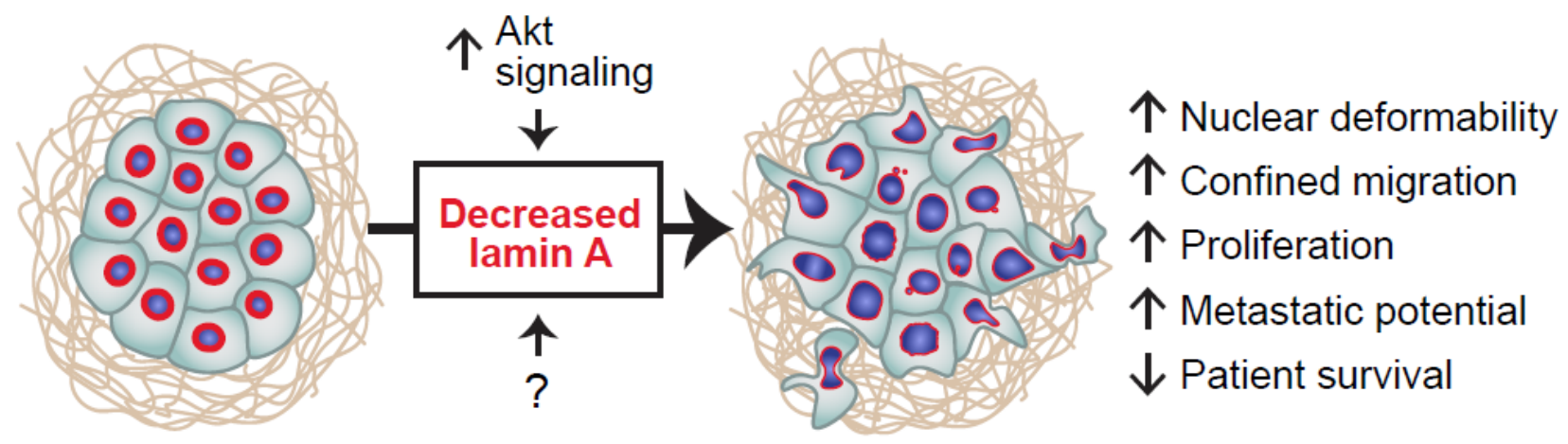

Figure 9. Lamin A levels influence multiple features of metastatic breast cancer. Downregulation of lamin A in breast cancer tumor cells, which may be mediated through increased Akt signaling, is associated with a gain of metastatic capacity. Decreased lamin A levels lead to increased nuclear deformability, enhanced migration through confined environments, and increased proliferation rate in metastatic cancers. Accordingly, decreased levels of lamin A are associated with reduced disease-free survival in breast cancer patients. 


\section{References}

Agrelo, R., F. Setien, J. Espada, M.J. Artiga, M. Rodriguez, A. Perez-Rosado, A. Sanchez-Aguilera, M.F. Fraga, M.A. Piris, and M. Esteller. 2005. Inactivation of the lamin A/C gene by $\mathrm{CpG}$ island promoter hypermethylation in hematologic malignancies, and its association with poor survival in nodal diffuse large B-cell lymphoma. $J$ Clin Oncol. 23:3940-3947.

Alhudiri, I.M., C.C. Nolan, I.O. Ellis, A. Elzagheid, E.A. Rakha, A.R. Green, and C.J. Chapman. 2019. Expression of Lamin A/C in early-stage breast cancer and its prognostic value. Breast Cancer Res Treat. 174:661-668.

Aljada, A., J. Doria, A.M. Saleh, S.H. Al-Matar, S. AlGabbani, H.B. Shamsa, A. Al-Bawab, and A.A. Ahmed. 2016. Altered Lamin A/C splice variant expression as a possible diagnostic marker in breast cancer. Cell Oncol (Dordr). 39:161-174.

Andres, V., and J.M. Gonzalez. 2009. Role of A-type lamins in signaling, transcription, and chromatin organization. J Cell Biol. 187:945-957.

Aslakson, C.J., and F.R. Miller. 1992. Selective events in the metastatic process defined by analysis of the sequential dissemination of subpopulations of a mouse mammary tumor. Cancer Res. 52:1399-1405.

Banerjee, A., Z.S. Wu, P. Qian, J. Kang, V. Pandey, D.X. Liu, T. Zhu, and P.E. Lobie. 2011. ARTEMIN synergizes with TWIST1 to promote metastasis and poor survival outcome in patients with ER negative mammary carcinoma. Breast Cancer Res. 13:R112.

Barati, M.T., M.J. Rane, J.B. Klein, and K.R. McLeish. 2006. A proteomic screen identified stress-induced chaperone proteins as targets of Akt phosphorylation in mesangial cells. Journal of Proteome Research. 5:1636-1646.

Bastos de Oliveira, F.M., D. Kim, J.R. Cussiol, J. Das, M.C. Jeong, L. Doerfler, K.H. Schmidt, H. Yu, and M.B. Smolka. 2015. Phosphoproteomics reveals distinct modes of Mec1/ATR signaling during DNA replication. Mol Cell. 57:1124-1132.

Bastos de Oliveira, F.M., D. Kim, M. Lanz, and M.B. Smolka. 2018. Quantitative Analysis of DNA Damage Signaling Responses to Chemical and Genetic Perturbations. Methods Mol Biol. 1672:645-660.

Batulan, Z., V.K. Pulakazhi Venu, Y. Li, G. Koumbadinga, D.G. Alvarez-Olmedo, C. Shi, and E.R. O'Brien. 2016. Extracellular Release and Signaling by Heat Shock Protein 27: Role in Modifying Vascular Inflammation. Front Immunol. 7:285.

Bell, E.S., and J. Lammerding. 2016. Causes and consequences of nuclear envelope alterations in tumour progression. Eur J Cell Biol. 95:449-464.

Belt, E.J., R.J. Fijneman, E.G. van den Berg, H. Bril, P.M. Delis-van Diemen, M. Tijssen, H.F. van Essen, E.S. de Lange-de Klerk, J.A. Belien, H.B. Stockmann, S. Meijer, and G.A. Meijer. 2011. Loss of lamin A/C expression in stage II and III colon cancer is associated with disease recurrence. Eur J Cancer. 47:1837-1845.

Bertacchini, J., F. Beretti, V. Cenni, M. Guida, F. Gibellini, L. Mediani, O. Marin, N.M. Maraldi, A. de Pol, G. Lattanzi, L. Cocco, and S. Marmiroli. 2013. The protein kinase Akt/PKB regulates both prelamin A degradation and Lmna gene expression. FASEB J. 27:2145-2155.

Borowsky, A.D., R. Namba, L.J. Young, K.W. Hunter, J.G. Hodgson, C.G. Tepper, E.T. McGoldrick, W.J. Muller, R.D. Cardiff, and J.P. Gregg. 2005. Syngeneic mouse mammary carcinoma cell lines: two closely related cell lines with divergent metastatic behavior. Clin Exp Metastasis. 22:47-59.

Bos, P.D., X.H. Zhang, C. Nadal, W. Shu, R.R. Gomis, D.X. Nguyen, A.J. Minn, M.J. van de Vijver, W.L. Gerald, J.A. Foekens, and J. Massague. 2009. Genes that mediate breast cancer metastasis to the brain. Nature. 459:1005-1009.

Brady, C.A., and L.D. Attardi. 2010. p53 at a glance. J Cell Sci. 123:2527-2532.

Broers, J.L., B.M. Machiels, H.J. Kuijpers, F. Smedts, R. van den Kieboom, Y. Raymond, and F.C. Ramaekers. 1997. A- and B-type lamins are differentially expressed in normal human tissues. Histochem Cell Biol. 107:505-517. 
Bussolati, G., F. Maletta, S. Asioli, L. Annaratone, A. Sapino, and C. Marchio. 2014. "To be or not to be in a good shape": diagnostic and clinical value of nuclear shape irregularities in thyroid and breast cancer. Adv Exp Med Biol. 773:101-121.

Bustin, M., and T. Misteli. 2016. Nongenetic functions of the genome. Science. 352:aad6933.

Buxboim, A., J. Swift, J. Irianto, K.R. Spinler, P.C. Dingal, A. Athirasala, Y.R. Kao, S. Cho, T. Harada, J.W. Shin, and D.E. Discher. 2014. Matrix elasticity regulates lamin-A,C phosphorylation and turnover with feedback to actomyosin. Curr Biol. 24:1909-1917.

Caille, N., O. Thoumine, Y. Tardy, and J.J. Meister. 2002. Contribution of the nucleus to the mechanical properties of endothelial cells. J Biomech. 35:177-187.

Cailleau, R., M. Olive, and Q.V. Cruciger. 1978. Long-term human breast carcinoma cell lines of metastatic origin: preliminary characterization. In Vitro. 14:911-915.

Capietto, A.H., L. Martinet, and J.J. Fournie. 2011. Stimulated gammadelta T cells increase the in vivo efficacy of trastuzumab in HER-2+ breast cancer. J Immunol. 187:1031-1038.

Capo-chichi, C.D., K.Q. Cai, J. Smedberg, P. Ganjei-Azar, A.K. Godwin, and X.X. Xu. 2011. Loss of A-type lamin expression compromises nuclear envelope integrity in breast cancer. Chin J Cancer. 30:415-425.

Cenni, V., J. Bertacchini, F. Beretti, G. Lattanzi, A. Bavelloni, M. Riccio, M. Ruzzene, O. Marin, G. Arrigoni, V. Parnaik, M. Wehnert, N.M. Maraldi, A. de Pol, L. Cocco, and S. Marmiroli. 2008. Lamin A Ser404 is a nuclear target of Akt phosphorylation in C2C12 cells. J Proteome Res. 7:4727-4735.

Chen, B., J. Wang, D. Dai, Q. Zhou, X. Guo, Z. Tian, X. Huang, L. Yang, H. Tang, and X. Xie. 2017. AHNAK suppresses tumour proliferation and invasion by targeting multiple pathways in triple-negative breast cancer. J Exp Clin Cancer Res. 36:65.

Chen, P., M. Cescon, and P. Bonaldo. 2013. Collagen VI in cancer and its biological mechanisms. Trends Mol Med. 19:410-417.

Chen, Z., Q. Wu, C. Yan, and J. Du. 2019. COL6A1 knockdown suppresses cell proliferation and migration in human aortic vascular smooth muscle cells. Exp Ther Med. 18:1977-1984.

Chiu, K.H., Y.H. Chang, Y.S. Wu, S.H. Lee, and P.C. Liao. 2011. Quantitative secretome analysis reveals that COL6A1 is a metastasis-associated protein using stacking gel-aided purification combined with iTRAQ labeling. J Proteome Res. 10:1110-1125.

Cho, H.M., J.D. Rosenblatt, Y.S. Kang, M.L. Iruela-Arispe, S.L. Morrison, M.L. Penichet, Y.G. Kwon, T.W. Kim, K.A. Webster, H. Nechustan, and S.U. Shin. 2005. Enhanced inhibition of murine tumor and human breast tumor xenografts using targeted delivery of an antibody-endostatin fusion protein. Mol Cancer Ther. 4:956-967.

Cho, S., J. Irianto, and D.E. Discher. 2017. Mechanosensing by the nucleus: From pathways to scaling relationships. J Cell Biol. 216:305-315.

Cho, S., M. Vashisth, A. Abbas, S. Majkut, K. Vogel, Y. Xia, I.L. Ivanovska, J. Irianto, M. Tewari, K. Zhu, E.D. Tichy, F. Mourkioti, H.Y. Tang, R.A. Greenberg, B.L. Prosser, and D.E. Discher. 2019. Mechanosensing by the Lamina Protects against Nuclear Rupture, DNA Damage, and Cell-Cycle Arrest. Dev Cell. 49:920-935 e925.

Clarke, R. 1996. Human breast cancer cell line xenografts as models of breast cancer. The immunobiologies of recipient mice and the characteristics of several tumorigenic cell lines. Breast Cancer Res Treat. 39:69-86.

Collas, P. 1999. Sequential PKC- and Cdc2-mediated phosphorylation events elicit zebrafish nuclear envelope disassembly. J Cell Sci. 112 ( Pt 6):977-987.

Condor, M., C. Mark, R.C. Gerum, N.C. Grummel, A. Bauer, J.M. Garcia-Aznar, and B. Fabry. 2019. Breast Cancer Cells Adapt Contractile Forces to Overcome Steric Hindrance. Biophys J. 116:1305-1312.

Coradeghini, R., P. Barboro, A. Rubagotti, F. Boccardo, S. Parodi, G. Carmignani, C. D'Arrigo, E. Patrone, and C. Balbi. 2006. Differential expression of nuclear lamins in normal and cancerous prostate tissues. Oncol Rep. 15:609-613.

Davidson, P.M., and B. Cadot. 2021. Actin on and around the Nucleus. Trends Cell Biol. 31:211-223.

Davidson, P.M., C. Denais, M.C. Bakshi, and J. Lammerding. 2014. Nuclear deformability constitutes a ratelimiting step during cell migration in 3-D environments. Cell Mol Bioeng. 7:293-306. 
Davidson, P.M., G.R. Fedorchak, S. Mondesert-Deveraux, E.S. Bell, P. Isermann, D. Aubry, R. Allena, and J. Lammerding. 2019. High-throughput microfluidic micropipette aspiration device to probe time-scale dependent nuclear mechanics in intact cells. Lab Chip. 19:3652-3663.

Davidson, P.M., J. Sliz, P. Isermann, C. Denais, and J. Lammerding. 2015. Design of a microfluidic device to quantify dynamic intra-nuclear deformation during cell migration through confining environments. Integr Biol (Camb). 7:1534-1546.

de Las Heras, J.I., and E.C. Schirmer. 2014. The nuclear envelope and cancer: a diagnostic perspective and historical overview. Adv Exp Med Biol. 773:5-26.

de Leeuw, R., Y. Gruenbaum, and O. Medalia. 2018. Nuclear Lamins: Thin Filaments with Major Functions. Trends Cell Biol. 28:34-45.

Denais, C., and J. Lammerding. 2014. Nuclear mechanics in cancer. Adv Exp Med Biol. 773:435-470.

Denais, C.M., R.M. Gilbert, P. Isermann, A.L. McGregor, M. Te Lindert, B. Weigelin, P.M. Davidson, P. Friedl, K. Wolf, and J. Lammerding. 2016. Nuclear envelope rupture and repair during cancer cell migration. Science. 352:353-358.

Dexter, D.L., H.M. Kowalski, B.A. Blazar, Z. Fligiel, R. Vogel, and G.H. Heppner. 1978. Heterogeneity of tumor cells from a single mouse mammary tumor. Cancer Res. 38:3174-3181.

Doerschuk, C.M., N. Beyers, H.O. Coxson, B. Wiggs, and J.C. Hogg. 1993. Comparison of neutrophil and capillary diameters and their relation to neutrophil sequestration in the lung. J Appl Physiol (1985). 74:3040-3045.

Dubik, N., and S. Mai. 2020. Lamin A/C: Function in Normal and Tumor Cells. Cancers (Basel). 12.

Earle, A.J., T.J. Kirby, G.R. Fedorchak, P. Isermann, J. Patel, S. Iruvanti, S.A. Moore, G. Bonne, L.L. Wallrath, and J. Lammerding. 2020. Mutant lamins cause nuclear envelope rupture and DNA damage in skeletal muscle cells. Nat Mater. 19:464-473.

Echarri, A., and M.A. Del Pozo. 2015. Caveolae - mechanosensitive membrane invaginations linked to actin filaments. J Cell Sci. 128:2747-2758.

Fogh, J. 1975. Human tumor cells in vitro. Plenum Press, New York.

Fong, L.G., J.K. Ng, J. Lammerding, T.A. Vickers, M. Meta, N. Cote, B. Gavino, X. Qiao, S.Y. Chang, S.R. Young, S.H. Yang, C.L. Stewart, R.T. Lee, C.F. Bennett, M.O. Bergo, and S.G. Young. 2006. Prelamin A and lamin A appear to be dispensable in the nuclear lamina. J Clin Invest. 116:743-752.

Frock, R.L., B.A. Kudlow, A.M. Evans, S.A. Jameson, S.D. Hauschka, and B.K. Kennedy. 2006. Lamin A/C and emerin are critical for skeletal muscle satellite cell differentiation. Genes Dev. 20:486-500.

Fruman, D.A., and C. Rommel. 2014. PI3K and cancer: lessons, challenges and opportunities. Nat Rev Drug Discov. 13:140-156.

Gazdar, A.F., V. Kurvari, A. Virmani, L. Gollahon, M. Sakaguchi, M. Westerfield, D. Kodagoda, V. Stasny, H.T. Cunningham, Wistuba, II, G. Tomlinson, V. Tonk, R. Ashfaq, A.M. Leitch, J.D. Minna, and J.W. Shay. 1998. Characterization of paired tumor and non-tumor cell lines established from patients with breast cancer. Int J Cancer. 78:766-774.

Goddette, D.W., and C. Frieden. 1986. Actin polymerization. The mechanism of action of cytochalasin D. J Biol Chem. 261:15974-15980.

Gong, G., P. Chen, L. Li, H. Tan, J. Zhou, Y. Zhou, X. Yang, and X. Wu. 2015. Loss of lamin A but not lamin C expression in epithelial ovarian cancer cells is associated with metastasis and poor prognosis. Pathol Res Pract. 211:175-182.

Gonzalez-Cruz, R.D., J.S. Sadick, V.C. Fonseca, and E.M. Darling. 2018. Nuclear Lamin Protein C Is Linked to Lineage-Specific, Whole-Cell Mechanical Properties. Cell Mol Bioeng. 11:131-142.

Gonzalo, S. 2014. DNA damage and lamins. Adv Exp Med Biol. 773:377-399.

Gruenbaum, Y., and R. Foisner. 2015. Lamins: nuclear intermediate filament proteins with fundamental functions in nuclear mechanics and genome regulation. Annu Rev Biochem. 84:131-164.

Guilak, F., J.R. Tedrow, and R. Burgkart. 2000. Viscoelastic properties of the cell nucleus. Biochem Biophys Res Commun. 269:781-786. 
Guy, C.T., R.D. Cardiff, and W.J. Muller. 1992. Induction of mammary tumors by expression of polyomavirus middle T oncogene: a transgenic mouse model for metastatic disease. Mol Cell Biol. 12:954-961.

Hahn, W.C., C.M. Counter, A.S. Lundberg, R.L. Beijersbergen, M.W. Brooks, and R.A. Weinberg. 1999. Creation of human tumour cells with defined genetic elements. Nature. 400:464-468.

Hanson, P.I., R. Roth, Y. Lin, and J.E. Heuser. 2008. Plasma membrane deformation by circular arrays of ESCRT-III protein filaments. J Cell Biol. 180:389-402.

Harada, T., J. Swift, J. Irianto, J.W. Shin, K.R. Spinler, A. Athirasala, R. Diegmiller, P.C. Dingal, I.L. Ivanovska, and D.E. Discher. 2014. Nuclear lamin stiffness is a barrier to 3D migration, but softness can limit survival. J Cell Biol. 204:669-682.

Hetzer, M.W. 2010. The nuclear envelope. Cold Spring Harb Perspect Biol. 2:a000539.

Iorns, E., K. Drews-Elger, T.M. Ward, S. Dean, J. Clarke, D. Berry, D. El Ashry, and M. Lippman. 2012. A new mouse model for the study of human breast cancer metastasis. PLoS One. 7:e47995.

Irianto, J., C.R. Pfeifer, R.R. Bennett, Y. Xia, I.L. Ivanovska, A.J. Liu, R.A. Greenberg, and D.E. Discher. $2016 a$. Nuclear constriction segregates mobile nuclear proteins away from chromatin. Mol Biol Cell. 27:4011-4020.

Irianto, J., C.R. Pfeifer, I.L. Ivanovska, J. Swift, and D. Discher. 2016b. Nuclear lamins in cancer. Cellular and Molecular Bioengineering. 9:258-267.

Isermann, P., and J. Lammerding. 2013. Nuclear mechanics and mechanotransduction in health and disease. Curr Biol. 23:R1113-1121.

Ivorra, C., M. Kubicek, J.M. Gonzalez, S.M. Sanz-Gonzalez, A. Alvarez-Barrientos, J.E. O'Connor, B. Burke, and V. Andres. 2006. A mechanism of AP-1 suppression through interaction of c-Fos with lamin A/C. Genes Dev. 20:307-320.

Jiang, K., P. Liu, H. Xu, D. Liang, K. Fang, S. Du, W. Cheng, L. Ye, T. Liu, X. Zhang, P. Gong, S. Shao, Y. Wang, and S. Meng. 2020. SASH1 suppresses triple-negative breast cancer cell invasion through YAP-ARHGAP42-actin axis. Oncogene.

Johnson, B.R., R.T. Nitta, R.L. Frock, L. Mounkes, D.A. Barbie, C.L. Stewart, E. Harlow, and B.K. Kennedy. 2004. Atype lamins regulate retinoblastoma protein function by promoting subnuclear localization and preventing proteasomal degradation. Proc Natl Acad Sci U S A. 101:9677-9682.

Kang, Y., P.M. Siegel, W. Shu, M. Drobnjak, S.M. Kakonen, C. Cordon-Cardo, T.A. Guise, and J. Massague. 2003. A multigenic program mediating breast cancer metastasis to bone. Cancer Cell. 3:537-549.

Kennedy, B.K., and J.K. Pennypacker. 2014. RB and lamins in cell cycle regulation and aging. Adv Exp Med Biol. 773:127-142.

Kenny, P.A., G.Y. Lee, C.A. Myers, R.M. Neve, J.R. Semeiks, P.T. Spellman, K. Lorenz, E.H. Lee, M.H. BarcellosHoff, O.W. Petersen, J.W. Gray, and M.J. Bissell. 2007. The morphologies of breast cancer cell lines in threedimensional assays correlate with their profiles of gene expression. Mol Oncol. 1:84-96.

Keydar, I., L. Chen, S. Karby, F.R. Weiss, J. Delarea, M. Radu, S. Chaitcik, and H.J. Brenner. 1979. Establishment and characterization of a cell line of human breast carcinoma origin. Eur J Cancer. 15:659-670.

Khawaled, S., S.S. Suh, S.K. Abdeen, J. Monin, R. Distefano, G. Nigita, C.M. Croce, and R.I. Aqeilan. 2019. WWOX Inhibits Metastasis of Triple-Negative Breast Cancer Cells via Modulation of miRNAs. Cancer Res. 79:17841798.

Kim, D., Y. Liu, S. Oberly, R. Freire, and M.B. Smolka. 2018. ATR-mediated proteome remodeling is a major determinant of homologous recombination capacity in cancer cells. Nucleic Acids Res. 46:8311-8325.

Kochin, V., T. Shimi, E. Torvaldson, S.A. Adam, A. Goldman, C.G. Pack, J. Melo-Cardenas, S.Y. Imanishi, R.D. Goldman, and J.E. Eriksson. 2014. Interphase phosphorylation of lamin A. J Cell Sci. 127:2683-2696.

Lacroix, M., and G. Leclercq. 2004. Relevance of breast cancer cell lines as models for breast tumours: an update. Breast Cancer Res Treat. 83:249-289.

Lammerding, J., L.G. Fong, J.Y. Ji, K. Reue, C.L. Stewart, S.G. Young, and R.T. Lee. 2006. Lamins A and C but not lamin B1 regulate nuclear mechanics. J Biol Chem. 281:25768-25780. 
Lammerding, J., P.C. Schulze, T. Takahashi, S. Kozlov, T. Sullivan, R.D. Kamm, C.L. Stewart, and R.T. Lee. 2004. Lamin A/C deficiency causes defective nuclear mechanics and mechanotransduction. J Clin Invest. 113:370378.

Lasfargues, E.Y., and W.G. Coutinho. 1981. Human Breast Tumor Cells in Culture; New Concepts in Mammary Carcinogenesis. In New Frontiers in Mammary Pathology. K.H. Hollmann, J. de Brux, and J.M. Verley, editors. Springer US, Boston, MA. 117-143.

Lasfargues, E.Y., W.G. Coutinho, and E.S. Redfield. 1978. Isolation of two human tumor epithelial cell lines from solid breast carcinomas. J Natl Cancer Inst. 61:967-978.

Lautscham, L.A., C. Kammerer, J.R. Lange, T. Kolb, C. Mark, A. Schilling, P.L. Strissel, R. Strick, C. Gluth, A.C. Rowat, C. Metzner, and B. Fabry. 2015. Migration in Confined 3D Environments Is Determined by a Combination of Adhesiveness, Nuclear Volume, Contractility, and Cell Stiffness. Biophys J. 109:900-913.

Lee, H., W.J. Adams, P.W. Alford, M.L. McCain, A.W. Feinberg, S.P. Sheehy, J.A. Goss, and K.K. Parker. 2015. Cytoskeletal prestress regulates nuclear shape and stiffness in cardiac myocytes. Exp Biol Med (Maywood). 240:1543-1554.

Lee, Y.R., M.S. Park, H.K. Joo, K.M. Kim, J. Kim, B.H. Jeon, and S. Choi. 2018. Therapeutic positioning of secretory acetylated APE1/Ref-1 requirement for suppression of tumor growth in triple-negative breast cancer in vivo. Sci Rep. 8:8701.

Lelekakis, M., J.M. Moseley, T.J. Martin, D. Hards, E. Williams, P. Ho, D. Lowen, J. Javni, F.R. Miller, J. Slavin, and R.L. Anderson. 1999. A novel orthotopic model of breast cancer metastasis to bone. Clin Exp Metastasis. 17:163-170.

Marmiroli, S., J. Bertacchini, F. Beretti, V. Cenni, M. Guida, A. De Pol, N.M. Maraldi, and G. Lattanzi. 2009. A-type lamins and signaling: the PI 3-kinase/Akt pathway moves forward. J Cell Physiol. 220:553-561.

Marusyk, A., D.P. Tabassum, P.M. Altrock, V. Almendro, F. Michor, and K. Polyak. 2014. Non-cell-autonomous driving of tumour growth supports sub-clonal heterogeneity. Nature. 514:54-58.

Matsumoto, A., M. Hieda, Y. Yokoyama, Y. Nishioka, K. Yoshidome, M. Tsujimoto, and N. Matsuura. 2015. Global loss of a nuclear lamina component, lamin A/C, and LINC complex components SUN1, SUN2, and nesprin-2 in breast cancer. Cancer Med. 4:1547-1557.

Maurer, M., and J. Lammerding. 2019. The Driving Force: Nuclear Mechanotransduction in Cellular Function, Fate, and Disease. Annu Rev Biomed Eng. 21:443-468.

Maynard, S., G. Keijzers, M. Akbari, M.B. Ezra, A. Hall, M. Morevati, M. Scheibye-Knudsen, S. Gonzalo, J. Bartek, and V.A. Bohr. 2019. Lamin A/C promotes DNA base excision repair. Nucleic Acids Res. 47:11709-11728.

McGregor, A.L., C.R. Hsia, and J. Lammerding. 2016. Squish and squeeze-the nucleus as a physical barrier during migration in confined environments. Curr Opin Cell Biol. 40:32-40.

Mekhdjian, A.H., F. Kai, M.G. Rubashkin, L.S. Prahl, L.M. Przybyla, A.L. McGregor, E.S. Bell, J.M. Barnes, C.C. DuFort, G. Ou, A.C. Chang, L. Cassereau, S.J. Tan, M.W. Pickup, J.N. Lakins, X. Ye, M.W. Davidson, J. Lammerding, D.J. Odde, A.R. Dunn, and V.M. Weaver. 2017. Integrin-mediated traction force enhances paxillin molecular associations and adhesion dynamics that increase the invasiveness of tumor cells into a three-dimensional extracellular matrix. Mol Biol Cell. 28:1467-1488.

Minn, A.J., G.P. Gupta, P.M. Siegel, P.D. Bos, W. Shu, D.D. Giri, A. Viale, A.B. Olshen, W.L. Gerald, and J. Massague. 2005. Genes that mediate breast cancer metastasis to lung. Nature. 436:518-524.

Miroshnikova, Y.A., J.K. Mouw, J.M. Barnes, M.W. Pickup, J.N. Lakins, Y. Kim, K. Lobo, A.I. Persson, G.F. Reis, T.R. McKnight, E.C. Holland, J.J. Phillips, and V.M. Weaver. 2016. Tissue mechanics promote IDH1-dependent HIF1alpha-tenascin C feedback to regulate glioblastoma aggression. Nat Cell Biol. 18:1336-1345.

Mitchell, M.J., C. Denais, M.F. Chan, Z. Wang, J. Lammerding, and M.R. King. 2015. Lamin A/C deficiency reduces circulating tumor cell resistance to fluid shear stress. Am J Physiol Cell Physiol. 309:C736-746.

Mukherjee, A., A. Barai, R.K. Singh, W. Yan, and S. Sen. 2020. Nuclear plasticity increases susceptibility to damage during confined migration. PLoS Comput Biol. 16:e1008300. 
Murthy, M.S., E.F. Scanlon, M.L. Jelachich, S. Klipstein, and R.A. Goldschmidt. 1995. Growth and metastasis of human breast cancers in athymic nude mice. Clin Exp Metastasis. 13:3-15.

Mymrikov, E.V., A.S. Seit-Nebi, and N.B. Gusev. 2011. Large potentials of small heat shock proteins. Physiol Rev. 91:1123-1159.

Naeem, A.S., Y. Zhu, W.L. Di, S. Marmiroli, and R.F. O'Shaughnessy. 2015. AKT1-mediated Lamin A/C degradation is required for nuclear degradation and normal epidermal terminal differentiation. Cell Death Differ. 22:2123-2132.

Nagelkerke, A., S.J. van Kuijk, F.C. Sweep, I.D. Nagtegaal, N. Hoogerbrugge, J.W. Martens, M.A. Timmermans, H.W. van Laarhoven, J. Bussink, and P.N. Span. 2011. Constitutive expression of gamma-H2AX has prognostic relevance in triple negative breast cancer. Radiother Oncol. 101:39-45.

Nair, N.U., A. Das, V.M. Rogkoti, M. Fokkelman, R. Marcotte, C.G. de Jong, E. Koedoot, J.S. Lee, I. Meilijson, S. Hannenhalli, B.G. Neel, B.V. de Water, S.E. Le Devedec, and E. Ruppin. 2019. Migration rather than proliferation transcriptomic signatures are strongly associated with breast cancer patient survival. Sci Rep. 9:10989.

Neve, R.M., K. Chin, J. Fridlyand, J. Yeh, F.L. Baehner, T. Fevr, L. Clark, N. Bayani, J.P. Coppe, F. Tong, T. Speed, P.T. Spellman, S. DeVries, A. Lapuk, N.J. Wang, W.L. Kuo, J.L. Stilwell, D. Pinkel, D.G. Albertson, F.M. Waldman, F. McCormick, R.B. Dickson, M.D. Johnson, M. Lippman, S. Ethier, A. Gazdar, and J.W. Gray. 2006. A collection of breast cancer cell lines for the study of functionally distinct cancer subtypes. Cancer Cell. 10:515-527.

Nitta, R.T., S.A. Jameson, B.A. Kudlow, L.A. Conlan, and B.K. Kennedy. 2006. Stabilization of the retinoblastoma protein by A-type nuclear lamins is required for INK4A-mediated cell cycle arrest. Mol Cell Biol. 26:53605372.

Ogba, N., N.G. Manning, B.S. Bliesner, S.K. Ambler, J.M. Haughian, M.P. Pinto, P. Jedlicka, K. Joensuu, P. Heikkila, and K.B. Horwitz. 2014. Luminal breast cancer metastases and tumor arousal from dormancy are promoted by direct actions of estradiol and progesterone on the malignant cells. Breast Cancer Res. 16:489.

Onitilo, A.A., J.M. Engel, R.T. Greenlee, and B.N. Mukesh. 2009. Breast cancer subtypes based on ER/PR and Her2 expression: comparison of clinicopathologic features and survival. Clin Med Res. 7:4-13.

Ortega, M.A., O. Fraile-Martinez, A. Asunsolo, J. Bujan, N. Garcia-Honduvilla, and S. Coca. 2020. Signal Transduction Pathways in Breast Cancer: The Important Role of PI3K/Akt/mTOR. J Oncol. 2020:9258396.

Owusu-Ansah, K.G., G. Song, R. Chen, M.I.A. Edoo, J. Li, B. Chen, J. Wu, L. Zhou, H. Xie, D. Jiang, and S. Zheng. 2019. COL6A1 promotes metastasis and predicts poor prognosis in patients with pancreatic cancer. Int $J$ Oncol. 55:391-404.

Ozzello, L., and M. Sordat. 1980. Behavior of tumors produced by transplantation of human mammary cell lines in athymic nude mice. Eur J Cancer. 16:553-559.

Pajerowski, J.D., K.N. Dahl, F.L. Zhong, P.J. Sammak, and D.E. Discher. 2007. Physical plasticity of the nucleus in stem cell differentiation. Proc Natl Acad Sci U S A. 104:15619-15624.

Peter, M., J. Nakagawa, M. Doree, J.C. Labbe, and E.A. Nigg. 1990. In vitro disassembly of the nuclear lamina and $M$ phase-specific phosphorylation of lamins by cdc2 kinase. Cell. 61:591-602.

Pickup, M.W., H. Laklai, I. Acerbi, P. Owens, A.E. Gorska, A. Chytil, M. Aakre, V.M. Weaver, and H.L. Moses. 2013. Stromally derived lysyl oxidase promotes metastasis of transforming growth factor-beta-deficient mouse mammary carcinomas. Cancer Res. 73:5336-5346.

Pombo, A., and N. Dillon. 2015. Three-dimensional genome architecture: players and mechanisms. Nat Rev Mol Cell Biol. 16:245-257.

Prat, A., J.S. Parker, O. Karginova, C. Fan, C. Livasy, J.I. Herschkowitz, X. He, and C.M. Perou. 2010. Phenotypic and molecular characterization of the claudin-low intrinsic subtype of breast cancer. Breast Cancer Res. 12:R68.

Price, J.E. 1996. Metastasis from human breast cancer cell lines. Breast Cancer Res Treat. 39:93-102. 
Puchalapalli, M., X. Zeng, L. Mu, A. Anderson, L. Hix Glickman, M. Zhang, M.R. Sayyad, S. Mosticone Wangensteen, C.V. Clevenger, and J.E. Koblinski. 2016. NSG Mice Provide a Better Spontaneous Model of Breast Cancer Metastasis than Athymic (Nude) Mice. PLoS One. 11:e0163521.

Raab, M., M. Gentili, H. de Belly, H.R. Thiam, P. Vargas, A.J. Jimenez, F. Lautenschlaeger, R. Voituriez, A.M. Lennon-Dumenil, N. Manel, and M. Piel. 2016. ESCRT III repairs nuclear envelope ruptures during cell migration to limit DNA damage and cell death. Science. 352:359-362.

Reddy, K.L., and A.P. Feinberg. 2013. Higher order chromatin organization in cancer. Semin Cancer Biol. 23:109115.

Redwood, A.B., S.M. Perkins, R.P. Vanderwaal, Z. Feng, K.J. Biehl, I. Gonzalez-Suarez, L. Morgado-Palacin, W. Shi, J. Sage, J.L. Roti-Roti, C.L. Stewart, J. Zhang, and S. Gonzalo. 2011. A dual role for A-type lamins in DNA double-strand break repair. Cell Cycle. 10:2549-2560.

Roncato, F., O. Regev, S.W. Feigelson, S.K. Yadav, L. Kaczmarczyk, N. Levi, D. Drago-Garcia, S. Ovadia, M. Kizner, Y. Addadi, J.C. Sabino, Y. Ovadya, S.F. de Almeida, E. Feldmesser, G. Gerlitz, and R. Alon. 2021. Reduced Lamin A/C Does Not Facilitate Cancer Cell Transendothelial Migration but Compromises Lung Metastasis. Cancers (Basel). 13.

Sahai, E. 2007. Illuminating the metastatic process. Nat Rev Cancer. 7:737-749.

Schape, J., S. Prausse, M. Radmacher, and R. Stick. 2009. Influence of lamin A on the mechanical properties of amphibian oocyte nuclei measured by atomic force microscopy. Biophys J. 96:4319-4325.

Schindelin, J., I. Arganda-Carreras, E. Frise, V. Kaynig, M. Longair, T. Pietzsch, S. Preibisch, C. Rueden, S. Saalfeld, B. Schmid, J.Y. Tinevez, D.J. White, V. Hartenstein, K. Eliceiri, P. Tomancak, and A. Cardona. 2012. Fiji: an open-source platform for biological-image analysis. Nat Methods. 9:676-682.

Schreiber, K.H., and B.K. Kennedy. 2013. When lamins go bad: nuclear structure and disease. Cell. 152:13651375.

Shafie, S.M., and L.A. Liotta. 1980. Formation of metastasis by human breast carcinoma cells (MCF-7) in nude mice. Cancer Lett. 11:81-87.

Shah, P., C.M. Hobson, S. Cheng, M.J. Colville, M.J. Paszek, R. Superfine, and J. Lammerding. 2020. Nuclear Deformation Causes DNA Damage by Increasing Replication Stress. Curr Biol.

Simon, N., A. Antignani, R. Sarnovsky, S.M. Hewitt, and D. FitzGerald. 2016. Targeting a Cancer-Specific Epitope of the Epidermal Growth Factor Receptor in Triple-Negative Breast Cancer. J Natl Cancer Inst. 108.

Sinha, B., D. Koster, R. Ruez, P. Gonnord, M. Bastiani, D. Abankwa, R.V. Stan, G. Butler-Browne, B. Vedie, L. Johannes, N. Morone, R.G. Parton, G. Raposo, P. Sens, C. Lamaze, and P. Nassoy. 2011. Cells respond to mechanical stress by rapid disassembly of caveolae. Cell. 144:402-413.

Sorlie, T., C.M. Perou, R. Tibshirani, T. Aas, S. Geisler, H. Johnsen, T. Hastie, M.B. Eisen, M. van de Rijn, S.S. Jeffrey, T. Thorsen, H. Quist, J.C. Matese, P.O. Brown, D. Botstein, P.E. Lonning, and A.L. Borresen-Dale. 2001. Gene expression patterns of breast carcinomas distinguish tumor subclasses with clinical implications. Proc Natl Acad Sci U S A. 98:10869-10874.

Soule, H.D., J. Vazguez, A. Long, S. Albert, and M. Brennan. 1973. A human cell line from a pleural effusion derived from a breast carcinoma. J Natl Cancer Inst. 51:1409-1416.

Stephens, A.D., E.J. Banigan, S.A. Adam, R.D. Goldman, and J.F. Marko. 2017. Chromatin and lamin A determine two different mechanical response regimes of the cell nucleus. Mol Biol Cell. 28:1984-1996.

Stephens, A.D., P.Z. Liu, E.J. Banigan, L.M. Almassalha, V. Backman, S.A. Adam, R.D. Goldman, and J.F. Marko. 2018. Chromatin histone modifications and rigidity affect nuclear morphology independent of lamins. Mol Biol Cell. 29:220-233.

Stoitzner, P., K. Pfaller, H. Stossel, and N. Romani. 2002. A close-up view of migrating Langerhans cells in the skin. J Invest Dermatol. 118:117-125.

Sugiyama, Y., A. Suzuki, M. Kishikawa, R. Akutsu, T. Hirose, M.M. Waye, S.K. Tsui, S. Yoshida, and S. Ohno. 2000. Muscle develops a specific form of small heat shock protein complex composed of MKBP/HSPB2 and HSPB3 during myogenic differentiation. J Biol Chem. 275:1095-1104. 
Sullivan, T., D. Escalante-Alcalde, H. Bhatt, M. Anver, N. Bhat, K. Nagashima, C.L. Stewart, and B. Burke. 1999. Loss of A-type lamin expression compromises nuclear envelope integrity leading to muscular dystrophy. J Cell Biol. 147:913-920.

Swift, J., I.L. Ivanovska, A. Buxboim, T. Harada, P.C. Dingal, J. Pinter, J.D. Pajerowski, K.R. Spinler, J.W. Shin, M. Tewari, F. Rehfeldt, D.W. Speicher, and D.E. Discher. 2013. Nuclear lamin-A scales with tissue stiffness and enhances matrix-directed differentiation. Science. 341:1240104.

Tate, C.R., L.V. Rhodes, H.C. Segar, J.L. Driver, F.N. Pounder, M.E. Burow, and B.M. Collins-Burow. 2012. Targeting triple-negative breast cancer cells with the histone deacetylase inhibitor panobinostat. Breast Cancer Res. 14:R79.

Thompson, E.W., S. Paik, N. Brunner, C.L. Sommers, G. Zugmaier, R. Clarke, T.B. Shima, J. Torri, S. Donahue, M.E. Lippman, and et al. 1992. Association of increased basement membrane invasiveness with absence of estrogen receptor and expression of vimentin in human breast cancer cell lines. J Cell Physiol. 150:534-544.

To, W.S., and K.S. Midwood. 2011. Plasma and cellular fibronectin: distinct and independent functions during tissue repair. Fibrogenesis Tissue Repair. 4:21.

Tseng, Y., J.S. Lee, T.P. Kole, I. Jiang, and D. Wirtz. 2004. Micro-organization and visco-elasticity of the interphase nucleus revealed by particle nanotracking. J Cell Sci. 117:2159-2167.

Van Berlo, J.H., J.W. Voncken, N. Kubben, J.L. Broers, R. Duisters, R.E. van Leeuwen, H.J. Crijns, F.C. Ramaekers, C.J. Hutchison, and Y.M. Pinto. 2005. A-type lamins are essential for TGF-beta1 induced PP2A to dephosphorylate transcription factors. Hum Mol Genet. 14:2839-2849.

Vargas, J.D., E.M. Hatch, D.J. Anderson, and M.W. Hetzer. 2012. Transient nuclear envelope rupturing during interphase in human cancer cells. Nucleus. 3:88-100.

Venables, R.S., S. McLean, D. Luny, E. Moteleb, S. Morley, R.A. Quinlan, E.B. Lane, and C.J. Hutchison. 2001. Expression of individual lamins in basal cell carcinomas of the skin. Br J Cancer. 84:512-519.

Walsh, L.A., M.J. Alvarez, E.Y. Sabio, M. Reyngold, V. Makarov, S. Mukherjee, K.W. Lee, A. Desrichard, S. Turcan, M.G. Dalin, V.K. Rajasekhar, S. Chen, L.T. Vahdat, A. Califano, and T.A. Chan. 2017. An Integrated Systems Biology Approach Identifies TRIM25 as a Key Determinant of Breast Cancer Metastasis. Cell Rep. 20:16231640.

Wan, F., H. Wang, Y. Shen, H. Zhang, G. Shi, Y. Zhu, B. Dai, and D. Ye. 2015. Upregulation of COL6A1 is predictive of poor prognosis in clear cell renal cell carcinoma patients. Oncotarget. 6:27378-27387.

Wang, X., H. Liu, M. Zhu, C. Cao, Z. Xu, Y. Tsatskis, K. Lau, C. Kuok, T. Filleter, H. McNeill, C.A. Simmons, S. Hopyan, and Y. Sun. 2018. Mechanical stability of the cell nucleus - roles played by the cytoskeleton in nuclear deformation and strain recovery. J Cell Sci. 131.

Wazir, U., M.H. Ahmed, J.M. Bridger, A. Harvey, W.G. Jiang, A.K. Sharma, and K. Mokbel. 2013. The clinicopathological significance of lamin $A / C$, lamin B1 and lamin B receptor mRNA expression in human breast cancer. Cell Mol Biol Lett. 18:595-611.

Weigelin, B., G.J. Bakker, and P. Friedl. 2012. Intravital third harmonic generation microscopy of collective melanoma cell invasion. IntraVital. 1:32-43.

Wennemers, M., H. Stegeman, J. Bussink, Y.M. Versleijen-Jonkers, H.W. van Laarhoven, J.A. Raleigh, M.A. Varia, F.C. Sweep, and P.N. Span. 2013. Hypoxia regulation of phosphokinases and the prognostic value of pAKT in breast cancer. Int J Biol Markers. 28:151-160.

Willis, N.D., T.R. Cox, S.F. Rahman-Casans, K. Smits, S.A. Przyborski, P. van den Brandt, M. van Engeland, M. Weijenberg, R.G. Wilson, A. de Bruine, and C.J. Hutchison. 2008. Lamin A/C is a risk biomarker in colorectal cancer. PLoS One. 3:e2988.

Wolf, K., M. Te Lindert, M. Krause, S. Alexander, J. Te Riet, A.L. Willis, R.M. Hoffman, C.G. Figdor, S.J. Weiss, and P. Friedl. 2013. Physical limits of cell migration: control by ECM space and nuclear deformation and tuning by proteolysis and traction force. J Cell Biol. 201:1069-1084.

Wong, X., and C.L. Stewart. 2020. The Laminopathies and the Insights They Provide into the Structural and Functional Organization of the Nucleus. Annu Rev Genomics Hum Genet. 21:263-288. 
Wu, Z., L. Wu, D. Weng, D. Xu, J. Geng, and F. Zhao. 2009. Reduced expression of lamin A/C correlates with poor histological differentiation and prognosis in primary gastric carcinoma. J Exp Clin Cancer Res. 28:8.

Yin, J.J., K. Selander, J.M. Chirgwin, M. Dallas, B.G. Grubbs, R. Wieser, J. Massague, G.R. Mundy, and T.A. Guise. 1999. TGF-beta signaling blockade inhibits PTHrP secretion by breast cancer cells and bone metastases development. J Clin Invest. 103:197-206.

Yoon, C.H., M.J. Kim, H. Lee, R.K. Kim, E.J. Lim, K.C. Yoo, G.H. Lee, Y.H. Cui, Y.S. Oh, M.C. Gye, Y.Y. Lee, I.C. Park, S. An, S.G. Hwang, M.J. Park, Y. Suh, and S.J. Lee. 2012. PTTG1 oncogene promotes tumor malignancy via epithelial to mesenchymal transition and expansion of cancer stem cell population. J Biol Chem. 287:1951619527.

Yoshida, M., M. Kijima, M. Akita, and T. Beppu. 1990. Potent and specific inhibition of mammalian histone deacetylase both in vivo and in vitro by trichostatin A. J Biol Chem. 265:17174-17179.

Zwerger, M., D.E. Jaalouk, M.L. Lombardi, P. Isermann, M. Mauermann, G. Dialynas, H. Herrmann, L.L. Wallrath, and J. Lammerding. 2013. Myopathic lamin mutations impair nuclear stability in cells and tissue and disrupt nucleo-cytoskeletal coupling. Hum Mol Genet. 22:2335-2349. 


\section{Supplemental Figures and Figure Legends}

A

Microfluidic micropipette aspiration device

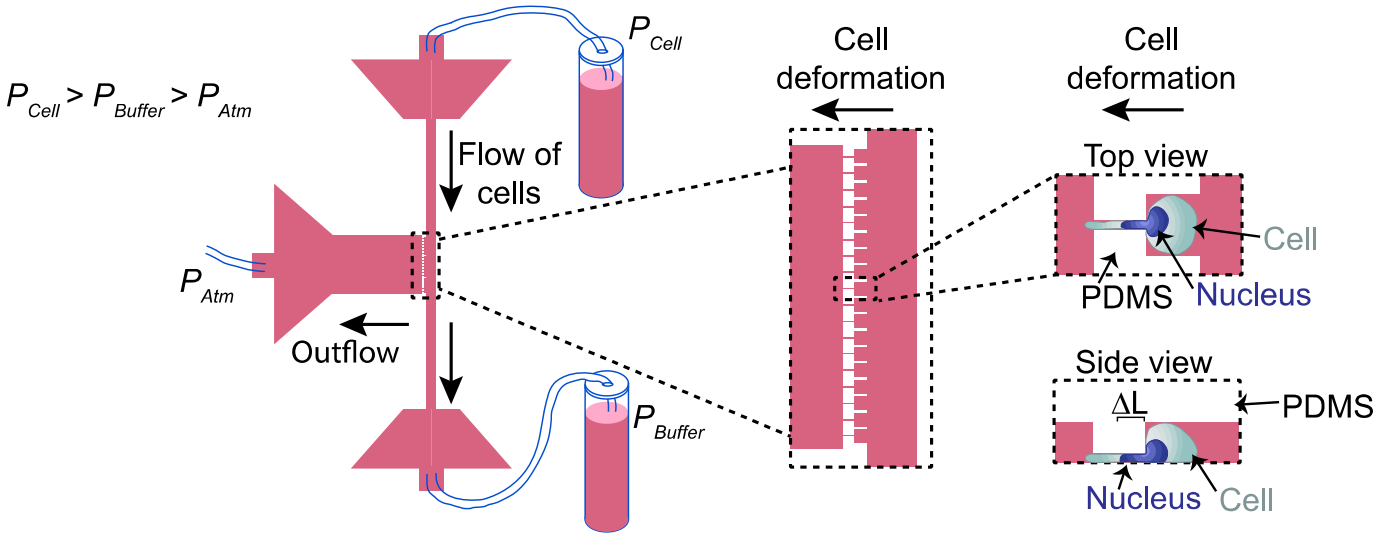

B

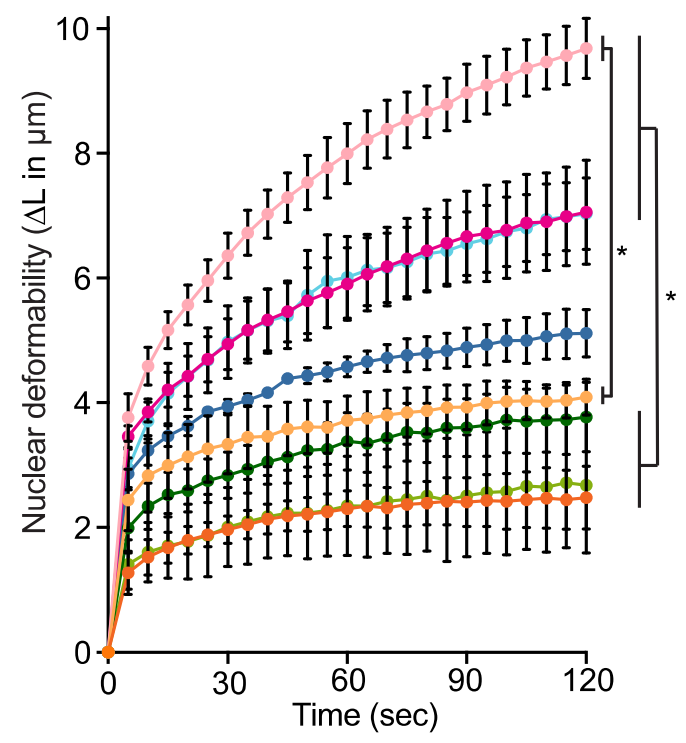

D

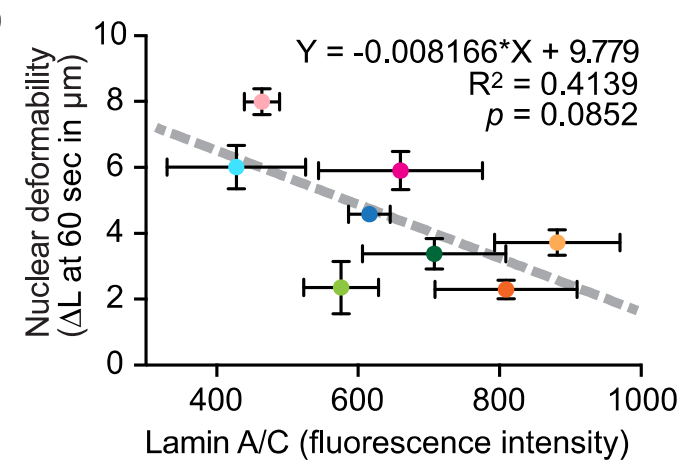

F

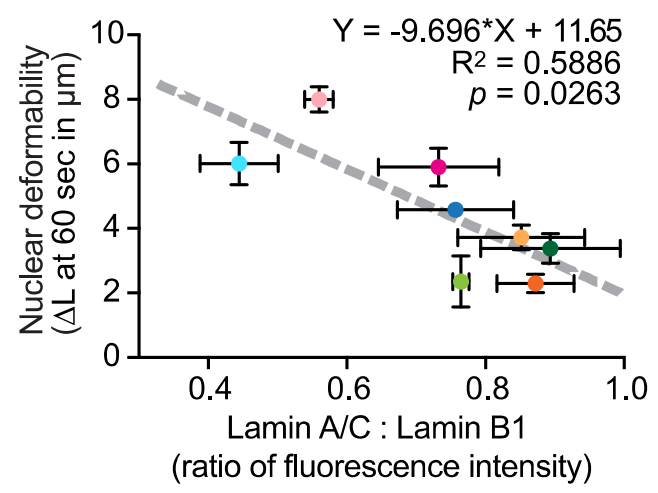

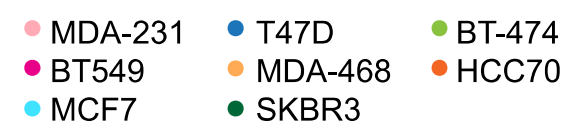

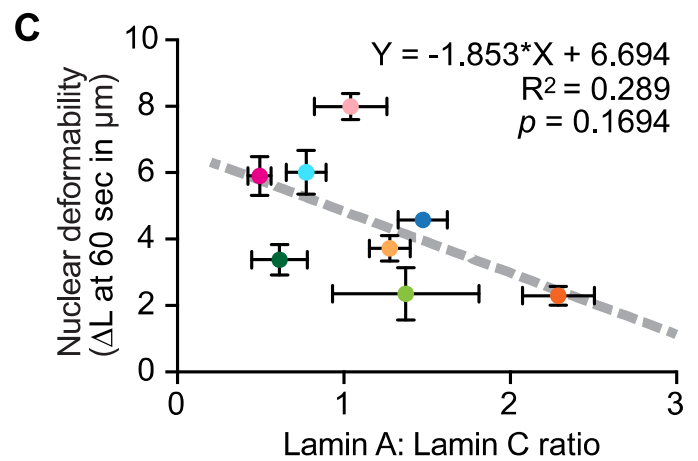

E

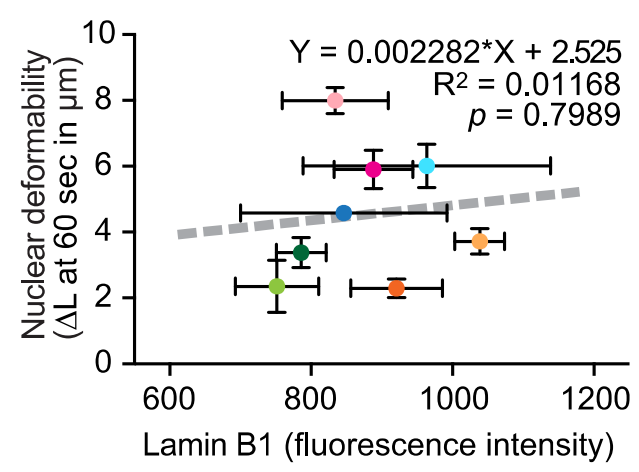

G

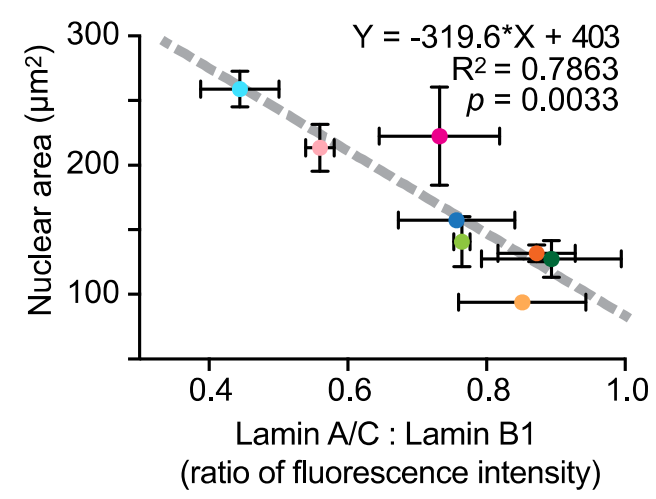


Figure S1. Characterization of lamin levels, nuclear deformability, and nuclear area in a panel of breast cancer cell lines. Related to Figure 1. (A) Schematic of the microfluidic micropipette aspiration device for high throughput assessment of nuclear deformability. A constant pressure gradient is applied across the three ports, such that cells flow into $10 \times 20 \mu \mathrm{m}^{2}$ pockets. Nuclear protrusion $(\Delta \mathrm{L})$ into the $3 \times 5 \mu \mathrm{m}^{2}$ channels is monitored over time by imaging nuclei labeled with Hoechst 33342 or another fluorescent DNA stains. Back-flushing channels manually from the outflow port allows a new set of cells to enter the channels. (B) Nuclear protrusion curves for eight different representative human breast cancer cell lines with different degrees of nuclear deformability. $N=3$, mean $\pm \mathrm{SEM}, *, p<0.05$. Statistical analysis by two-way repeated measures (RM) ANOVA with Tukey's multiple comparisons. MDA-231, BT549, MDA-468, and HCC70 curves are also shown in Figure 1B. (C) Nuclear deformability, assessed based on the nuclear protrusion length into the micropipette at 60 seconds of aspiration ( $N=3$ independent experiments), shows an inverse correlation with the ratio of lamin A to lamin $C$ determined by western blot analysis $(N=3)$. Data are plotted as mean \pm SEM and the linear regression results are indicated on the graph. (D-F) Quantification of nuclear rim lamin intensity $(N=3)$ by immunofluorescence reveals an inverse correlation between nuclear deformability and A-type lamin levels or lamin A/C: lamin B1 ratio, but not for lamin B1 alone. Deformability measurements $(N=3)$ were taken as nuclear protrusion $(\Delta \mathrm{L})$ after 60 seconds of micropipette aspiration in a microfluidic device. Data are plotted as mean \pm SEM; the linear regression results are indicated on each graph. (G) Nuclear area $(N=3)$ and lamin nuclear rim immunofluorescence staining intensity $(N=3)$ were quantified in adherent cells plated on glass coverslips. Larger nuclear spread area correlates with decreased lamin A/C : lamin B1 ratio. Data are plotted as mean \pm SEM and the linear regression analysis is indicated on graph. 


\section{Microfluidic device for studying confined migration}

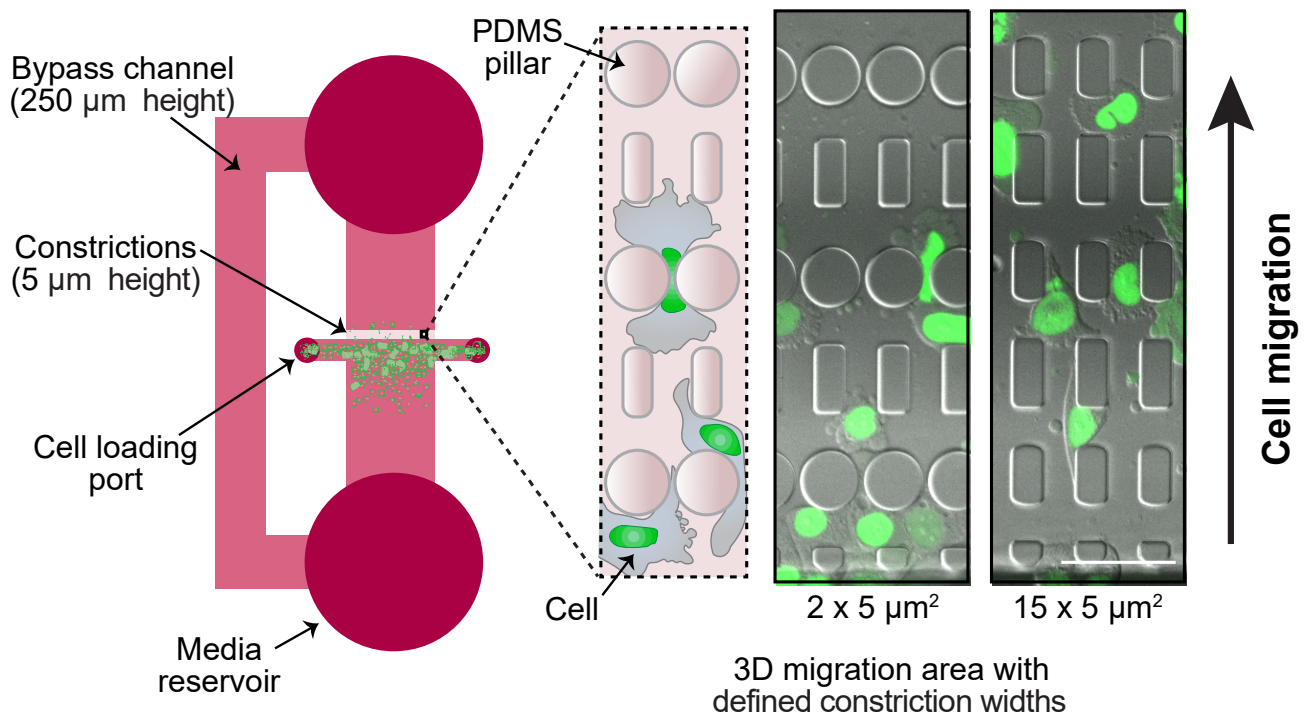

Figure S2. Schematic of the PDMS microfluidics devices used for analysis of cell migration through confined 3-D environments. Related to Figure 3. The devices are sterilized, coated with collagen or fibronectin, and filled with media prior to addition of cells through the loading ports into the $250 \mu \mathrm{m}$ tall space in front of a $5 \mu \mathrm{m}$ tall migration area containing channels with precisely defined constrictions. Constrictions are either $1 \times 5 \mu \mathrm{m}^{2}, 2 \times 5 \mu \mathrm{m}^{2}$, or $15 \times 5 \mu \mathrm{m}^{2}$ in size. If necessary, a chemoattractant gradient can be set up across the device by loading the appropriate media into the media reservoirs on each side of the pillar array. A $0.1 \%$ to $12 \%$ FBS gradient was used for migration experiments involving MDA-468 cells but was not needed to stimulate movement of MDA-231 or BT-549 cells. Cells are imaged at 10-minute intervals. Transit times are quantified based on the movement of the fluorescently labeled nucleus through the constrictions. Shown are representative images for $2 \times 5 \mu \mathrm{m}^{2}$ and $15 \times 5 \mu \mathrm{m}^{2}$ constrictions containing NLS-GFP-expressing MDA-468 cells $\approx 20$ hours post-seeding in the device. Scale bar $=50 \mu \mathrm{m}$. 
A

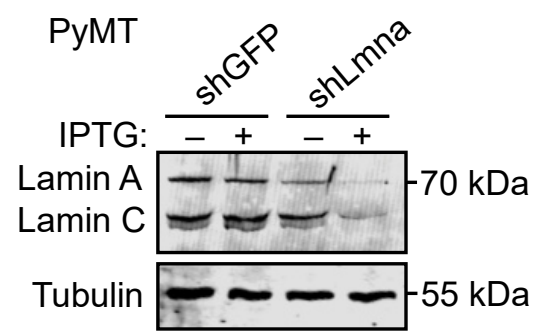

C

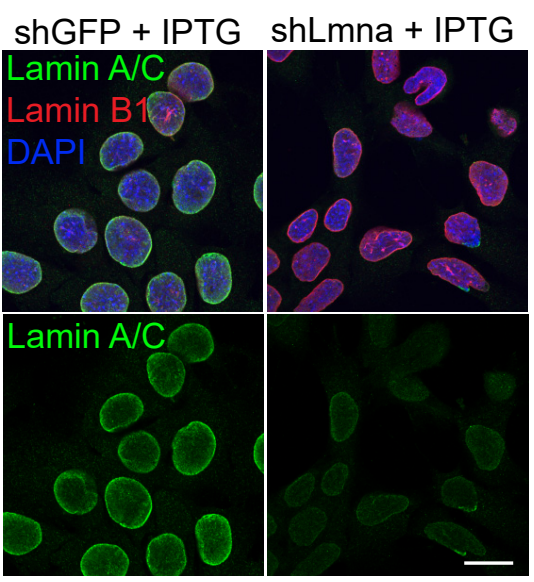

B

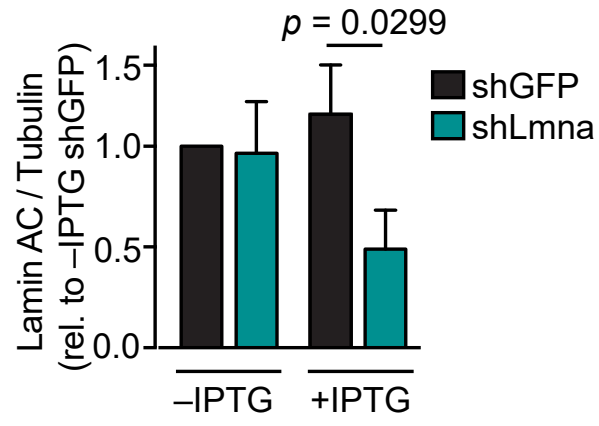

D

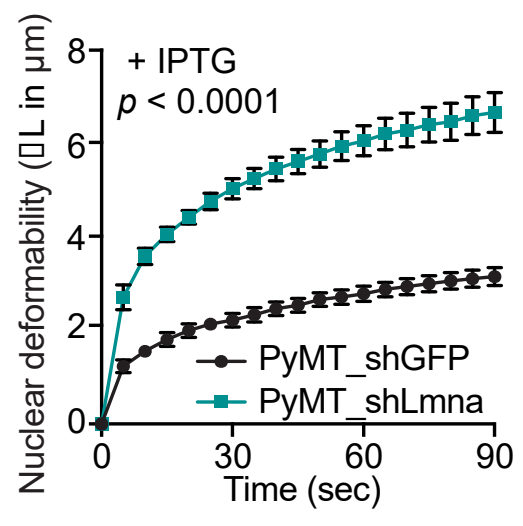

Figure S3. Depletion of lamin A/C increases nuclear deformability. Related to Figure 4. (A-B) Western blot and corresponding quantification ( $N=3$, mean \pm SEM) of lamin $A / C$ levels in PyMT cells expressing IPTG-inducible shRNA to Lmna or non-targeting (shGFP) control. Cells were cultured in media with or without $0.25 \mathrm{mM}$ IPTG for $48 \mathrm{~h}$ prior to analysis. Statistical analysis based on one-way ANOVA with Tukey's multiple comparisons test. (C) Representative images of immunofluorescent staining of lamins in PyMT cells expressing IPTG-inducible shRNA to Lmna or shGFP control and treated with IPTG for $48 \mathrm{~h}$. Scale bar $=20 \mu \mathrm{m}$. (D) PyMT cells depleted for A-type lamins as in (A) and (B) exhibit increased nuclear deformability as quantified by micropipette aspiration in a microfluidic device $(N=4$, mean \pm SEM). Statistical analysis based on two-way RM ANOVA. 
A

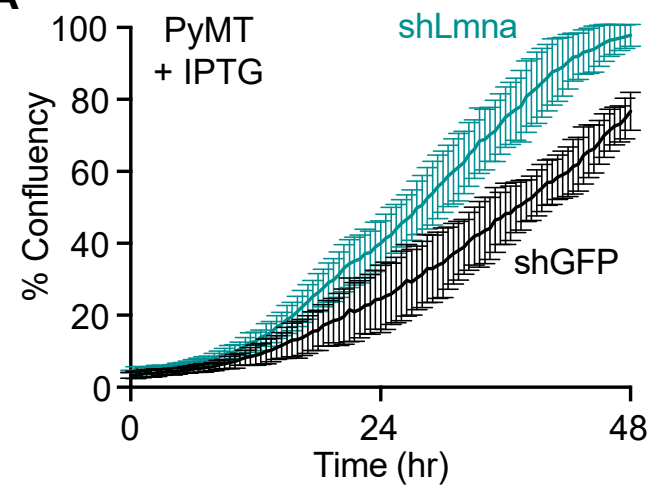

B

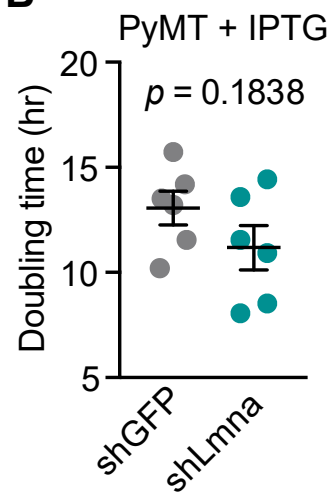

Figure S4. Depletion of lamin A/C does not significantly alter PyMT cell proliferation. Related to Figure 6. (A) Representative proliferation curves for PyMT cells with IPTG-inducible lamin A/C depletion (shLmna) or shGFP control. Data shown were acquired from a single experimental replicate where measurements were collected from images taken every 0.5 hour from 3 wells per condition and plotted as mean \pm SD. (B) Doubling times were calculated for PyMT IPTGinducible shLmna and shGFP control cells from $N=6$ independent experiments. Data plotted as mean \pm SEM and statistical analysis by two-tailed unpaired Student's $t$ test. 
A

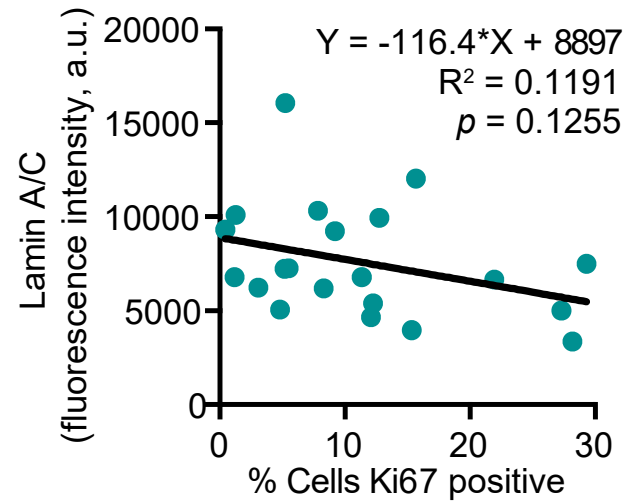

B

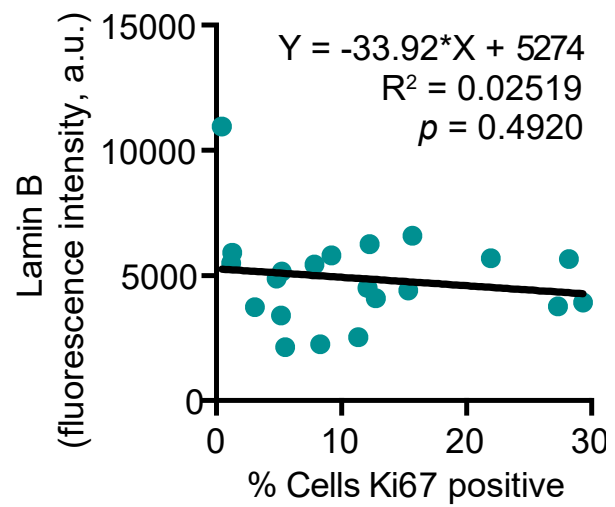

Figure S5. Relationship between lamin levels and proliferative index in human breast tumors. Related to Figure 7. (AB) The average Lamin A/C and lamin B nuclear rim staining intensity was quantified per tumor ( $N=21$ human tumors) and assessed for correlation with the percentage of proliferative cells as determined by quantification of immunofluorescent staining of Ki67. Total cell count was based on the number of DAPI-stained nuclei and cells were counted as proliferative when Ki67 positivity was 2 -fold above background. The linear regression results are indicated on each graph.

\section{Supplemental Video Legends}

Video 1. Nuclear deformability of MDA-231 and HCC70 cells in a micropipette aspiration microfluidic device, related to Figure 1. Time-lapse fluorescence microscopy showing deformation of MDA-231 (left) and HCC70 (right) nuclei fluorescently labeled with Hoechst 33342 (cyan in merge, white in single channel images). Images were captured at 5 second intervals and played at 5 frames per second. Scale bar $=50 \mu \mathrm{m}$

Video 2. Migration of MDA-468 shLMNA and shControl cells in a microfluidic device, related to Figure 3. Time-lapse fluorescence microscopy showing migration of MDA-468 depleted for lamin A/C via shLMNA (right) and shControl cells (left) cells through $2 \times 5 \mu \mathrm{m}^{2}$ constrictions in a microfluidic device in a $0.1 \%$ to $12 \%$ FBS gradient. MDA-468 nuclei are visible due to expression of NLS-GFP (green). Images were captured at 10-minute intervals and played at 5 frames per second. Scale bar $=50 \mu \mathrm{m}$

Video 3. Migration of MDA-231 Control and lamin A overexpressing cells in a microfluidic device, related to Figure 3. Time-lapse fluorescence microscopy showing migration of MDA-231 control cells (left) and cells with exogenous expression of lamin A ("+LamA", right) through $2 \times 5 \mu \mathrm{m}^{2}$ constrictions in a microfluidic device. Cells express GFP (green). Images were captured at 10-minute intervals and played at 6 frames per second. Scale bar $=50 \mu \mathrm{m}$ 